\title{
Unraveling the History of the Vowels of Seventeen Northern Vanuatu Languages
}

\author{
Alexandre François
}

LACITO-CNRS, PARIS

\begin{abstract}
Data collected on the I7 languages spoken in the Banks and Torres Islands (northern Vanuatu) reveal strikingly diverse vowel systems, differing both in the quality and the quantity of their phonemes. Except for Mota, which still perpetuates the five vowels of Proto-Oceanic, the languages of this area have historically increased their inventories to as many as I 3 and even I 6 vowels. The aim of this paper is to track the systematic correspondences between modern languages and their common ancestor, and to reconstruct the processes that led to the present-day phonemic diversity. The phonemicization of new vowels, including diphthongs and long vowels, is shown to result from stress-induced vowel reduction and metaphony. This general process of "vowel hybridization" yielded results that differed from one language to another, and sometimes within the same language. After describing and classifying the various patterns of sound changes attested, this paper shows how a proper understanding of vowel hybridization proves indispensable for the reconstruction of both the lexicon and the historical morphology of these northern Vanuatu languages.
\end{abstract}

\section{INTRODUCTION}

1.1 HISTORICAL EXPANSION OF VOWEL INVENTORIES. In comparison with the five-vowel system that has been reconstructed for Proto-Oceanic (POC) or for the putative Proto-North-Central Vanuatu (PNCV), the modern languages spoken in northern Vanuatu possess much richer inventories. ${ }^{I}$ With the notable exception of Mota, which remains conservative in this respect as in many others, the remaining I6 languages of the Banks and Torres groups have historically expanded their vowel inventories from five to as many as I3 phonological vowel qualities. ${ }^{2}$ Furthermore, in two languages, the

I. This study originates in a presentation I gave at the 6th International Conference on Oceanic Linguistics (COOL6), Port Vila, Vanuatu, in July 2004. I would like to thank Françoise and Jean-Claude Rivierre, Martine Mazaudon, Boyd Michailovsky, Meredith Osmond, Malcolm Ross, and two anonymous reviewers for useful comments on earlier drafts of this paper.

2. The data cited in the present paper were collected by the author during three field surveys: May-July I998 for the languages of Mwotlap, Vurës, and Mwesen; July-September 2003 for Volow, Vera'a, Lemerig, Nume, Dorig, Koro, Olrat, Lakon, and Mwerlap; July-August 2004 for Mota, Lehali, Lo-Toga, and Hiu. Data for Lehalurup come from Codrington (I885) and Tryon (I976). I completed my data on Mota with Codrington and Palmer (I896), those on Vera'a and Vurës with Hyslop (n.d. a; n.d. b). 


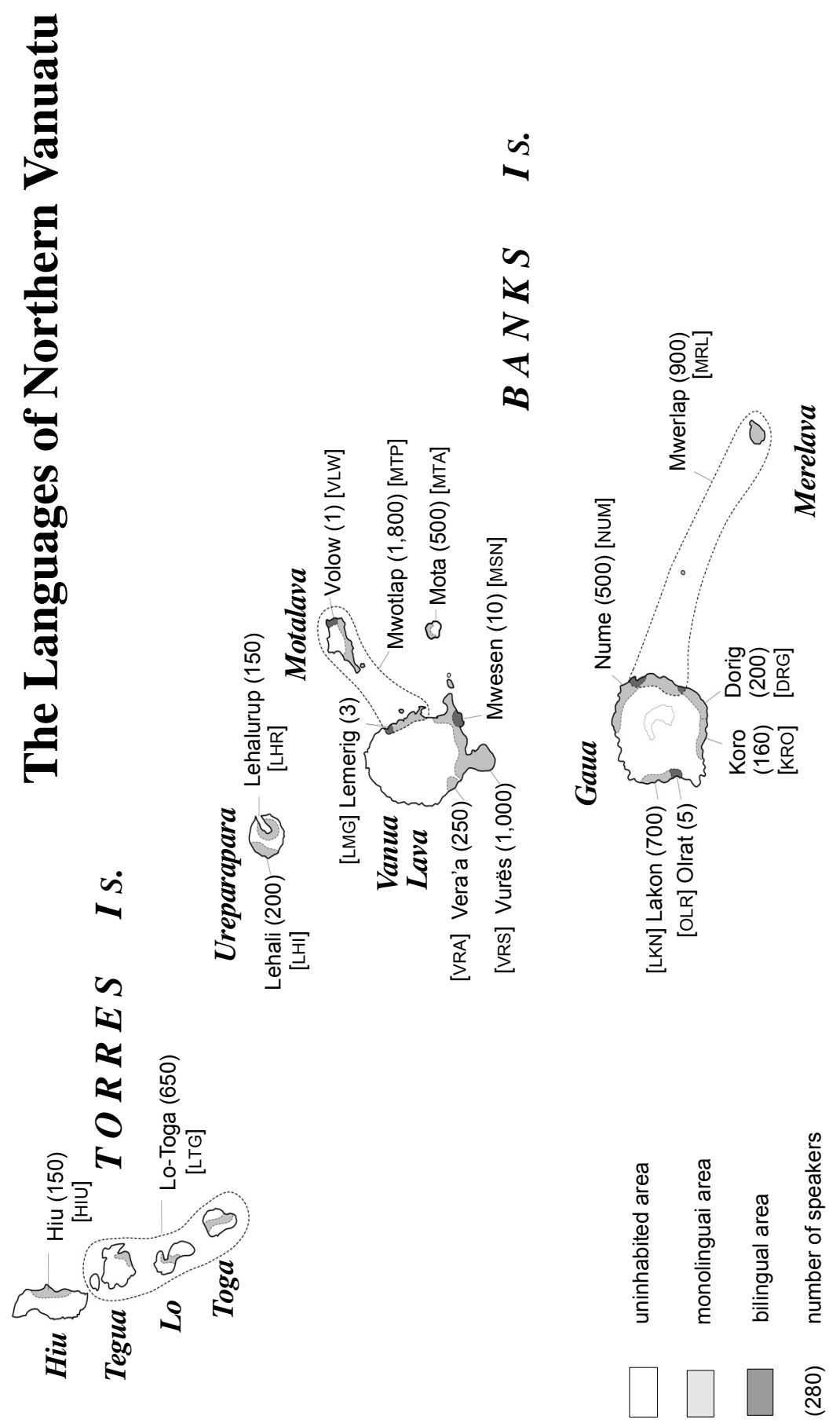


phonemicization of vowel length combined with each vowel quality has led to inventories of I4 $(2 \times 7)$ and even I6 $(2 \times 8)$ vowel phonemes. On the opposite page is a map of the $I 7$ languages spoken in the area, indicating for each language a three-letter abbreviation and the approximate number of speakers. This information is reproduced in table I, together with the number and quality of each language's vowel phonemes.

Although expansion of vowel inventories is a common feature among the languages of the Torres and Banks Islands, it has, in fact, led to quite diverse results from one language to another in such a way that it appears impossible to provide a simple, unique analysis for the whole phenomenon. What I propose here is to first outline the general principle(s) common to all the languages, and then to review in some detail the particular innovations that characterize each language separately.

Throughout this paper, I refer to the I 7 languages spoken in the Torres and Banks groups using shortcut phrases such as "northern Vanuatu languages." Note that this designation must be understood as purely geographic, with no claim as to the existence of a

\section{TABLE 1. THE SEVENTEEN LANGUAGES AND THEIR VOWEL SYSTEMS ${ }^{\dagger}$}

\begin{tabular}{|c|c|c|c|c|c|c|}
\hline LGG & NAME & NO. SPKRS & LOCATION & CODE & NO. V $s$ & VOWEL INVENTORY \\
\hline $\mathrm{HIU}$ & Hiu & I 50 & Hiu & HIW & 8 & i e a $ә$ ө о \\
\hline LTG & Lo-Toga & 650 & Lo, Toga & LHT & $8+5$ & 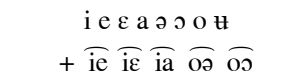 \\
\hline LHI & Lehali & 300 & E. Ureparapara & TQL & 8 & i e $\varepsilon æ a \supset$ o u \\
\hline LHR & Lehalurup & 200 & W. Ureparapara & URR & $8+\mathrm{I}$ & i e $\varepsilon$ a $\curvearrowright o u+\overparen{i e}$ \\
\hline VLW & Volow & I & Motalava & MLV & 7 & i I $\varepsilon$ a $\supset U \mathrm{u}$ \\
\hline МТР & Mwotlap & $\mathrm{I}, 800$ & Motalava & MLV & 7 & i I $\varepsilon$ a $\supset U \mathrm{u}$ \\
\hline LMG & Lemerig & 3 & N. Vanua Lava & VLR & IO & i I $\varepsilon$ a $\mathrm{p} \propto \varnothing \supset U \mathrm{u}$ \\
\hline VRA & Vera'a & 250 & W. Vanua Lava & VLR & 7 & i I $\varepsilon$ a $\supset U \mathrm{u}$ \\
\hline VRS & Vurës & $\mathrm{I}, \mathrm{OOO}$ & S. Vanua Lava & MSN & $9+\mathrm{I}$ & i i $\varepsilon$ a $\varnothing \ddot{\mathrm{u}} \supset v+\overparen{\mathrm{ia}}$ \\
\hline MSN & Mwesen & IO & E. Vanua Lava & MSN & 7 & i I $\varepsilon$ a $\supset U \mathrm{u}$ \\
\hline MTA & Mota & 500 & Mota & MTT & 5 & i e a o u \\
\hline NuM & Nume & 500 & NE Gaua & TGS & 7 & i I $\varepsilon$ a $\supset U \mathrm{u}$ \\
\hline DRG & Dorig & 200 & SE Gaua & Wwo & $7+\mathrm{I}$ & i I $\varepsilon$ a $\supset U \mathrm{u}+\mathrm{a}:$ \\
\hline KRO & Koro & I6o & S. Gaua & $\mathrm{KRF}$ & $7+\mathrm{I}$ & i i $\varepsilon$ a $\supset U \mathrm{u}+\overparen{\varepsilon a}$ \\
\hline OLR & Olrat & 5 & W. Gaua & - & $2 \times 7$ & $\begin{array}{l}\text { i I } \varepsilon \text { a } \supset \text { u + } \\
\text { i: I: } \varepsilon: \text { a: o: U: u: }\end{array}$ \\
\hline LKN & Lakon & 700 & W. Gaua & LKN & $2 \times 8$ & 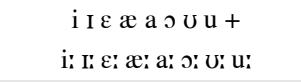 \\
\hline MRL & Mwerlap & 900 & Merelava, E. Gaua & MRM & $9+3$ & i і $\varepsilon$ а в $ө$ н $U+\overparen{\varepsilon a} \widehat{\partial B} \widetilde{v \Theta}$ \\
\hline
\end{tabular}

Given for each language are: (I) the three-letter abbreviation I use in this paper; (2) the language's full name; (3) the number of its speakers; (4) its geographical location; (5) its international (ISO 639-3) code as given in Ethnologue (Gordon 2005), where the reader can find alternate names; (6) the number of its vowel phonemes, including diphthongs and long vowels; and (7) the inventory of these phonemes. 
specific Northern Vanuatu subgroup of languages that would encompass these languages exclusively (see the discussion in 3.4). This paper therefore intends neither to confirm nor challenge the subgrouping hypotheses set forth by Clark (I985), which defines a "Northern Vanuatu" branch within his "North and Central Vanuatu." In Clark's terms, the Torres and Banks languages would form just a subset of the Northern Vanuatu group, along with languages from several islands further south. However, even if the present study is not directly concerned with subgrouping matters, the methodological and historical issues it addresses should constitute a preliminary step in any future attempt toward classifying the Torres and Banks languages genetically (see 6.I.2).

1.2 EMERGENCE OF NEW VOWEL QUALITIES. The historical process described here is, first and foremost, an issue of qualitative phonetic change. If we take the example of Vurës, how can we explain the shift from a five-vowel protosystem to a modern inventory of nine vowel qualities (figure I)? The change from one system to the other is both a matter of quantity (shift from five to nine vowels) ${ }^{3}$ and of quality: some vowels have appeared that did not exist formerly, and certain vowels can be said to have disappeared from the system, at least in their original form. One objective of the present study will be to track for each language the regular correspondences that might exist between the initial inventory and the modern attested system.

A second aspect of our investigation will be to describe the impressive diversity of situations among the languages of the area, including between languages situated close to each other. For example, the vowel system of Vurës (figure I) differs strikingly from that of Mwesen (figure 2), although in other respects these two varieties may be considered just dialects of the same language. 4

\section{FIGURE 1. FROM FIVE TO NINE VOWELS IN VURËS}

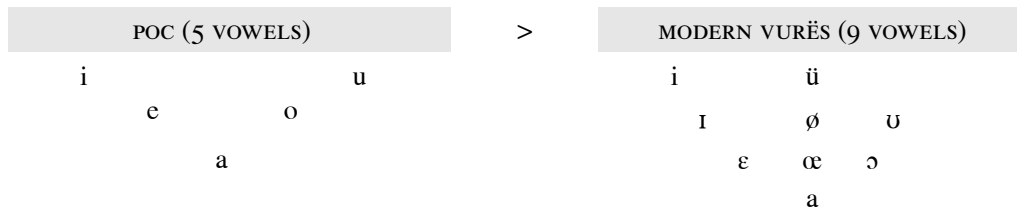

\section{FIGURE 2. FROM FIVE TO SEVEN VOWELS IN MWESEN}

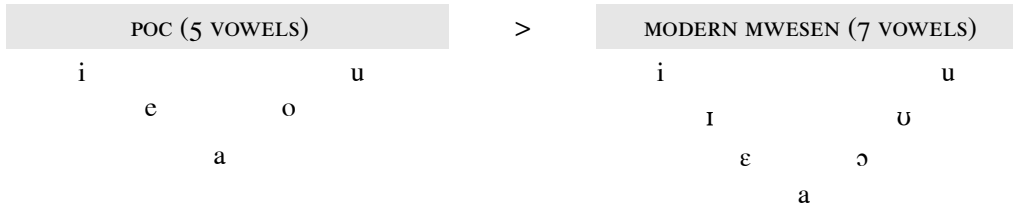

3. Vurës can even be said to possess Io vowels if the diphthong /ia/ is counted as a genuine phoneme (4.3.I).

4. Vurës and Mwesen are listed together under the single language name "Mosina" in Grimes et al. (I995) or Gordon (2005). This follows Tryon (1976:89), who on lexicostatistical evidence treated Vetumboso and Mosina—respectively, Vurës and Mwesen—as two dialects of the same language. 


\section{DEFINING REGULARITIES}

2.1 MANY REFLEXES FOR A SINGLE PROTOVOWEL. My first attempt will be to figure out the phonetic correspondences between the vowels of the protosystem and the modern vowels. A preliminary approach consists in choosing certain etyma sufficiently well represented in the languages of the area, 5 and getting a first overview of their modern reflexes. For example, one may want to check what modern vowels reflect the protovowel *a by examining the lexical reflexes of, say, POC *paRu 'hibiscus': 6

(I) POC *paru 'hibiscus': HIU $\beta$ R̆; LTG $\beta$ or, LHI $\beta$ y; LHR ?; VLW $n-\beta \varepsilon y$; MTP $n \varepsilon-\beta \varepsilon y ;$ LMG $n-\beta \varepsilon r$; VRA $f \varepsilon r$; VRS $\beta a r ;$ MSN $\beta$ or; MTA $\beta a r ;$ NUM far;

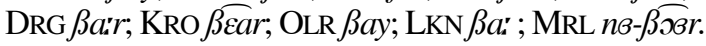

The first observation suggested by this set of cognate forms is the great diversity of reflexes deriving from a single protovowel. In this example, *a is reflected as [a], [a: ], [0],

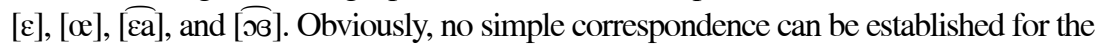
whole group of languages, and it would even be difficult to propose isoglosses that would make sense from a dialectological point of view. Clearly, phonetic correspondences will have to be stated separately for each language: for example, (I) would suggest *a $>[0]$ in HIU, LTG, LHI, MSN, but *a > [ع] in VLW, MTP, LMG, VRA; *a > [œ] in VRS; and so on.

But the situation gets more complex again if a second cognate set is considered. Let us observe the vowels corresponding to *a in the lexical reflexes of POC *pani 'stingray':

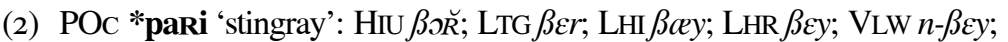
MTP $n \varepsilon-\beta \varepsilon y ;$ LMG $n-\beta \varepsilon r ;$ VRA $f \varepsilon r ;$ VRS $\beta a r ;$ MSN $\beta \varepsilon r$; MTA $\beta a r ;$ NuM $f \varepsilon r ;$

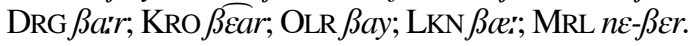

The correspondences that were initially suggested by (I) appear to be confirmed in some languages (e.g., *a $>[0]$ in HIU, *a $>[\varepsilon]$ in MTP, *a $>[œ]$ in VRS, *a $>$ [عa] in KRO), but contradicted in others: reflexes of *a differ between (I) and (2) in LTG, LHI, MSN, NUM, LKN, MRL. In other words, the first difficulty we defined (discrepancies of reflexes across closely cognate languages) is now duplicated by a second difficulty (discrepancies of reflexes language-internally). Unlike consonant correspondences, which are generally consistent and straightforward (e.g., POC *p $>$ [f] in VRA, NuM; *p $>[\beta]$ everywhere

5. Whenever possible, the etyma cited in this study are given in their Proto-Oceanic (POC) form; they either come from common knowledge among Oceanists, or more specifically from Ross, Pawley, and Osmond $(\mathrm{I} 998,2003)$. When no relevant POc example can be found, I cite the reconstructions proposed by Clark ( 1985 ; in prep.) for the putative protolanguage named Proto-North-Central Vanuatu (PNCV), to which all the languages of the Banks and Torres Islands belong.

6. Languages are cited following roughly a northwest to southeast axis, in the same order as in the appendices. In some languages where the noun article (usually a reflex of $* n a$ ) has been accreted to the phonological word (see 5.2.3), it appears as a prefix in the modern reflex. When the etymon has been integrated within a word that is synchronically indivisible, the boundary is indicated with a "l", e.g., (I3) ni-si/ok.

All forms are transcribed using standard IPA, with two exceptions. First, following wide usage among Oceanists, voiced stops in all languages cited here (whether modern or reconstructed) must be understood as prenasalized: thus $|\mathrm{b}|,|\mathrm{g}|,|\mathrm{d}|,\left|\mathrm{b}^{\mathrm{w}}\right|,\left|\mathrm{gb}^{\mathrm{w}}\right|$ stand respectively for $/{ }^{\mathrm{m}} \mathrm{b} /$, $/{ }^{\mathrm{n}} \mathrm{d} /, / \mathrm{l} \mathrm{g} /, /^{\mathrm{m}} \mathrm{b}^{\mathrm{w}} /, /{ }^{\prime n} \mathrm{gb}^{\mathrm{w}} /$. Second, the symbol $|\breve{\mathrm{R}}|$ represents what I identify as a UVULAR FLAP-a consonant of Hiu that, to my knowledge, has never been observed anywhere else in the world, and therefore lacks an appropriate IPA symbol. 
else), the modern distribution of vowels in this area of northern Vanuatu thus appears to be much more problematic.

2.2 DEFINING THE CONDITIONING FACTOR. This sort of complex situation is familiar to language comparatists and normally requires each discrepancy between correspondences to be attributed to a conditioning factor. So, what could be the formal factor that might account for the different reflexes of *a between (I) and (2), in each language taken separately?

Choosing very similar etyma, namely *paru and *pari, makes it possible to quickly eliminate two possible criteria suggested by other languages of the world, and specifically by the comparatist tradition. One possible factor that is known to affect the evolution of vowels is their position within the word, and the position of stress (see section 5). But because the position of *a is exactly the same in *paru and *pari-the penultimate syllable, demonstrably the one receiving word stress (Lynch 2000)—-this criterion cannot provide the explanation for the differences between (I) and (2).

A second hypothesis, widely supported by other languages, would be the influence of the consonant context. However, northern Vanuatu languages generally show relatively few cases of assimilation, or phonetic influence whatsoever, between consonants and vowels. If this kind of phenomenon does exist marginally, ${ }^{7}$ it sometimes provides a clue to account for certain exceptions, but never constitutes the primary key to regular vowel correspondences. And, of course, this argument has to be ruled out in the case of (I) and (2), because *a appears in exactly the same consonant environment in the two etyma.

The only plausible hypothesis that remains is to take into account the context of surrounding vowels in the protoform. And indeed, the northern Vanuatu data reveal that the evolution of a given stressed vowel was systematically conditioned by the vowel of the following syllable. In (I) and (2), the distinctive evolution of *a in *paru vs. *pari was thus directly conditioned by the presence of *u vs. *i in the next syllable.

This hypothesis was tested on a large number of cognate forms in all these languages, and yielded satisfying results. At this stage of the presentation, and for the sake of space, only three new cognate sets will illustrate this point. The reader can compare the reflexes of *a in the modern forms that reflect (3) POC *patu 'stone', (4) POC *kani 'eat', and (5) POC *mate 'die, dead'.

(3) POC *patu 'stone': HIU $\beta o t$; LTG $\beta o t$; LHI $\beta o t$; LHR $\beta \varepsilon t$; VLW $n-\beta \varepsilon t$; MTP $n \varepsilon-\beta \varepsilon t$; LMG $n-\beta \varepsilon ?$; VRA $f \varepsilon 2$; VRS $\beta \varepsilon t ;$ MSN $\beta o t ;$ MTA $\beta a t ;$ NuM $f a t ;$

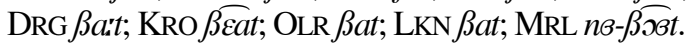

(4) POC *kani 'eat': HIU yon; LTG yen; LHI yan; LHR yen; VLW yen; MTP $\gamma \varepsilon n ;$ LMG $\gamma \varepsilon n ;$ VRA $\gamma \varepsilon n ;$ VRS $\gamma \varepsilon n ;$ MSN $\gamma \varepsilon n$; MTA $\gamma a n ;$ NuM $\gamma \varepsilon n ;$ DRG yain; KRO yean; OLR yIn; LKN yan; MRL yen.

7. One example concerns the labiovelars when a rounded vowel has labiovelarized a consonant: e.g., *molis 'Citrus sp.' > VRS $\widehat{y m}^{w} \phi l$. Yet this is far from being systematic, as shown by *mule 'go back' > VRS mul. François (200 I:76-77) gives the reverse situation in Mwotlap, that is, the influence of labiovelar consonants on adjacent vowels. 
(5) POC *mate 'die, dead': HIU met; LTG met; LHI mat; LHR mat; VlW mat; MTP mat; LMG mar; VRA ma?; VRS miat; MSN mat; MTA mate; NUM mat; DRG mat; KRO mat; OLR mat; LKN mat; MRL met.

If one examines the modern reflexes of*a in each language, (I) *paru and (3) *patu clearly belong in a single correspondence set that could be called $* \mathrm{a}(\mathrm{C}) \mathrm{u}$, whereas (2) *pari and (4) *kani group together under *a(C)i. As for the cognate set (5)*mate, it shares very little with the other sets, and must be assigned to a third correspondence set $* a(C) e$.

The destiny of $\mathrm{V}_{\mathrm{I}}$ is so intimately linked to the nature of the following vowel $\mathrm{V}_{2}$ that one could metaphorically speak of a process of "hybridization," as if the reflex of $V_{I}$ were in fact the result of the combination of two protovowels $V_{1}$ and $V_{2}$. Crucially, this newly coined term of "vowel hybridization" has the advantage of remaining essentially descriptive of the data, and neutral with regard to any specific historical interpretation. For example, simple observation shows that in Lakon the combination of vowels *a...u is regularly reflected as /a/, while *a...i and *a...e both hybridized into /æ/. These factual correspondences can be stated regardless of their phonetic explanation, which remains hypothetical and subject to discussion (section 3 ).

In sum, the evolution of a given (stressed) protovowel $V_{I}$ can be shown to be much more regular than it may have appeared at the beginning of this study, provided that (a) each language is considered separately, and (b) the quality of $\mathrm{V}_{2}$ (the vowel of the following syllable in the protoform) is taken into account.

2.3 MAPPING REGULAR VOWEL CORRESPONDENCES. Now that the main principle of evolution has been understood, it becomes possible to track the vowel correspondences for each language taken separately. I will choose Mwesen, because it shows the most straightforward and regular situation of the whole area.

The preliminary observations proposed in (I) to (5) can be continued for Mwesen by listing successively and systematically the modern reflexes for each combination of vowels in the protolanguage. Knowing that the latter had an inventory of five vowel phonemes $\{\mathrm{i}$ e a o $\mathrm{u}\}$, the combinations $\mathrm{V}_{\mathrm{I}}-\mathrm{V}_{2}$ amount to 25. Each of these will be illustrated here with a single (regular) example, though it must be clear that they have all been checked on several lexical items. These 25 illustrative examples are given in table 2 .

Once all 25 combinations have been tested for a given language, it becomes possible to display them in a simple two-dimensional chart. If the vowel $\mathrm{V}_{\mathrm{I}}$ is listed in rows, and the conditioning vowel $\mathrm{V}_{2}$ in columns, then the result of their hybridization (hereafter $V^{\prime}$ ) appears in the corresponding square. Table 3 shows the regular vowel correspondences for Mwesen. Such charts provide a clear and simple way to visualize the phonological evolution of vowels in each language (see appendix I). Whereas the most striking quality of table 3 is its neat pattern and perfect symmetry - a true seventeenth-century "French garden"- other northern Vanuatu languages, as we shall see, are often much less orderly in their correspondences.

8. To be precise, there are a couple of inconsistencies from one cognate set to another, but they are marginal. For example, in Vurës, both combinations $* a(C) i$ and $* a(C) u$ unpredictably show $/ œ /$ and $/ \varepsilon /$ as their possible reflexes; and likewise, Olrat reflects $* a(C) i$ sometimes as /a/ and sometimes as /I/. See 4.2. 
3. A FUNCTIONALLY BASED HISTORICAL EXPLANATION. So far, my only attempt has been to give an overview of the observable data. Regular patterns have emerged from this observation, resulting in tables such as table 3 ; but no historical interpretation has been proposed. This will be the topic of the present section: how can we explain the general evolution observed in these I6 languages, namely, the regular changes in vowel qualities, and their corollary in terms of new vowel inventories?

3.1 PROSODIC STRESS AND VOWEL REDUCTION. If each etymon is compared with its modern reflexes, an important observation that has been left unmentioned thus far is the phenomenon of vowel reduction. The Mwesen examples (table 2) illustrate how protoforms with two syllables $\left({ }^{*} \mathrm{CVCV}\right)$ are regularly reflected by a monosyllable (usually CVC); vowel reduction also occurs from three syllables to two,

\section{TABLE 2. VOWEL CORRESPONDENCES BETWEEN POC AND MWESEN}

\begin{tabular}{|c|c|c|c|c|c|}
\hline POC $v_{1}$ & POC V $V_{2}$ & MSN REFLEX OF $V_{I}$ & POC ETYMON & MSN REFLEX & \\
\hline \multirow[t]{5}{*}{ i... } & $\ldots i$ & $\mathrm{i}$ & *kinit & yin & 'pinch' \\
\hline & ...e & I & *talise & tIlIs & 'Terminalia' \\
\hline & $\ldots a$ & I & *kurita & WIrIt & 'octopus' \\
\hline & ...o & I & $*_{\text {sipo }}$ & SIW & 'go down' \\
\hline & $\ldots \mathrm{u}$ & $\mathrm{i}$ & *taci-gu & tisi-k & 'my sibling' \\
\hline \multirow[t]{5}{*}{ e... } & $\ldots i$ & I & $*$ sei & SI & 'who' \\
\hline & $\ldots \mathrm{e}$ & $\varepsilon$ & *bebe & $\mathrm{p} \boldsymbol{\varepsilon p}$ & 'butterfly' \\
\hline & $\ldots \mathrm{a}$ & $\varepsilon$ & *pea & $\beta \varepsilon$ & 'where' \\
\hline & $\ldots 0$ & $\varepsilon$ & *bareko & $\mathrm{p} \boldsymbol{\varepsilon} \mathrm{x}$ & 'breadfruit' \\
\hline & $\ldots \mathrm{u}$ & I & *abe-gu & $\mathrm{pI}-\mathrm{k}$ & 'my body' \\
\hline \multirow[t]{5}{*}{$\mathbf{a} \ldots$} & $\ldots \mathrm{i}$ & $\varepsilon$ & *[ka]yari & ๆ $\varepsilon$ & 'Canarium sp.' \\
\hline & ...e & $\mathrm{a}$ & *kape & үa $\phi$ & 'crab sp.' \\
\hline & $\ldots \mathrm{a}$ & $\mathrm{a}$ & *padan & ßan & 'Pandanus sp.' \\
\hline & ...o & $\mathrm{a}$ & *jalaton & salat & 'Dendrocnide' \\
\hline & $\ldots \mathrm{u}$ & 0 & *kaRu & yor & 'swim' \\
\hline \multirow[t]{5}{*}{$\mathbf{o} \ldots$} & $\ldots i$ & $U$ & *boni & $\widetilde{\mathrm{kp}}^{\mathrm{w}} \mathrm{oy}$ & 'night' \\
\hline & ...e & 0 & *qone & on & 'sand' \\
\hline & $\ldots a$ & 0 & *ñorap & nor & 'yesterday' \\
\hline & $\ldots 0$ & 0 & $* \operatorname{toto}(\mathrm{k})$ & $\mathrm{t} \mathfrak{t}$ & 'cut, chop' \\
\hline & $\ldots \mathrm{u}$ & $U$ & $*$ tolu & ni-tul & 'three' \\
\hline \multirow[t]{5}{*}{$\mathbf{u} \ldots$} & $\ldots i$ & $\mathrm{u}$ & *upi & $\mathbf{u} \phi$ & ‘blow’ \\
\hline & ...e & U & *kasupe & yusuw & 'rat' \\
\hline & $\ldots a$ & $U$ & *quran & or & 'lobster' \\
\hline & ...o & $U$ & *puro & wor & 'bubble up' \\
\hline & $\ldots \mathrm{u}$ & $\mathrm{u}$ & *sayapulu(q) & saywul & 'ten' \\
\hline
\end{tabular}

TABLE 3. REGULAR VOWEL CORRESPONDENCES FOR MWESEN

\begin{tabular}{c|ccccc} 
& $* \ldots i$ & $* \ldots e$ & $* \ldots a$ & $* \ldots o$ & $* \ldots u$ \\
$* i \ldots$ & $\mathrm{i}$ & $\mathrm{I}$ & $\mathrm{I}$ & $\mathrm{I}$ & $\mathrm{i}$ \\
$* e \ldots$ & $\mathrm{I}$ & $\varepsilon$ & $\varepsilon$ & $\varepsilon$ & $\mathrm{I}$ \\
$* a \ldots$ & $\varepsilon$ & $\mathrm{a}$ & $\mathrm{a}$ & $\mathrm{a}$ & 0 \\
$* o \ldots$ & $\mathrm{u}$ & 0 & 0 & 0 & $\mathrm{U}$ \\
$* u \ldots$ & $\mathrm{u}$ & $\mathrm{U}$ & $\mathrm{u}$ & $\mathrm{U}$ & $\mathrm{u}$
\end{tabular}


from four to two, and so on. Examples (I) to (5) show the same observation for the remaining languages of the area: thus in (4), an etymon with two open syllables *kani is systematically reflected by one closed syllable in modern languages.

This process of vowel reduction is undoubtedly an effect of phonetic stress. In a protoform with two syllables, only the one receiving stress was preserved, while the unstressed vowel eventually disappeared (e.g., *'mate > mat). This is typologically a familiar phenomenon, also witnessed by Latin ciuitātem [ki'wi'tartem] > Catalan ciutat [siw'tat] 'city'. In the case of northern Vanuatu languages, there is every likelihood that the final consonants of POC forms had been lost at some stage (e.g., 'ten' *sayapuluq >

*sayapulu); this resulted in vowel-final lexemes that systematically received primary stress on their penultimate syllable, and secondary stress every second syllable leftward (e.g., *, saya'pulu). Vowel reduction affected word-medial as well as word-final posttonic syllables, ${ }^{9}$ which explains why words with four syllables were regularly reduced to two: for example, * sana'pulu > MSN say'wul.

The loss of word-final posttonic vowels explains why, in essentially all the languages of the area, words are now systematically stressed on their final rather than their penultimate syllable (contra Lynch 2000:77). Exactly the same evolution is attested in modern French: due to the progressive loss of all etymological posttonic vowels, French has become a perfectly oxytone language.

As for the deletion of word-medial unstressed vowels, also known as syncope, it is rather rare among Oceanic languages, unlike in western Austronesia. According to Blevins and Blust (2003), "general syncope is inhibited by the absence of pre-existing closed syllables," as is the case in several Oceanic subgroups, including North-Central Vanuatu. In their view, "syncopating sound change is common where closed syllables pre-exist, and rare or absent where they do not"-a universal tendency that "receives empirical support within the Austronesian language family." In this perspective, it is worthwhile to underline that the Torres and Banks languages provide counterevidence to that tendency. General syncope has taken place massively in languages that lacked closed syllables when vowel reduction began.

\subsection{LEXICAL DISTINCTIVENESS AND THE STRUCTURAL ECONOMY}

OF THE SYSTEM. Vowel reduction occurred in all of the 17 languages of my corpus, although with varying impact upon their phonologies. In one language, Mota, it only affected part of the lexicon, namely those words where the unstressed-either medial or final-vowels were high, that is, /i/ or / $\mathrm{l} /$. Thus compare (4) *kani 'eat' > yan, but (5) *mate 'die' > mate. The homophones that were triggered through this process - e.g., (I) *paru 'hibiscus' > $\beta$ ar vs. (2) *pari 'stingray' > $\beta$ ar-were not so numerous as to impede communication. This limited impact upon the lexicon can arguably be seen as the reason why Mota has kept its five-vowel system intact up until now. This, by the way, makes it the most conservative language of the area.

But the scenario turned out to be more complex for the $\mathrm{I} 6$ remaining languages. In all of these, vowel reduction affected the whole lexicon, whatever the quality of the unstressed vowel. This can be seen in (5), where all languages but Mota have reduced

9. The specifics of word-medial and especially word-initial syllables are presented in section 5 . 
the two CV syllables of *mate to a single CVC one. In this situation, the effect of vowel reduction upon the lexicon was going to be much more extensive, at least potentially, than in Mota. Indeed, it virtually ensured that the lexical contrasts that could exist between five disyllables of the type $\mathrm{CaCi}-\mathrm{CaCe}-\mathrm{CaCa}-\mathrm{CaCo}-\mathrm{CaCu}$ would all merge into a single syllable of the type $* C a C$. In a purely statistical perspective, it would have meant reducing lexical distinctiveness by virtually 80 percent. Needless to say, such a drastic increase in the number of homophones in the language would have considerably threatened the success of communication.

In fact, none of these northern Vanuatu languages let vowel reduction affect its whole lexicon without some sort of functionally driven reaction, as it were, that would preserve at least some level of lexical distinctiveness. Although the details eventually differed from one language to another, they all followed the same overall strategy: namely, an increase in the number of their vowel phonemes. One can take the example of Mwesen (table 3), and see that a potential set of five disyllables $\mathrm{CaCi}-\mathrm{CaCe}-\mathrm{CaCa}-\mathrm{CaCo}-\mathrm{CaCu}$ did not merge into a single form $* \mathrm{CaC}$, but into three distinct forms $\mathrm{C} \varepsilon \mathrm{C}-\mathrm{CaC}-\mathrm{CoC}$, which is obviously a more efficient outcome from a functional point of view.

Of course, what were initially $25(=5 \times 5)$ potential $\mathrm{V}_{\mathrm{I}}-\mathrm{V}_{2}$ combinations did not give birth to 25 distinct vowel qualities. The emergence of phonetic differences was in fact counterbalanced by a reverse phenomenon of phonetic convergence, whereby several new vowels resulting from diverse combinations would merge together into a single phoneme. For example, in Mwesen (knowing that languages behave diversely in this respect) the vowel resulting from *a...i merged with the one resulting from *e...a, namely, the phoneme $/ \varepsilon /$. Yet this second process of phoneme conflation never reverted back to the initial five-vowel system. The push toward the expansion of phoneme inventories has proved everywhere stronger than the reverse merging trend to such an extent that the final systems ended up having at least seven, and up to I 3 distinct vowel qualities. Although this certainly did not completely prevent homophones from appearing, such an expansion of vowel inventories at the system level cushioned the effects of vowel reduction upon communication.

The relevance of such a functional interpretation has long been illustrated for other languages, as early as Martinet's seminal study Économie des changements phonétiques (I955). Here is what Martinet says about Germanic umlaut (I970:200; my translation): "Originally, umlaut must have consisted in the transfer of certain features from the vowel affected by syncope or apocope, to a preceding stable vowel-generally the one in the stressed initial syllable. ... Resulting from this, new vowel phonemes emerged, which compensated for the loss of the unstressed vowels with respect to distinctiveness. It is probable that speakers were subconsciously inclined to anticipate the articulation of the disappearing vowel because this vowel helped identify the word or form." "'o This type of historical process has also received the name of "trans-

IO. "L'Umlaut ... a dû consister, à l'origine, dans le transfert de certains traits des voyelles atteintes par la syncope ou l'apocope à une voyelle stable précédente, en général celle de la syllabe initiale accentuée. ... Il en est résulté de nouveau phonèmes vocaliques compensant, sur le plan distinctif, la chute des voyelles inaccentuées, et l'on peut croire que les sujets ont été inconsciemment entraînés à anticiper l'articulation de la voyelle qui disparaissait parce que cette voyelle contribuait à l'identification du mot ou de la forme."' 
phonologization" (Hagège and Haudricourt 1978) — that is, the structural preservation of lexical distinctiveness by transferring some phonetic features from one segment to another. Other examples of a similar process involving an increase in vowel inventories include the transfer of the nasality feature from consonants to vowels, and the emergence of a tone system to compensate the loss of certain contrasts between consonants. ${ }^{\text {I }}$ In our case, what is being transferred is the distinctiveness potential of disyllables to monosyllables via the expansion of vowel systems. One could also formulate the principle in Saussurian terms, focusing on the structural economy of the system: as words become shorter (reduction on the horizontal, syntagmatic axis), a larger phoneme inventory is necessary (expansion on the vertical, paradigmatic axis).

Vowel reduction is also attested in other parts of Oceania, but with varying consequences. In some languages, such as South Efate (Thieberger 2004:74) or the various languages of southern Vanuatu (Lynch 200I:IO3-6), the deletion of unstressed final and medial vowels had no particular effect upon vowel phonemes. Conversely, in areas such as Micronesia, vowel reduction resulted in the expansion of vowel inventories in much the same way as in northern Vanuatu. Chuukese ended up having nine phonemic vowels (Dyen I949, Goodenough I992; see below) and Kosraean I2 (Lee and Wang I984:403).

3.3 METAPHONY OR METATHESIS? Although this structural explanation is probably the key to the overall history of vowel inventories in northern Vanuatu, it only accounts for the phonological level, but does not explain all the details of what happened exactly from the phonetic point of view. That is, now that we have seen why new vowels were structurally useful at that particular point in the history of these languages, we have to explain how they appeared.

The general process one can think of here is umlaut: that is, the anticipatory spread of certain phonetic features from one vowel to the vowel of the preceding syllable. The best-known form of umlaut took place in the history of Germanic languages. During this process, a posttonic high front vowel $* i$ regularly fronted a preceding back vowel before disappearing. For example, the Proto-Germanic singular/plural pair *mu:s 'mouse' vs. *murs-iz 'mice' eventually became a contrast *mu's vs. *müis in Old English. Because the term umlaut is often restricted to high vowels, I prefer to use the wider term METAPHONY, which covers "any type of assimilation between nonadjacent vowels in a word" (Trask I996:22 I).

In the case of northern Vanuatu languages, a possible scenario that would account for most of the modern data would resort to the notion of metaphony: some sort of regular assimilation (or feature transfer) from $V_{2}$ to $V_{I}$ took place before $V_{2}$ disappeared altogether. If we take the example of *pari 'stingray', one can assume a first stage of the type *ßari $>*$ *æri, ${ }^{12}$ whereby final [i] affected tonic [a], bringing about a fronted allophone such as [æ] - the latter being nothing more, at this stage, than a contextual variant of the phoneme /a/ before /(C)i/. Likewise, a form like 'hibiscus' *paru > *ßaru would have developed a back variant such as [p], thus * ßaru $>*$ * pru. In a second stage, when

II. As far as the Oceanic group is concerned, these two historical processes are especially attested in the languages of New Caledonia: see Ozanne-Rivierre and Rivierre (1989) for nasal vowels, and Rivierre (200I) for the emergence of tones. See also Blust (I990:248-5I) for other Austronesian languages. 
the process of vowel reduction eliminated the posttonic vowels, these two phonetic allophones [æ] and [p] eventually became phonemicized, as only these two vowel qualities were then able to maintain the lexical distinction *ßær 'stingray' vs. * $\beta \mathbf{p r}$ 'hibiscus'. What has later occurred to these two new phonological entities (whether they remained distinct or eventually merged with each other, or whether they merged with other vowels of the new system) differs from one language to another. But at least this scenario can explain how the original lexical distinction *pari : *paru was able to be preserved in several modern languages, even after the loss of the final vowels-e.g., LTG $\beta \boldsymbol{\varepsilon} r$ : $\beta \boldsymbol{r} r$;

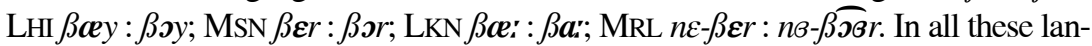
guages, what were once no more than allophonic variations of a single phoneme /a/ were eventually frozen in the form of phonemic contrasts.

Although the scenario I reconstruct here of phonetically conditioned variants that later acquired the status of phonemes cannot be directly witnessed in any modern language of the area, its likelihood is confirmed by certain observations that were made in other parts of Oceania. Goodenough (I992) describes the same evolutionary path in two Micronesian languages, Kiribati and Chuukese. Kiribati still has no more than five vowels on the phonological level, yet each shows metaphonic variation, depending on the quality of the posttonic vowel: for example, $/ \mathrm{CaCe} /$ surfaces as $\left[{ }^{\prime} \mathrm{CæC}{ }^{e}\right], / \mathrm{CaCo} /$ as $\left[{ }^{1} \mathrm{CbC}^{\circ}\right]$. Chuukese went beyond this allophonic stage when it lost its word-final vowels: then, as Goodenough (IO3) puts it, "all the work of differentiation fell on the first vowels, and what was before a phonetic difference had now to be recognized analytically as a phonemic one"-for example, /æ/ vs. / $/$ /. This is how metaphony was able to trigger an increase of the Chuukese phoneme inventory from five to nine vowels.

In principle, the metaphony hypothesis should equally well be able to explain the other instances of vowel change that took place between POC and the modern languages of northern Vanuatu. If we consider the Mwesen examples of table 3, we can imagine that the final $[\mathrm{u}]$ in *tolu 'three' raised the stressed vowel from [o] to [u] before disappearing, hence $*$ tolu $>* t u l^{\mathrm{u}}>t v l$; and conversely that the final [a] in (*quray $>$ ) *ura 'lobster' lowered [u] to [u], hence *ura $>*^{*} \mathrm{r}^{\mathrm{a}}>v$, and so on. As long as the changes are phonetically expected, they can easily be explained in terms of feature assimilation at a distance- - that is, in terms of metaphony.

This scenario is in fact not the only possible way to account for the vowel hybridization processes attested in the area. Another proposal, suggested by A. Pawley (pers. comm.), would suggest a parallel with the evolution attested in Rotuman (Besnier I987):

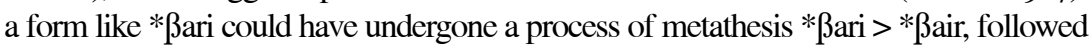
by a merger of the two then adjacent vowels * $\beta$ air $>* \beta æ r$. Similarly one could recon-

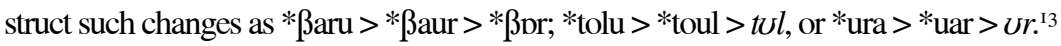

I2. Depending on the languages and the lexical items, POC $*_{\mathrm{R}}$ either disappeared altogether or merged with *r; but in no language of northern Vanuatu does * $\mathrm{R}$ surface with a reflex different from *r. That is why I choose here, for the sake of simplicity, to spell $*_{\mathrm{r}}$ the reflex of $*_{\mathrm{R}}$ when proposing intermediate reconstructions. Anyway, the relative chronology of consonant changes $\left({ }^{*} \mathrm{R}>r,{ }^{*} \mathrm{p}>\beta, \ldots\right)$ goes beyond the present discussion, which focuses on vowels.

I3. Note, however, that a sequence $/ \mathrm{uCa} /$ in Rotuman yields a sequence glide + vowel rather than a plain vowel: e.g., puka 'creeper sp.' > puak > pwok (Besnier I987:208). 
Note that these two explanations rely on the same logic, namely, the notion of phonetic assimilation and feature transfer across syllable boundaries. ${ }^{14}$ Therefore, they have essentially the same explanatory power with regard to the vowel changes attested in the corpus: both models can easily explain changes that are phonetically expected (such as $* \mathrm{aCi}>\varepsilon \mathrm{C}$ ), and both will have equal difficulty in accounting for those changes that are more unusual (such as $* \mathrm{aCi}>0 \mathrm{C}$ ).

In sum, the only fact that is established with certainty is the general process whereby a pair of vowels such as *a...i in * ßari eventually hybridized into a single vowel such as $/ æ /$ in * $\beta æ r$. What is then a matter for debate is the precise nature of the missing link that should be reconstructed between these two ends: the metaphony hypothesis suggests an intermediate form * ßæri, whereas the metathesis scenario reconstructs a form * $\beta$ air. Technically, the two scenarios are equally plausible here-except that metaphony is typologically much more common. Overall, this second hypothesis is probably too costly to account for regular sound change in so many distinct languages; and metaphony must be retained as the most probable historical scenario.

3.4 SHARED OR PARALLEL INNOVATION? The reader must note that I have so far deliberately avoided any commitment as to whether the historical process under discussion occurred only once, at the level of a common ancestor, or if it happened after these languages had separated from each other in a series of parallel changes that would have taken place in each language separately.

I will touch briefly on a few arguments that suggest we are dealing with parallel changes. First, if we were to situate the process at the level of a common ancestor, we might have to go back in time to a putative "Proto-Torres-Banks" ancestral to the I6 languages of our corpus, and exclusive to other northern Vanuatu languages (see I.I). However, the existence of such a common ancestor has not yet been demonstrated. Furthermore, because Mota is the only language in the area that did not go through this phonological process all the way, we then might be tempted to exclude it from this genetic subgroup, which would not make sense in other respects. ${ }^{15}$

Furthermore, if one were to demonstrate the antiquity of the change in the genetic tree, one would have to show not only that all these languages underwent the process as a type of phonetic change, but that they went through the same actual patterns of change. Yet the diversity of resulting vowel inventories attested from one language to another (section 4), and the impossibility of reconstructing any common system from which to derive all modern inventories make the shared-innovation hypothesis difficult to advocate. In sum, supposing some subgroup encompassing all the languages of the Torres and Banks were to be demonstrated by future research, the phonological evidence related to vowel change would clearly have to be excluded from the set of possible shared innovations.

I4. In this sense, an autosegmental representation of these processes that distinguishes tiers for consonants vs. vowels may provide an efficient model for both the metaphony and the metathesis hypotheses (Besnier I987). See also 5.2.3.

I5. Setting aside the issue of vowel hybridization, most features typical of Banks languages are also represented in Mota, whether regarding the phonology of consonants, the morphosyntax (e.g., possessive classifiers, TAM markers), or the lexicon (appendix 2). 
A possible argument in favor of defining vowel hybridization as an areal phenomenon is the existence of a very similar phonological process in a language of Espiritu Santo that I have not yet mentioned. According to Guy (I977), Sakao has expanded its vowel inventory from five to I 2 vowels, demonstrably by going through a parallel development (see Sakao vowel correspondences in appendix I):

(6) Vowel hybridization in Sakao (after Guy I977):

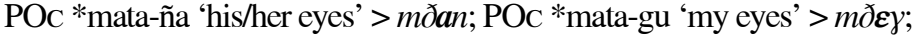

POC *pulu-ña 'his/her hair' > uloen; POC *pulu-gu 'my hair' > ulüy;

POC *tolu 'three' > ð $\propto l$; POC *qone 'sand' > n/on;

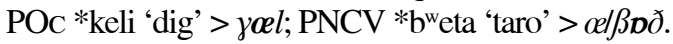

While it is genetically rather remote from the Torres and Banks languages and shares more features with other languages of Santo (Tryon I976:80), the area of Sakao lies just opposite Gaua; that is, it is the language of Santo that is geographically closest to the Banks area. Although further evidence would be required to ascertain this language-contact hypothesis, it seems likely that such a parallel evolution between geographically neighboring languages is not totally accidental.

All these arguments tend to demonstrate that the process of vowel hybridization with its reshaping of vowel inventories is the result of parallel innovations that took place in several languages of northern Vanuatu. Overall, this process may have occurred separately up to 17 times - that is, all the languages of my corpus other than Mota, plus Sakao. ${ }^{16}$ It is difficult to determine whether what took place here should be described as an areal phenomenon that spread from one place to another through language contact, or as drift (Sapir I92 I). Drift is perhaps the scenario that functionally might be better motivated, because it "occurs when languages [that] are no longer in contact move in similar directions due to the continued, independent operation of inherited structural pressures" (Blevins and Blust 2003). Yet, the existence of ongoing contact between these northern Vanuatu languages suggests the two historical motivations may well have interacted here.

As far as dates are concerned, my personal intuition-which cannot be demonstrated - is that these processes probably occurred fairly recently: say, during the last few centuries. What can be demonstrated, however, is their relative chronology in comparison with other instances of sound change in certain languages. For example, in Lakon, the difference between $\widetilde{y m}^{w}$ as $\underline{I} k<*^{*} \mathrm{~m}^{\mathrm{w}}$ atiga (\#I09) ${ }^{17}$ 'purple swamphen' and $\underline{t} \underline{l}$ $<*$ tolu 'three' shows the assibilation of /t/ before high front vowels took place before, not after, the hybridization process. ${ }^{18}$ Because this assibilation is attested with Lakon but not with its neighbors, this pleads once more against the antiquity of vowel changes in the genetic tree of northern Vanuatu languages.

Corollary to these conclusions, the historical scenario I have reconstructed in the present section must be taken for what it is: an outline of the general principles that

I6. To my knowledge, the languages of Maewo, Pentecost, and northwest Santo, south of our area, did not go through the process. Neither did the three languages of Vanikoro (pers. data) to the north.

I7. Example numbers preceded by "\#" refer to the list of northern Vanuatu reconstructions that is proposed in appendix 2.

I8. This relative chronology hypothesis is corroborated by the existence of such forms as LKN matwus $<*$ matakut-i 'fear' or paelas $<$ *balat-i 'take with tongs' (see 6. I.3). 
guided the shift from a five-vowel protosystem to richer inventories in the modern languages. While all these languages have essentially gone down the same track in terms of functional and structural evolution, the specifics of each history may have to be reconstructed for each language separately. Although this task is beyond the scope of the present study, I shall now give at least an overview of the variety of situations attested across the area.

4. CROSS-LANGUAGE DIVERSITY. The choice of Mwesen as an illustration for the general discussion (2.3) was explicitly justified by its simplicity and exemplary nature. The other languages differ from Mwesen in both the quantity and quality of vowels resulting from the historical process of hybridization. For some of these languages, it is just a matter of phonetic correspondences being different, with no need of further discussion. But other systems have developed peculiarities such as diphthongs or long vowels that require a more specific presentation.

4.1 CROSS-LANGUAGE DISCREPANCIES. The methodology presented in 2.3 and illustrated by Mwesen makes it possible to establish a chart of regular vowel correspondences for each language of the sample. The 17 charts can be seen in appendix I. Quite remarkably, they all differ from each other, including between neighboring or otherwise close languages. To begin with, I will cite here certain languages that, though differing from Mwesen in their vowel correspondences, do not require any further discussion. The six languages Lehali, Lehalurup, Volow, Mwotlap, Lemerig, and Nume can be considered as following basically the same pattern as Mwesen. For all of them, each combination of protovowels $\mathrm{V}_{\mathrm{I}}-\mathrm{V}_{2}$ is regularly reflected by a single short monophthongal vowel $\mathrm{V}^{\prime}$ : ${ }^{(}(\mathrm{C}) \mathrm{V}_{\mathrm{I}}(\mathrm{C}) \mathrm{V}_{2}>(\mathrm{C}) \mathrm{V}^{\prime}(\mathrm{C})$.

Certain correspondences, however, appear to be paradoxical from a phonetic point of view, especially if compared with the "well-behaved" vowels of Mwesen. For example, the combination *a...u is almost systematically reflected in several of these languages by the front vowel / / / - see (3) above. Volow is even more consistent in providing almost any combination $* \mathrm{~V}_{\mathrm{I}}$... u with a front vowel reflex, as if some sort of dissimilation had taken place. Thus compare the five reflexes of $* \mathrm{~V}_{\mathrm{I}} \ldots \mathrm{u}$ in Mwesen $\{\mathrm{i} \mathrm{i} \supset \cup \mathrm{u}\}$ and in Volow $\{$ i I $\varepsilon$ I i $\}$ :

(7) $* \mathrm{~V}_{\mathrm{I}} \ldots \mathrm{u}$ is regularly reflected with [+front] [+spread] vowels in Volow: POc *taci-gu 'my younger sibling' > tihi- $\eta$ 'my same-sex sibling';

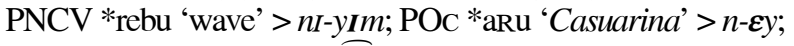
POC *motus 'island' > nI- $\widetilde{y m}^{w} I t$ 'bush'; POC *pusuR 'bow' >n-ih.

In order to account for such language-specific distribution patterns, certain intermediate stages may have to be reconstructed on a case-by-case basis. For example, following Guy (I977) for Sakao, one could suggest that VLW *i and *u first merged into a single nonback, nonrounded vowel (such as central $*_{-i}$ ) before hybridizing with the preceding stressed vowel.

Vurës can be added to the preceding list, with one peculiarity. It has developed a series of front rounded vowels $/ \propto /, / \varnothing /, / \mathrm{i} /$. These result from the combination of the 
three nonfront $\mathrm{V}_{\mathrm{I}} * \mathrm{a} / \mathrm{o} / \mathrm{u}$ with a high $\mathrm{V}_{2}$. When $\mathrm{V}_{\mathrm{I}}$ was rounded and $\mathrm{V}_{2}$ was high front $*_{i}$, the change corresponded somewhat to a classical case of umlaut:

(8) $* \mathrm{~V}_{\mathrm{I}} \ldots$.. i is regularly reflected with [+front] [+rounded] vowels in Vurës: POC *boni 'night' > $\overline{k p}^{w} \emptyset$; ; POC *quRis 'Spondias dulcis' > ür.

But when $\mathrm{V}_{2}$ was itself a back vowel $*^{\mathrm{u}}$, the fronting $*_{\mathrm{o}} . . \mathrm{u}>\phi$ and $* \mathrm{u} . . \mathrm{u}>\ddot{u}$ was more unusual. Once again, it looks as though some sort of dissimilation had taken place — which is always more difficult to explain than assimilation.

(9) $* \mathrm{~V}_{\mathrm{I}} \ldots \mathrm{u}$ is regularly reflected with [+front] [+rounded] vowels in Vurës: POC *motus 'island' > $\widehat{\eta m}^{w} \emptyset t$ 'bush'; POC *pusur 'bow' > $\beta$ ïis.

These vowel correspondences, which are exclusive to Vurës, account for the genesis of its unique vowel system (see figure I). Front rounded vowels are also found in Lemerig and Lehalurup. Note also the three central rounded vowels $/ \mathrm{s} /, / \Theta /, / \mathrm{tz} /$ developed in Mwerlap and in Hiu — the latter being better described, for phonological reasons, as / / /, / / /, / $\mathrm{t} /$.

While differences between vowel systems normally result from a distinct set of correspondences, the reverse is not necessarily true. That is, two languages may have quite different charts in appendix I, but still present exactly the same phoneme inventory. For example, the same system of seven vowel qualities $\{$ i i $\varepsilon$ a $\supset \cup u$ u is found in Mwesen, Mwotlap, Vera'a, Nume, Olrat (table I), despite substantial differences with regard to the precise vowel correspondences that led to that inventory (appendix I).

4.2 LANGUAGE-INTERNAL INCONSISTENCIES. Unlike Mwesen, whose vowel correspondences are remarkably systematic, a characteristic of most other languages is the existence of more than one reflex for certain $V_{1}-V_{2}$ combinations, generally with no possibility of defining any conditioning factor.

Examples (I) and (3) have already shown that Vurës may reflect the combination *a...u either as $/ \varepsilon /(*$ patu $>\beta \varepsilon t$ ) or as /œ/ (*paru $>\beta \propto e r)$, with no obvious motivation. Likewise, *a...i sometimes became $/ \varepsilon /(*$ kani $>\gamma \varepsilon n)$ and sometimes-though much less often—/œ/ (*pari > ßœr). Other examples for VRS include:

(Io) Inconsistent reflexes of $*_{\mathrm{a}} . . . \mathrm{i}$ and $*$ a...u in Vurës:

POC *RapiRapi 'evening' > *raßira $\beta \mathrm{i}>\operatorname{r\varepsilon } \beta \mathrm{r} \varepsilon \beta$;

(\#I32) 'sara $\beta$ i 'rub, stroke' > sœrœ $\beta$;

POC *koras-i 'grate coconut' > yeres; (\#7) ${ }^{\circ}$ asi 'song' > $\boldsymbol{e s}$;

POC *manuk 'bird' > men; POC *ñatuq 'Burckella obovata' > nœt.

Similarly in Mwotlap, the combination *o...i normally hybridized as /I/, and sometimes—quite rarely in fact—as $/ \mathrm{s} / \mathrm{I}^{19}$

( I I) Some reflexes of $*$ o...i in Mwotlap:

POC *boni 'night' >nu- $\overline{k p}^{w} U \eta$;

POC *poli 'buy' > wil; POC *molis 'Citrus sp.' >nI- $\widehat{\eta m m}^{w} I l$;

$\mathrm{PNCV} *$ domi 'think' $>$ dIm; PNCV *doni 'coconut leaf mat' $>$ nI-dIn.

The same two outcomes are attested for *o...u. Compare the expected (but rare) shift $*_{\mathrm{o}} \ldots \mathrm{u}>/ \mathrm{v} /$ with the less expected (but much more frequent) shift $*_{\mathrm{o}} \ldots \mathrm{u}>\mathrm{/I} /$ :

I9. The history of Mwotlap vowels is presented in detail in François (2001:83-I Io). 
(I2) Some reflexes of *o...u in Mwotlap:

POC *topu 'sugarcane' $>n u-t u w$;

POC *katou 'hermit crab' > na-ytr; POC *motus 'broken' > $\widehat{\eta m}^{w} I t$;

POC *tolu 'three' > $\beta_{I}$-trl; POC *nako-gu 'my face' $>$ na-nyI- $k$.

Finally, the usual reflex of *a... a is /a/ (POC *baga 'Ficus sp.' > na-bak). Yet, in a number of lexical items, some form of dissimilation (see Lynch 2003) has taken place:

(I3) An unpredictable case of dissimilation (*a...a > ) in Mwotlap:

POC *asaq 'grate, rub' > $s h$ 'rub';

POC *waga 'canoe' > ni-si/sk;

POC *ma- ${ }^{n}$ rin ri(n) 'cold' $\rightarrow$ *mamariri > momyiy;

POC *[ma-]Raqan 'light' $\rightarrow$ *mamara?a $>$ momya;

POC *sayapulu(q) 'ten'> sonwul.

These multiple reflexes appear in the relevant boxes of each appendix chart. The only case when an alternative reflex is not indicated in a chart is when it is only witnessed in one or two items. For example, whereas the outcome of *u...i in Mwotlap is almost always /i/ (POC *suri 'bone' > ni-hiy) and rarely /u/ (POC *susuri 'sew' > susuy), it appears as /I/ only in one item (POC *quris 'Spondias dulcis' >n-ry). Likewise, *a...u becomes systematically MTP / $\varepsilon$ /, except in just two words: POC *raun 'leaf' > na-yo, PNCV *nau 'Ist singular pronoun' $>n$ s. Because such reflexes are clearly exceptions, they are not listed in the chart.

Most of the time, it appears impossible to define any conditioning context-let alone any phonetic motivation - for these language-internal inconsistencies. When it has been feasible, the condition for each alternative reflex is indicated in the chart. A typical example of conditioning is the presence or absence of a consonant between the two vowels at the time of their hybridization. Thus in Vurës, *e... a hybridized into $\overparen{i a} /$ when the two vowels were separated by a consonant (4.3. I below), but became /I/ when they were immediately adjacent. In other words, Vurës requires two distinct rules here: $\{* \mathrm{eCa}>\widetilde{\mathrm{iaC}} /\} ;\left\{*_{\mathrm{ea}}>/ \mathrm{I} /\right\} .^{20}$

(14) Some reflexes of word-final *ea in Vurës:

POC *pea 'where' > al $\beta r ;$ PNCV *ßare?a 'outside' > * $\beta$ area $>\beta$ arr; PNCV *maraya 'eel' $>*$ marea $>$ marı.

4.3 DIPHTHONGS AND LONG VOWELS. Another peculiarity of the vowel systems in the languages under consideration is the emergence not only of new vowel qualities, but also of diphthongs and long vowels.

4.3.1 Diphthongs. Certain modern languages show diphthongs in places where their neighbors just have plain monophthongal vowels. One example is Vurës, which normally reflects as $\overparen{\text { ia }} /$ the combinations *a...e or *e... a (but see a subcase in [I4] above):

20. A similar distinction must be made for *e/o...a in Vera'a (see fn. 26); for *a...(i/u) in Koro and Dorig (see [20] below); and for *a...(i/u) in Mwerlap. See also Guy's discussion ( I977) on Sakao. All such cases are indicated by angle brackets " $\langle\ldots\rangle$ " in the charts of appendix I. 
(I5) Some reflexes of $*$ a...e in Vurës:

POC *kape 'crab' > jia $\beta$; PNCV *?ata-mate 'ghost' > timiat;

$\mathrm{PNCV} * \mathrm{~m}^{\mathrm{w}} \mathrm{ab}^{\mathrm{w}} \mathrm{e}$ 'Inocarpus' > $\widehat{\text { pmm }}$ 'iak.

(i6) Some reflexes of *e... in Vurës:

PNCV *b ${ }^{w}$ eta 'taro' $>\overparen{k p}$ wiat; PNCV *mena 'ripe' > $\overparen{\text { mian}}$;

$\mathrm{PNCV} * \mathrm{~m}^{\mathrm{w}}$ era 'child' > $\widetilde{\eta m}^{w}$ irym $\widetilde{T}^{\text {wiar }}$ 'children'.

It is difficult to tell whether this emergence of a diphthong is historically a direct outcome of the process $(* \mathrm{a} . . . \mathrm{e}>\overparen{i a})$, or if some different vowel must be reconstructed as an intermediate link (say *a...e $>* a ̈$ ), which for some reason would have later diphthongized $(* \ddot{a}>\widetilde{i a})$. This question can probably not be solved: all that can be established with certainty, at least at this stage of our observation, is the factual correspondence between certain sequences $* V_{1} \ldots V_{2}$ and a certain diphthong.

Another example of a diphthong is Koro $/ \overline{\varepsilon a} /$, a regular reflex for the two combinations *a...i and *a...u: see (I) $\widehat{\beta \varepsilon a r},(2) \widehat{\beta \varepsilon a}$, (3) $\widehat{\beta \varepsilon a t}$. The same phoneme $\widetilde{\varepsilon a /}$ appears in Mwerlap, along with two rounded diphthongs $/ \overline{3} /$ and $/ \widetilde{\mathrm{v \theta}} /$. The former results from *a...u, as illustrated in (I) and (3). As for $/ \widetilde{\mathrm{U \Theta}} /$, it normally corresponds to *o...u:

(I7) Some reflexes of *o...u in Mwerlap:

POC *tolu 'three' >i-t $\widehat{\boldsymbol{U \theta} \boldsymbol{\theta}} l$; POC *topu 'Saccharum' $>$ nв-t $\widehat{\boldsymbol{\theta} \boldsymbol{\theta}}$;

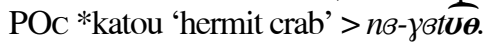

The third diphthong $/ \overline{\varepsilon a} /$ proceeds from four different combinations:

(I8) The four combinations at the source of $/ \overline{\varepsilon a} /$ in Mwerlap:

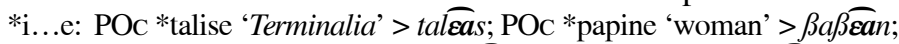

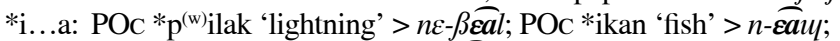

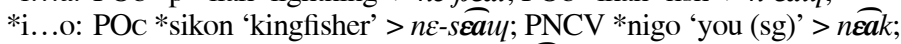

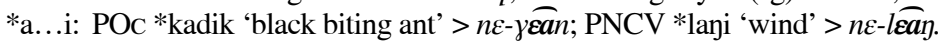

In comparison with its neighbors, Mwerlap has a rich vowel inventory-I2 phonemes

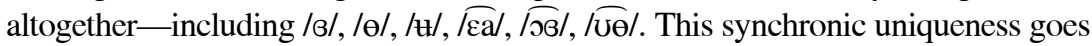
along with an unusual distribution of vowel correspondences from the historical point of view: compare the neatly ordered chart of Mwesen (table 3) with the paradoxes and asymmetries of Mwerlap (appendix I). If one adds to this a certain level of dialectal variation observed within Mwerlap, it is not surprising that the surrounding populations perceive Mwerlap as a particularly difficult language.

Finally, the existence of diphthongs is what makes the difference between the two dialects of Lo-Toga, namely Lo and Toga. Whereas Toga essentially has monophthongs, the

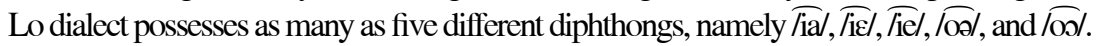
Insofar as the latter may be considered authentic phonemes, then Lo possesses I 3 vowel phonemes altogether, which is one of the largest inventories in the area (see table I):

(I9) Diphthongs in the dialect Lo of Lo-Toga:

$$
\begin{aligned}
& \text { POC *api 'fire' > TGA } \varepsilon \beta \sim \text { LO } \overparen{i \varepsilon} \beta \\
& \text { POC *kona 'bitter' > TGA yonə Lo yön } \\
& \text { PNCV *domi 'think' > TGA təm } \sim \text { Lo toəm } \\
& \text { POC *boni 'night' > TGA } k^{w} \partial \eta \sim \text { LO } k^{w} \widetilde{\boldsymbol{o \partial} \eta}
\end{aligned}
$$


However, the correspondences of Lo regarding diphthongs are less systematic than those of Vurës, Koro, or Mwerlap: each of these phonemes occurs in no more than about a dozen lexical items. For example, most etyma ending in ${ }^{*} a . .$. i are reflected in Lo with a monophthong $/ \varepsilon /$, not with $/ \mathrm{i} \varepsilon /$.

4.3.2 The emergence of vowel length. In comparison with its neighbors, Dorig is unique in having created a single long vowel. Whereas most sequences $* \mathrm{~V}_{\mathrm{I}} \ldots \mathrm{V}_{2}$ hybridized into short vowels (e.g., POC *bebe 'butterfly' $>b \varepsilon b$ ), the combination of *a with a high vowel $i$ or $u$ regularly brought about a long vowel /a:/. Thus compare the long vowel in (I) $\beta a r r$, (2) $\beta a r r$, (3) $\beta a a^{r}$, with the short vowel in (5) $m a t .^{21}$ No combination other than $*_{\mathrm{aCi}}$ or $*_{\mathrm{aCC}}$ yielded any long vowel in Dorig. As a result, the phoneme inventory of this language now consists of seven short vowels $\{$ i i $\varepsilon$ a $\rho \cup u$ u plus a single long vowel /a:/. The phonemic status of this long vowel is made obvious by such minimal pairs as lan 'fly' (POC/PNCV *lano) vs. la'y 'wind' (PNCV *lani).

The only case where *a...(i,u) is reflected by a short vowel $/ a /$ in Dorig is when the two vowels were (in premodern Dorig) immediately adjacent - that is, not separated by any consonant. One can imagine that the sequences *ai or *au were first reflected by a long vowel /a:/, and later shortened to /a/ in word-final position:

(20) Some short reflexes of $*_{a}$... i and $*_{a}$...u in Dorig:

POC *[ka]yaRi 'Canarium almond' > *nai $>$ *na: $>$ na

PNCV *bataßu 'breadfruit' $>$ *batau $>$ *bta: $>$ bta

This emergence of one long vowel in Dorig must be carefully distinguished from the emergence of vowel length as a phonological feature in two contiguous languages of West Gaua, Olrat and Lakon. What happened in these two languages is that the loss of a certain consonant in syllable-final position triggered compensatory lengthening upon the preceding vowel: $\{* \mathrm{VC}>\mathrm{V}:\}$. The lengthening process did not concern the same consonant in the two languages: for Olrat, the lost consonant was $/ \mathrm{\gamma} /(<\mathrm{POC} * \mathrm{k})$, whereas for Lakon it was $/ \mathrm{r} /\left(<\mathrm{POC} *_{\mathrm{r}}\right.$ or $\left.*_{\mathrm{R}}\right)$. Yet the process in itself is perfectly parallel in the two languages - see (2I-22):

(2I) Compensatory lengthening in Olrat: $\left\{\mathrm{V \gamma} \rightarrow \mathrm{V}: / \_\#\right\}$

POC *sake 'up' $>$ *saye $>$ *say $>$ sa'

POC *bareko 'breadfruit' $>$ * paeyo $>*$ pey $>$ p $\varepsilon^{\prime}$

PNCV *liko-ti 'tie up, tether' $>*$ liyo $>*$ liy $>\boldsymbol{l}_{\boldsymbol{I}}$ '

POC *paka-rua 'twice' $>*$ ßaya-rua $>* \beta a y-r u>\beta a$ '- $r$

(22) Compensatory lengthening in Lakon: $\left\{\mathrm{Vr} \rightarrow \mathrm{V}: / \_\#\right\}$

POC *paru 'hibiscus' $>* \beta a r u>* \beta a r>\beta a$ '

POC *pani 'stingray' $>*$ *ari $>* \beta æ r>\beta a \boldsymbol{c}^{\prime}$

POC *bore 'dream' $>* \mathrm{kp}^{\mathrm{w}}$ ore $>* \mathrm{kp}^{\mathrm{w}}$ or $>\widehat{k p^{w}} \boldsymbol{o r}^{\prime}$

POC *quRis 'Spondias dulcis' $>$ *uri $>$ *ur $>\boldsymbol{u}$ '

Incidentally, because the consonant was only lost syllable-finally in a CVC pattern, this implies that the process under discussion necessarily happened after the process of

2I. The match is perfect between Dorig /a:/ and the diphthong / $\overparen{\varepsilon a} /$ in Koro, a dialect of the same language (4.3.I). 
vowel reduction. A corollary to this point is that long vowels in Olrat and Lakon may occur anywhere in the word, but exclusively in open (CV) syllables.

This process of consonant loss with resulting compensatory lengthening triggered the emergence of vowel length as a distinctive phonemic feature in these two languages. ${ }^{22}$ The synchronic analysis provides genuine minimal pairs such as OLR la 'take' (PNCV *lai) vs. la: 'marry' (POc/PNCV *laki), or LKN pu 'bamboo' (PNCV *bue) vs. pu' 'swell' (PNCV *bura < POC *pura 'elephantiasis'). As a result, not only did these two languages expand their vowel inventories through hybridization just like their neighbors (seven distinct vowel qualities for Olrat, eight for Lakon), but later on they even duplicated these into two sets, short vs. long. This is why Olrat can be said to have I4 phonemic vowels, and Lakon as many as I6 - which is, by the way, the largest inventory of all northern Vanuatu languages.

In summary, it is now obvious that the emergence of vowel length followed different historical paths across the three languages under discussion. On the one hand, Dorig only developed one long vowel as a direct (or indirect) result of vowel hybridization; this is why it has its place in the appendix I chart of Dorig. On the other hand, Olrat and Lakon developed vowel length in a phonological process that evidently occurred after hybridization had taken place; this is why the charts of these two languages do not mention long vowels. ${ }^{23}$

4.4 POLYSYLLABIC OUTCOMES. Finally, the three languages Hiu, LoToga, and Vera'a require specific comments, for the shape of their words follows a phonological structure that is slightly different from their neighbors. So far, all the examples of vowel reduction presented in this study have taken the form of a reduction in the number of syllables, whereby two open syllables $\mathrm{CV}_{\mathrm{I}} \mathrm{CV}_{2}$ became a single syllable of the form $\mathrm{CV}^{\prime} \mathrm{C}$. Yet, although this general pattern is indeed well attested in the three languages under discussion here-see (I-5) - it does not represent all vowel combinations. In some instances, these three languages reflect a sequence CVCV in the protolanguage with another sequence CVCV. For example, while the POC disyllable *mule 'go back' is reduced to a monosyllable in Mwotlap $\widehat{y m}^{w} U l$, it keeps its CVCV structure in Hiu, Lo-Toga, and Vera'a:

(23) POC *mule 'go back': HIU $\eta^{w} u y \partial$, LTG $\eta^{w} u l$, VRA mulv.

A question regarding these three exceptional languages would be to define in which cases the CVCV pattern is reduced to a CVC syllable — as in (I) to (5) — and in which cases it is preserved-as in (23). I will examine Hiu and Lo-Toga first, and treat the more complex Vera'a in 4.4.2.

4.4.1 Low vowel resistance in the Torres Is. Despite their differences with regard to precise correspondences, the two languages of the Torres follow essentially identical patterns here. The charts of Hiu and Lo-Toga (appendix I) show that, out of $25 \mathrm{~V}_{1}-\mathrm{V}_{2}$ combinations, nine are regularly reflected as a sequence $\mathrm{CVCV}$ in the modern languages:

22. The two processes do not necessarily go together: for example, Lehali, Lehalurup, and Nume lost $/ \mathrm{y} /$ syllable-finally, yet with no compensatory lengthening.

23. There is a second difference between the two situations. Knowing that DRG /a:/ was shortened in open syllables (see [20]), it only occurs within closed syllables CVC; this is exactly the opposite with the long vowels of Olrat and Lakon. 
$*_{i} .$. e, *i...o, *i...a, *e...a, *a...a, *o...a, *u...a, *u...e, *u...o. ${ }^{24}$ This covers all the $\mathrm{V}_{1}-\mathrm{V}_{2}$ sequences where $\mathrm{V}_{2}$ either is absolutely low $(* a)$, or is lower than $\mathrm{V}_{\mathrm{I}}$. In both languages, the output of all these combinations is a vowel followed by an unstressed schwa.

(24) Some disyllabic reflexes of *CVCV in Hiu and Lo-Toga:

\begin{tabular}{|c|c|c|}
\hline OC *n raraq 'blood' & LTG 'tarə & $\sim$ HIU 'tă̌ \\
\hline POC *saman 'outrigger' & LTG 'hemə & $\sim$ HIU wo'som \\
\hline POC *alap 'take' & LTG 'sla & $\sim$ HIU 'sya \\
\hline POC *kuRita 'octopus' & LTG $\partial^{\prime}$ rita & $\sim$ HIU 'ř̈ita \\
\hline POC *bakewa 'shark' & LTG $p \partial^{\prime} \gamma \varepsilon w \partial$ & HIU pa'weya \\
\hline POC *aliton 'firewood' & LTG 'lita & Hu \\
\hline kasupe 'rat' & LTG $y \partial ' h t w a$ & \\
\hline
\end{tabular}

In comparison with other $\mathrm{V}_{1}-\mathrm{V}_{2}$ sequences that underwent complete vowel reduction $\left({ }^{*} \mathrm{CV}_{\mathrm{I}} \mathrm{CV}_{2}>\mathrm{CV}^{\prime} \mathrm{C}\right)$, the nine combinations under discussion here have shown a greater resistance, as it were, to phonetic attrition. Thus compare POC *mate 'dead' > LTG met with POC *mataq 'raw' > *mata > LTG meta. The importance of the [+low] feature in accounting for such resistance can also be observed in other languages of the world that have followed similar evolutionary paths involving syllable reduction. For example, the history of Romance languages (Old French, Occitan, Catalan ...) often showed how a contrast between masculine $*_{-}-o$ and feminine $*_{-} a$ endings eventually shifted to a contrast between zero and -a, as in Latin 'twisted' *tortu $(m)$ : *torta $(m)>*$ torto : *torta $>$ Cat. /tort/ :/torta/. This preservation of an unstressed vowel in the form of schwa is restricted to * $a$ in the Romance languages, but in Hiu and Lo-Toga it also includes $* e$ and $* o$ when they are lower than the preceding vowel $\mathrm{V}_{\mathrm{I}}$. Probably the best explanation for this phenomenon would refer to the sonority hierarchy between vowels (Jespersen I904): $a$ is more sonorous than $e l o$, which are more sonorous than $i / u$. The underlying principle would thus be straightforward: the more sonorous the vowel, the more it tends to resist phonetic attrition.

In a way, one could question whether this is still an instance of vowel hybridization in the strict sense of the term. However, it must be clear that patterns of change such as (24) still make it necessary to consider vowels in pairs, because a sequence $/ \mathrm{V}_{1} \ldots \mathrm{V}_{2} /$ changed as a whole into a different sequence $/ \mathrm{V}^{\prime}$... $/$. Unlike Catalan, where one can formulate a simple rule of the form "all word-final unstressed /-a/ became /-a/," in the case of Hiu and Lo-Toga the precise outcome of the change always depends on the nature of both protovowels $\mathrm{V}_{\mathrm{I}}$ and $\mathrm{V}_{2}$ : e.g., *u...e > LTG /t...ə/, but *o...e > LTG /o.../. All of these regular vowel correspondences appear in the appendix I charts of Hiu and Lo-Toga.

Furthermore, because the various forms of $\mathrm{V}_{2}$ lost their distinctive power as they merged into / $/$ /, what happened here is once again the same sort of transphonologization as the one defined earlier in 3.2. That is, what used to be two different vowel slots $\left\{{ }^{*} \mathrm{CV}_{1} \mathrm{CV}_{2}\right\}$ each with its own full inventory, eventually conflated into a single phonotactic structure $\left\{\mathrm{CV}^{\prime} \mathrm{C} ə\right\}$, where lexical distinctiveness ended up being concentrated in just one slot. For all these reasons, Hiu and Lo-Toga must definitely be included in the group of languages that historically went through the processes of vowel reduction and vowel hybridization.

24. The next section will show that Vera'a, on this matter, has exactly the same distribution. 
4.4.2 The special status of word-final vowels in Vera'a. The most complex situation with regard to the history of vowels appears in Vera'a. At first glance, such forms as sama 'outrigger' (POC *saman) or naka 'canoe' (POC *waga) would suggest that Vera'a has gone through neither vowel reduction nor vowel hybridization, and is simply conservative like Mota (cf. MTA sama and $a k a$ ). In fact, this parallelism is deceptive.

In a way similar to the two Torres languages, Vera'a regularly reflects certain $* \mathrm{CV}_{\mathrm{I}} \mathrm{CV}_{2}$ combinations as a closed syllable $\mathrm{CV}^{\prime} \mathrm{C}$ - see ( $\left.\mathrm{I}-5\right)$ - while others have preserved a disyllabic structure $\mathrm{CV}^{\prime} \mathrm{CV}_{\mathrm{f}}$. Interestingly, if we track them in the chart of regular correspondences of Vera'a, we find exactly the same nine pairs of vowels as the ones that were identified for Hiu and Lo-Toga: that is, those sequences in which $\mathrm{V}_{2}$ is [+low], whether intrinsically $(* a)$ or in comparison with $\mathrm{V}_{\mathrm{I}}$. A selection of examples is given in (25).

(25) Some disyllabic reflexes of *CVCV in Vera'a:

POC *talise 'Terminalia' > ?ilisז; POC *kuRita 'octopus' > wiri?r;

POC *aliton 'firewood' > ku/li? ; PNCV *b' ${ }^{w}$ eta 'taro' $>\overparen{k p^{w}} \boldsymbol{\varepsilon} \varepsilon \boldsymbol{\varepsilon}$;

POC * ${ }^{*}$ ata 'snake' > $\widetilde{\eta m}^{w} a$ ia; POC *na-ñoRap 'yesterday' > nonoro;

POC *kasupe 'rat' > yusuwo; POC *ma-tuqa 'ripe' > mu?uo.

The final vowel $\left(\mathrm{V}_{\mathrm{f}}\right)$ in all these forms calls for two comments.

First of all, $\mathrm{V}_{\mathrm{f}}$ has a special status in the phonology and morphology of Vera'a. Whereas it clearly belongs to the citation form of the word, and is always present at the end of an intonation unit, it is regularly dropped in the middle of a phrase (e.g., the first verb in a serial construction, or a noun followed by a modifier). Thus nigm ${ }^{w} I$ 'house' $\left(<*_{\mathrm{im}^{\mathrm{w}} \mathrm{a}}<\right.$ POC $\left.{ }^{*} \mathrm{Rumaq}\right)$ becomes shortened in phrases such as nigm ${ }^{w}$ rusu 'hospital (lit. house sick)' or nimm ${ }^{w}$ Pa?ar 'church (lit. house pray)'; likewise, naka 'canoe' loses its final vowel in nak susur 'canoe with no sail (lit. canoe paddle)'. This recalls the behavior of the posttonic schwa in Lo-Toga and Hiu, which is the only vowel that is prone to elide before another vowel: compare n-eka 'canoe' (POC *waga) with n-ek' o 'bamboo raft'. According to the phonological rules of these languages, such a deletion would never occur with full vowels. Thus no deletion is possible either for the final /a/ of MTA aka 'canoe', for the final /a/ of VRA Pala 'clam' (POC *talai), or the final stressed /ə/ of LTG y'to 'hermit crab' (POC *katou), for they all have the status of full vowels. This suggests that the final vowel $V_{\mathrm{f}}$ of Vera'a has a specific elidable status when (and only when) it proceeds from a posttonic [+low] $\mathrm{V}_{2}$ in a process of vowel reduction. ${ }^{25}$

A second observation concerns the phonetic quality of this vowel $V_{f}$ in Vera'a. Whereas the quality of the vowel $V_{2}$ in the etymon was independent from vowel $V_{1}$, this is no longer true in modern Vera'a, where the quality of $\mathrm{V}_{\mathrm{f}}$ is systematically correlated to that of the preceding vowel $V^{\prime}$, itself a direct reflex of protovowel $V_{I}$. This can be seen in (25): whenever $\mathrm{V}^{\prime}$ is a stressed $/ \mathrm{i} /$, then $\mathrm{V}_{\mathrm{f}}$ is systematically $/ \mathrm{I} /$, regardless of the precise nature of the protovowel $\mathrm{V}_{2}$. In fact, the nine sequences $* \mathrm{CV}_{\mathrm{I}} \mathrm{CV}_{2}$ with a [+low] $\mathrm{V}_{2}$ may be reflected

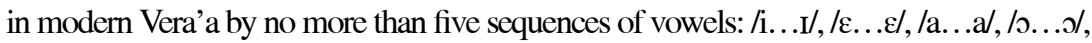
or $/ \mathrm{u} . . . v /{ }^{26}$ Clearly, while the quality of $\mathrm{V}_{2}$ during the initial step of vowel reduction was crucial in determining the general pattern of evolution for each etymon (i.e., whether

25. This status may be formulated in autosegmental terms, describing $\mathrm{V}_{\mathrm{f}}$ as a "floating vowel"see François (2000) about Mwotlap. 
$* \mathrm{CV}_{1} \mathrm{CV}_{2}$ was to be reflected by one or two syllables), it later played no role in determining the quality of the final vowel $\mathrm{V}_{\mathrm{f}}$. The latter is no more than a clone of the preceding stressed vowel — with the only caveat being that a high vowel had to be lowered by one

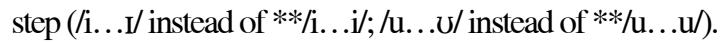

Historically speaking, a plausible hypothesis would suggest that Vera'a first went through a schwa stage. That is, sequences of two syllables $* \mathrm{CV}_{1} \mathrm{CV}_{2}$ satisfying the $\left\{\mathrm{V}_{2}=[+\right.$ low $\left.]\right\}$ condition changed initially into sequences ending with a central vowel $* / \mathrm{CV}^{\prime} \mathrm{C} ə$ /, resulting in forms very similar to the ones found in the modern Torres languages. Clearly, at this stage, some kind of vowel hybridization must have taken place, because phonological contrasts that were initially carried by two vowel slots eventually concentrated into a single vowel V'; see the discussion for Hiu and Lo-Toga. Later, a second process of vowel assimilation (rightward spread of phonetic features) occurred in Vera'a in such a way that the schwa was colored into becoming a (nonhigh) clone of V'. One would thus reconstruct *na-ñoRap > *nənərə > nonorə or *kuRita > *wəritə > wiri? (see 5.2.3 for initial syllables).

From this perspective, the tempting parallelism I first mentioned between Vera'a and Mota was a mere illusion. On the one hand, MTA $a k a$ has escaped vowel reduction and therefore preserved the two full vowels /a/ of the etymon. Conversely, VRA naka is the result of vowel hybridization, consisting phonologically of no more than one vowel /a/ that happens to surface in two subsequent syllables.

Considered from the perspective of the history of vowel systems, Vera'a is therefore another instance of vowel hybridization —albeit more complex than its neighbors.

4.5 SYNTHESIS. I have shown a correlation between, on the one hand, a stressinduced process of vowel reduction, and on the other hand, the phonemicization of new contrasts between vowels, resulting in an increase of vowel inventories in $\mathrm{I} 6$ out of the $\mathrm{I} 7$ languages spoken in the Torres and Banks Islands. After proposing a functional and structural hypothesis to account for the general evolution, a more detailed examination of the data has revealed the great variety of historical changes from one language to another, to such an extent that we will probably have to speak of parallel innovations that took place in each language separately. Yet, even if some languages proved unique in developing front rounded vowels, or diphthongs, or vowel length, or elidable word-final vowel slots, they have all followed essentially the same evolution involving vowel hybridization and its expansion of vowel inventories.

The following section examines certain specific cases of vowel change that occurred in word-internal and especially word-initial positions. Finally, section 6 mention the contribution of these phonological reconstructions to our understanding of the lexicon, morphology, and syntax of northern Vanuatu languages.

26. Another regular reflex concerns the two low mid vowels $/ \varepsilon /$ and $/ \rho /$ when the vowel changes resulted in a sequence $\mathrm{V}^{\prime} \mathrm{V}_{\mathrm{f}}$ with no consonant in between, that is, $* / \varepsilon \varepsilon /$ and */oo/. In this case, a dissimilation took place, whereby the first of the two adjacent low mid vowels $(\varepsilon, \diamond)$ became high

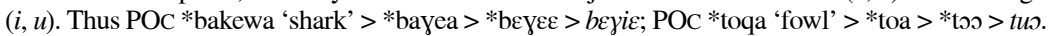
Note that these sequences /ie/ and /us/ are distributed into two syllable slots, unlike diphthongs. 
5. WORD-INTERNAL SPECIFIC RULES. So far, the present paper has been focusing on that part of protowords directly involved in vowel change: namely, the penultimate syllable that received primary word stress, associated with the immediately adjacent posttonic syllable. Indeed, the detailed examination of how these last two syllables of each etymon are reflected in modern languages provides all the keys that are necessary to solve most questions related to the history of vowels in the area.

Yet, the history of vowels in northern Vanuatu would not be completely described if no mention were made of the way longer etyma have been handled by the languages under discussion. I will discuss first the case of four- and six-syllable etyma, and leave for 5.2 the more complex analysis that is required by protoforms with an odd number of syllables.

\subsection{DO WORD-INTERNAL SYLLABLES REQUIRE SPECIFIC RULES?}

The general principle is that the same vowel changes occurred word-medially as wordfinally. That is, knowing that the protoforms were stressed on their penultimate syllable (primary stress noted by “'" ' in IPA) and received secondary stress every second syllable leftward (noted ","), one can say that the vowel correspondences that were defined in relation to primary stress normally apply also to word-internal syllables receiving secondary stress. For example, I have already mentioned POC *sayapuluq 'ten' > * saya'pulu > MSN say'wul (3.I).

Example (4) showed the set of correspondences for a two-syllable etymon *kani. Example (26) illustrates what can result from a sequence of two similar *a...i syllables in the reduplication of POC *Rapi 'evening'.

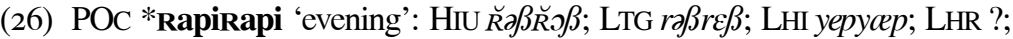

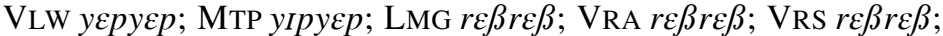
MSN $r \varepsilon \phi r \varepsilon \phi$; MTA $r a \beta r a \beta$; NUM $r \varepsilon \beta r \varepsilon \beta$; DRG $r a: \beta r I \beta$; KRO $r \varepsilon \beta r \varepsilon a \beta$; OLR raßraß; LKN raßßraß; MRL reprep.

Clearly, most languages (VLW, LMG, VRA, VRS, MSN, MTA, NUM, OLR, LKN, MRL) process the first half of the protoform ${ }^{*}$, Rapi' Rapi in the same way as the second half. Yet, other languages make a difference between word-internal and word-final syllables.

5.1.1 Asymmetries independent of vowel qualities. For two languages, namely Hiu and Lo-Toga, the asymmetry is systematic between primary and secondary stress, and does not depend on the actual vowels involved. Basically, only the last two syllables of the protoform will be reflected by a vowel of full quality, whereas all the rest will be reflected by schwa. This is an extreme effect of word stress in these two modern languages, which tend to centralize any vowel that does not receive primary stress.

(27) Some reflexes of four-syllable etyma in Lo-Toga:

POC *toka 'stay' $\rightarrow *$, toya'toya $>$ toya'toy

POC *matakut 'fear' $\rightarrow$ *ma,tayu'tayu $>$ mot 'y $^{\prime}$ 'toy

PNCV *domi 'think' $\rightarrow{ }^{*}$, domi'domi $>$ tom'torm

There are exceptions, however: words in which regular correspondences also apply word-internally: 
(28) Some reflexes of four-syllable etyma in Hiu and Lo-Toga:

POC *tabakau 'coconut leaf mat'> LTG, tepa'yo HIU, tapa'yo

POC *sanapulu(q) 'ten'> LTG, hega'wul HIU, tana' wiy

Lehali also tends to favor asymmetry within polysyllabic forms, regardless of the nature of the vowels:

(29) Some reflexes of four-syllable etyma in Lehali:

POC *Rapirapi 'evening' $\rightarrow{ }^{*}$ raßi'ra $\beta \mathrm{i}>$ yеружер

PNCV *bora 'coconut leaf basket' $\rightarrow$ *, bora'bora $>$ peypoy

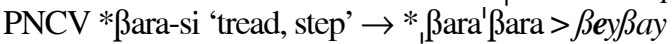

*urebarabara 'Ureparapara island' $\rightarrow$ *ure, bara'bara $>$ n/oypeypay

5.1.2 Asymmetries depending on vowel qualities. For the three remaining languages (Mwotlap, Dorig, Koro), the asymmetry between word-internal and word-final positions depends on the nature of the vowels. Most of the time, these languages treat all pairs of syllables *CVCV identically, whether they receive primary or secondary stress:

(30) Some symmetrical reflexes of four-syllable etyma in Mwotlap, Dorig, Koro: POC *pano 'go' $\rightarrow$ * „ßano'ßano > MTP/DRG/KRoßanßan

POC *sipo 'go down' $\rightarrow{ }^{*}$, sißo'sißo > MTP hrwhrw $\sim$ DRG/KRO sIwsIw

5.1.2.1 Primary vs. secondary stress in Mwotlap. Nevertheless, certain combinations of $* \mathrm{~V}_{1} \ldots \mathrm{V}_{2}$ have different reflexes according to where they appear in the protoword. Thus, while the regular outcome of word-final *a...i or *a...u in Mwotlap is $/ \varepsilon /($ see $[\mathrm{I}-4]$ ), it regularly takes the form of a higher vowel /I/ word-internally, that is, whenever the etymological vowel *a received secondary rather than primary stress. This was obvious in (26), where POC *Rapirapi > *, raßi'raßi > MTP угруєp. Other examples follow:

(3I) Some reflexes of word-internal *a...i and *a...u in Mwotlap:

POC *ma-takut 'afraid' $\rightarrow$ *ma, tayu'tayu $>$ mitrytey

POC *talina $>$ PNCV *dalina 'ear' $\rightarrow *$, dali' ya-na $>n I-$ drlna-n

PNCV *bwalika 'in-law' $\rightarrow{ }^{*}$, bwali' ${ }^{\text {wa }}$ a-na $>$ kp $^{w} I l y a-n$

PNCV *natu- 'offspring' $+{ }^{*} \mathrm{~m}^{\mathrm{w}} \mathrm{era}$ 'child' $\rightarrow{ }^{*}$ natu-'mwera $>$ nt $\widehat{\mathrm{tym}}^{w} \boldsymbol{\varepsilon} y$

POC *panua 'inhabited land' $\rightarrow{ }^{*}$ \& $\beta$ anu'a-gu $>n I-\beta I n \varepsilon-k$

POC *pari- 'reciprocal prefix' $\rightarrow{ }^{*}{ }_{1} \beta a r i->\beta r y-$

This specific rule affecting word-internal syllables is, in fact, no more than vestigial. The functional pressure toward morphological transparency has more recently triggered the elimination of such asymmetrical patterns of sound change (of the type yгpyzp), in favor of symmetrical structures. Due to this process of reanalysis and analogical reshaping, Mwotlap now possesses two sets of bisyllables originating from reduplicated ${ }^{*} \mathrm{CaCi}$ (or ${ }^{*} \mathrm{CaCu}$ ) roots. Those forms that are no longer perceived synchronically as reduplicative have maintained their asymmetrical shape up until now, as in (\#I54) 'tapitani 'goatfish' > MTP $n I-t I I t E \eta$. Other forms have been reanalyzed phonologically so as to fit a simpler, more iconic pattern, as in POC *tanis 'cry': *tanitani $\rightarrow$ tenteg 'cry: REDUP'. Likewise,

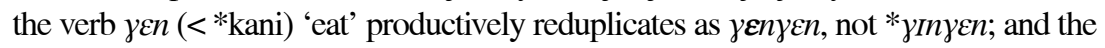
noun $n \varepsilon-\beta \varepsilon t$ (<*patu) 'stone' as $n \varepsilon-\beta \varepsilon t \beta \varepsilon t$ 'pebbles', not *nI- $\beta$ It $\beta \varepsilon t$. 
5.1.2.2 Asymmetries related to diphthongs. Another instance of asymmetry concerns diphthongs. Indeed, all the languages that possess diphthongal vowels (4.3) only allow them under primary stress, while word-internal syllables can only contain monophthongs. It is typologically well known that diphthongs tend to appear under word stress rather than in unstressed syllables. See, for example, the evolution from Latin to Spanish: Lat. 'focum 'hearth' > Sp. 'fuego 'fire' vs. late Latin fo' cāris 'hearth' > ho'gar. Thus, in Koro, the combinations *a...i and *a...u regularly brought about a diphthong $/ \overline{\varepsilon a} /$ under word stress, as in (I) and (2), but their outcome inside the word is normally $/ \varepsilon /$, as in (26) reßrea $\beta$. This raises the question as to how such forms should be represented. On the one hand, one may speak of an asymmetry in historical vowel correspondences, whereby $*_{\mathrm{a}}$... .i becomes a diphthong / / $/$ / under primary stress, but becomes a distinct phoneme / $/$ / elsewhere — see (3I) for Mwotlap. But this situation could also be formulated in synchronic terms, by saying that the diphthongal phoneme $\widetilde{\varepsilon a /}$ in Koro surfaces as [عa] under word stress, and as a monophthong $[\varepsilon]$ in other contexts-in such a way that a form like $[\mathrm{r} \varepsilon \beta \widetilde{\mathrm{r} \varepsilon a} \beta]$ would be considered the surface form of an underlying /rea $\widehat{\text { rea }} \beta /$. This formulation does not seem contradicted by currently available data. If things were to be considered from such a deep phonological level, Koro would then be counted in the group of "symmetrical" languages. Mwerlap shows a comparable situation: for example, the reduplicated form of /eal/ 'seek'

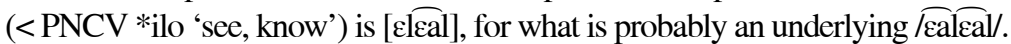

A similar pattern is also represented by Vurës, with its diphthong /ia/ already illustrated in (I5) and (I6). It only surfaces as [ia] under primary stress, whereas it takes the form of a monophthong [i] in all other contexts:

(32) Correspondence between stressed [ia] and unstressed [i] in Vurës:

PNCV *tabe 'love, honor' $\rightarrow$ *tabe-tabe $>$ timtiam 'loving'

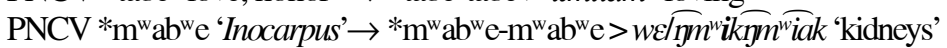

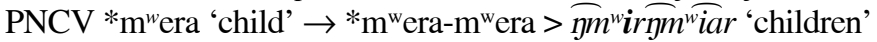

Two formulations are possible here. This contrast $[\mathrm{i}] /[$ [ia $]$ may alternatively be described either as the effect of an asymmetry in historical changes (/i/ and /ia/ being two different phonemes), or as a case of allophonic variation in synchrony ([i] and [ia] being two allophones of a unique phoneme $/$ ia $/) .{ }^{27}$

5.1.2.3 Asymmetries related to vowel length. Finally, one finds a similar phenomenon in Dorig, although it concerns vowel length rather than diphthongs.

Just as Koro, Mwerlap, and Vurës present a monophthong variant of their diphthongs in word-internal positions, the long vowel /a:/ of Dorig normally only occurs once within the word. ${ }^{28}$ Thus, the reduplication of a form like/yain/ 'eat' is not **yarnyar $n$ as would be expected. Now, two details are slightly unusual here. First, the shortened variant, as it were, of /a:/ is not [a] but [I]. Second, instead of affecting word-internal syllables as in all other

27. The synchronic morphology of Vurës tends to confirm the second of these hypotheses. Indeed, when $\overparen{\text { ia/ }}$ must be copied onto a prefix such as $m V$ - 'PRF' (5.2.4), the vowel of the latter is always a monophthong [i] (or [I]), never [ [ia]: e.g., $m V-+$ miat $\rightarrow$ mi-miat. This suggests that $[\mathrm{i}]$ is indeed the allophone taken by $/ \mathrm{ia} /$ in positions other than under primary stress.

28. Two exceptions are, however, mentioned in appendix 2: (\#9I) ma'nta: $b<{ }^{\circ} \operatorname{man}[\mathrm{i}, \mathrm{u}] \mathrm{tabu}$ 'Ptilinopus tannensis'; (\#I 54) ta'nta'y< 'tanitani 'goatfish'. 
languages reviewed so far (Lo-Toga, Lehali, Mwotlap, Koro, Vurës), the noncanonical reflex is found on the last syllable of the modern word. Compare (4) *kani 'eat' > yain with (33) *kanikani > ya'nyIn.

(33) Asymmetrical reflexes of *a...i and *a...u in Dorig:

POC *RapiRapi 'evening' $>$ *raßira $\beta \mathrm{i}>$ rat $\beta r i \beta$

POC *kanikani 'eat' > ya'nyIn

'sarusaru (\#I34) 'wear' > sarrsir

${ }^{\circ} \mathrm{m}^{[\mathrm{w}]} \mathrm{ab}{ }^{[\mathrm{w}]}$ usayi (\#IO4) 'breathe; take rest' > ma'bsry

Interestingly, although Dorig is otherwise a well-behaved oxytone language (e.g., [mar'mar] 'hard'), the presence of a long /a:/ word-internally tends to attract word stress: ['ra: $\beta \mathrm{rr} \beta]$.

5.2 DEALING WITH WORD-INITIAL SYLLABLES. So far, the demonstration has focused on the description of pairs of syllables starting from the end of the word, that is, the last two or four or six syllables of a given protoform. These pairs of syllables all shared the same structural feature, namely a sequence \{stressed $\sigma+$ posttonic $\sigma$ \}; and indeed this is the pattern for which all vowel changes have been defined so far (cf. the charts in appendix I).

I have said nothing yet about the third type of syllable that can be found in a protoform and that is neither stressed nor posttonic; namely, an unstressed word-initial (i.e., pretonic) syllable. Given the distribution of primary and secondary stress in the word, this means that the present section will be concerned with protoforms having an odd number of syllables - typically three or five. The rules that have been defined up to this point with regard to vowel hybridization do not make it possible to predict the evolution of this pretonic vowel (hereafter $\mathrm{V}_{\mathrm{i}}$ ). For example, how will these languages reflect the first /a/ in POC * panua 'inhabited land'?

(34) POC *panua 'inhabited land, village': HIU ßanie; LTG ßantz; LHI ßono;

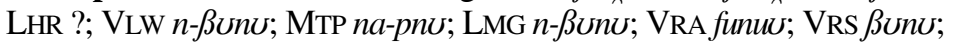
MsN $\beta u n v ;$ MTA $\beta a n u a ;$ Num funu; Drg ( $\beta n v) ;$ Kro $\beta u n v ;$ OlR $\beta u n v ;$ LKNßanv; MRL (ßUnv).

The following overview examines successively the four situations attested in my corpus: (a) $V_{i}$ remains unchanged; (b) $V_{i}$ disappears altogether; (c) $V_{i}$ assimilates to the following vowel; (d) $\mathrm{V}_{\mathrm{i}}$ becomes another vowel.

5.2.1 The pretonic vowel is maintained. Not surprisingly, Mota generally preserved pretonic vowels in a perfectly conservative way, as in ßапиа. The only exception to this principle is when $V_{i}$ was itself a high vowel $/ \mathrm{i} /$ or $/ \mathrm{u} /$, which indeed are the only phonemes subject to attrition in that language (3.2). This deletion of pretonic high vowels was not reported by Codrington (I885), and may well be a recent change. Thus, whereas Codrington noted MTA yilala 'know' ( $<$ POC *kilala), one frequently hears now in informal Mota the form ylala starting with two consonants. Other pairs include sinaya snaya 'vegetable food' (PNCV *sinaka); yire yre 'pandanus' (POC *kire); putepute ptepte 'sit'; liwoa lwoa 'big'; nila nya 'reach'. 
Apart from Mota, Lakon is the only language that has regularly preserved intact the pretonic vowel $\mathrm{V}_{\mathrm{i}}$ (e.g., ßanv). This is worthy of notice, because in other respects Lakon is perfectly representative of the process of vowel hybridization-including the deletion of all word-internal unstressed vowels other than the pretonic.

(35) The preservation of pretonic vowels in Lakon:

PNCV *dinori 'Cananga odorata' > tfinI:

POC *talise 'Terminalia' > talih

PNCV *b ${ }^{w}$ akare 'porcupine fish' $>* \widehat{k p}^{w}$ ayare $>\overparen{\text { pp}^{w}}$ ayar'

POC *bakewa 'shark' > *bayea $>$ paye

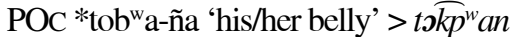

POC *buto-ña 'his/her navel' > puton

The assimilation of $\mathrm{V}_{\mathrm{i}}$ to the following vowel, which is the norm in many other languages (5.2.3), is only marginal in Lakon:

(36) The assimilation of certain pretonic vowels in Lakon:

PEOc *parage 'Pangium edule' $>$ * $\beta$ arake $>$ Bar rak

POC *[wa]lasi 'Semecarpus vitiensis' $>$ *alasi $>$ a loch

POC *katou 'hermit crab' > * yatou $>$ yItI

POC *kuRita 'octopus' $>$ * yurita $>$ wIrIt

POC *kasupe 'rat' $>$ * \asuße $>$ wohww

Furthermore, Lakon has even preserved certain pretonic vowels that were lost in all other languages of the area-including the otherwise conservative Mota. For example, compare the reflexes of word-initial *a in Lakon and Mota:

(37) The preservation of pretonic vowels in Lakon:

POC *aliton 'firewood' $>$ LKN alit $\sim$ MTA lito

PNCV *?anari 'Canarium' > *anai > LKN ayce MTA gai

PNCV * Raßua 'turtle' > *awua > *auwa > LKN aww MTA uwa

As far as the preservation of pretonic vowels is concerned, Mota and Lakon are therefore the two most conservative languages of the whole group. This will make these two languages valuable when it comes to lexical reconstruction (6.I).

5.2.2 The pretonic vowel is deleted. The total deletion of $V_{i}$ had different implications, and indeed shows a totally different distribution across the area, depending on the phonotactic structure of the protoform. Sometimes, the etymon—or more exactly, the form taken by the etymon in the last stage before vowel reduction took placelacked a consonant before and/or after $\mathrm{V}_{\mathrm{i}}$, thus taking the form $\# \mathrm{~V}_{\mathrm{i}} \mathrm{CV}$ - or $\# \mathrm{CV} \mathrm{i}$ - or $\# \mathrm{~V}_{\mathrm{i}} \mathrm{V}$ - In that case, the deletion of $\mathrm{V}_{\mathrm{i}}$ caused no problem in the majority of languages, as shown by the Mota examples in (37), as well as the Vera'a data in (38).

(38) The loss of pretonic vowels in Vera'a:

PNCV *?aßua 'turtle' $>$ *awua $>$ *a'uwa $>$ n/uw

(POC *qebal) PNCV *?eba-gu 'my mat' $>$ *e'ba-gu $>b o-k$

(POC * Rumaq) PNCV *yum ${ }^{\mathrm{w}} \mathrm{a}$-gu 'my house' $>*^{*}{ }^{\prime} \mathrm{m}^{\mathrm{w}} \mathrm{a}-\mathrm{gu}>\widehat{\eta m}^{w} \mathrm{o}-k$ 
(POC *waga) PNCV *waga-gu 'my canoe' $>$ *a'ga-gu $>k o-k$ 'POSS CLF for vehicles, I.SG'

But the situation was different when $V_{i}$ was surrounded by two consonants in a $\# \mathrm{CV}_{\mathrm{i}} \mathrm{CV}$ - pattern. In this case, its deletion logically implied the creation of an initial consonant cluster \#CCV- at the word boundary. This is a phonotactic pattern that most Oceanic languages avoid — and that indeed was avoided in my entire corpus, except for a single language: Dorig (and to a lesser extent, its dialect Koro).

(39) Emergence of word-initial consonant clusters in Dorig:

POC *kasupe 'rat' > *ya'suße > ysuw;

PEOC *bakuRa 'Calophyllum sp.' > *ba' yura $>$ byor;

PNCV *gamuyu 'you plural' > *kamiu > kmi;

PNCV $* b^{w}$ akare 'porcupine fish' $>* \widehat{\mathrm{kp}}^{\mathrm{w}} \underline{\mathrm{a}}^{\prime}$ yare $>\widehat{\boldsymbol{k p}}^{w} \mathrm{y}$ ar;

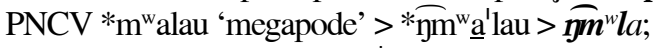

POC *kuRita 'octopus' $>$ * $\underline{u}^{\prime}$ 'rita $>$ writ.

As a consequence, a fair part of the Dorig lexicon consists of \#CCV- words, with no restriction whatsoever on the nature of the consonants that may cluster together. This phonological characteristic of Dorig is remarkable not only in the Pacific context, but also on a worldwide scale. As far as northern Vanuatu is concerned, word-initial CC clusters are sometimes attested (see the Mota examples cited earlier), but always marginally — unlike Dorig, where this phonotactic pattern is perfectly standard.

5.2.3 The pretonic vowel is a copy of the following vowel. The third solution, by far the best represented throughout my corpus, consists of the pretonic vowel $V_{i}$ totally assimilating to the vowel of the immediately following syllable. This change was in fact the norm for ten languages: LHI, LHR, VLW, LMG, VRA, VRS, MSN, NUM, KRO, and OLR - see (34) above. The phenomenon is illustrated here with Mwesen:

(40) Assimilation of $V_{i}$ to the following vowel in Mwesen:

PNCV *bisu-gu 'my finger' $>p \boldsymbol{u}^{\prime} s u$ - $k$; POC *katou 'hermit crab' $>\gamma \boldsymbol{u}^{\prime} t v$; POC *nako-ña 'his/her face' > n' $y 0-n$; POC *bakewa 'shark' > *bayoa > p' $\gamma o$; POC *tob ${ }^{w}$ a-ña 'his/her belly' > ta' $\mathrm{kp}^{w}$ an; POC *kapika 'Syzygium' > yı'ßIx; PNCV *gamami 'we EXCL'> ke'mem; PNCV *gamuyu 'you PL'> *kamiu $>$ ki'mi.

5.2.3.1 Historical interpretation vs. synchronic model. The loss of the phonetic identity of $\mathrm{V}_{\mathrm{i}}$ was to be expected during such a massive vowel reduction process as the one that took place in the entire area. This alteration was initially due to the prosodic status of $\mathrm{V}_{\mathrm{i}}$ as a pretonic vowel, and therefore to its articulatory and acoustic weakness. In a way, this makes the preservation of $\mathrm{V}_{\mathrm{i}}$ in Lakon even more striking. From a historical perspective, it is likely - though not necessary-that at least some of these languages went through a schwa stage, whereby all pretonic vowels became centralized before assimilating to the following vowel: POC *nako-ña > *nə'yənə > n' $y \supset n$. This hypothesis is validated somewhat by the forms attested in Hiu and LoToga, as if these two Torres languages provided the missing link to account for the forms found in the Banks Islands: for example, LTG pa'htt-k 'my finger', nə'yo-nə 'his/her face', ya'ßiza 'Syzygium', ka'mem 'we ExCL', ka'mi 'you PL'. 
In fact, an alternate analysis that would adopt a synchronic perspective would be possible for all these languages. Rather than assuming that $V_{i}$ preserved its vowel slot (unlike Dorig) while borrowing its phonetic quality from the next vowel, it would be equally accurate to say that $\mathrm{V}_{\mathrm{i}}$ disappeared altogether during the vowel reduction process in all these languages as well as in Dorig (*nako-ña > nyon); and that a phonological rule of VOWEL EPENTHESIS later took place in all these languages (except Dorig), that would break word-initial consonant clusters by inserting a clone of the following vowel (*nyon $\rightarrow$ nəyon). Indeed, this rule is required as it is by the synchronic phonological analysis of each of these languages, regardless of the etymology of the lexical items: for example, Eng. play cards was borrowed into Mwotlap under the form belkkat.

Even if they take a different perspective, the historical explanation (with a schwa stage and feature assimilation) and the synchronic analysis (with vowel epenthesis) are complementary and account for two facets of the same phenomenon (see François 2000). Certain instances of hesitation in fluent speech and reanalyses (François 200I:I029) strongly suggest that, from a cognitive point of view, these lexical items are in fact memorized as if they consisted of only a single vowel that distributes itself into as many vowel slots as it can. This can be formulated using the autosegmental approach and a multi-tiered representation separating vowels from consonants ("planar V/C segregation" in McCarthy [1989]):

(4I) MSN: 'his/her face' $\left\{n_{-} \gamma_{-} n\right\}_{C} \times\{0\}_{v} \Rightarrow /$ oyon/

Vera'a involves the distribution of the same vowel not only into two, but sometimes three vowel slots (see 4.4.2):

(42) VRA: 'yesterday' $\left\{\mathrm{n}_{-} \mathrm{n}_{-} \mathrm{r}_{-}\right\}_{\mathrm{C}} \times\{0\}_{\mathrm{V}} \Rightarrow$ /nэnorə/

To be precise, the word-final vowel slot of Vera' a goes with a condition, namely that this vowel must be [-high]. Hence the phonological formula of (43):

(43) VRA: 'octopus' $\left\{\mathrm{w}_{-} \mathrm{r}_{-}{ }{ }_{\text {_[-high }]}\right\}_{\mathrm{C}} \times\{\mathrm{i}\}_{\mathrm{v}} \Rightarrow /$ wiri? $\mathbf{I} /$

This analysis fits most of the data for this set of "vowel-copying" languages.

5.2.3.2 Vowel copy and the phonological word in Mwotlap. In general, Mwotlap treated pretonic vowels in exactly the same way as Mwesen and other similar languages, that is, by assimilating them to the following vowel, as in *gamami > kemem; *gamuyu $>$ kimi. But what makes the picture different here is that Mwotlap systematically treated the nominal article *na (as well as a number of other morphemes preceding nouns, adjectives, and verbs) as if it were integrated into the phonological noun. While still functioning syntactically like any article in the area, including the possibility of its absence, *na became a prefix in Mwotlap. ${ }^{29}$

On the one hand, all other languages treated a sequence $\{$ Article + Noun $\}$ as if it consisted of two distinct phonological words, leaving the article aside, and processing the first syllable of the noun root as a pretonic syllable: for example, *na mata-gu ('my eyes') became VRS na motoe- $k$. On the other hand, Mwotlap treated the same sequence as a sin-

29. The phonology, morphology, and syntax of noun articles in northern Vanuatu are outlined in François (forthcoming). 
gle word, in such a way that what was elsewhere a pretonic vowel $V_{i}$ was eventually to be processed as a word-internal posttonic vowel. When the noun consisted of an odd number of syllables (e.g., *ma'ta-gu with three), then the article *na logically received stress, in which case it was systematically preserved as /na/, as in * na-ma'ta-gu > MTP na-mte- $k$. In the latter form, no vowel copying took place, because the etymon had no pretonic vowel $\mathrm{V}_{\mathrm{i}}$ : thus * na-ma'ta-gu evolved like any four-syllable etymon would have in Mwotlap (cf. * taba'kau > tamye 'mat'). As a corollary to this point, the protoforms that can be chosen to illustrate the process of pretonic vowel assimilation in other languages, as in (34) or (40) above, are generally not relevant for Mwotlap, because the addition of a prefix changed the whole phonotactic structure: for example, in (34), МтP na-pnu does not illustrate the phenomenon of vowel copying as the other languages do.

This does not mean that Mwotlap ignored this vowel-cloning process altogether, but that it applied it to different forms. There are two kinds of etyma that can illustrate this point for Mwotlap. One would consist in taking the same etyma as for other languages, but only in those syntactic contexts where Mwotlap removes the article (François 200I:I87-2I4; forthcoming), as when the noun functions as a modifier to another noun, or is incorporated into a verb. In those cases, the protoform had no prefixed article, and thus behaved in the same way as in (40). Thus, while the article is included in the citation form na-pnv 'village' ( $<*$, na- $\beta a$ 'nua), it disappears in $n a-h \varepsilon$ $\beta \boldsymbol{U} n \boldsymbol{y}$ 'name of village' ( $<* \beta a$ 'nua). Indeed, like most of its neighbors, Mwotlap avoids consonant clusters word-initially, and automatically inserts a vowel slot after the first consonant: a form like **pnu would be excluded.

The second way to illustrate vowel copy in Mwotlap is by choosing etyma with an even number of syllables and seeing what their reflex will be with the article *na as an extra syllable. Remarkably, for all these protoforms, Mwotlap is perfectly systematic in applying the rule of vowel assimilation to the pretonic vowel $\mathrm{V}_{\mathrm{i}}$-in this case, to the article *na itself:

(44) The rule for vowel copy on the article *na in Mwotlap: POC *na kutu 'louse' > ni-yit; POC *na molis 'Citrus sp.' > nI- $\widehat{\eta m}^{w} I l$;

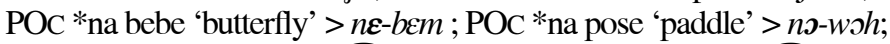
POC *na boni 'night' > nu- $\widehat{k p}^{w} U \eta$; POC *na bulit 'gum' > nu- $\widehat{k p}^{w} u l$; (POC *panua) *na ßanua-gu 'my country' $>n I-\beta I n \varepsilon-k$.

This process accounts for the emergence of one of the most complex rules of Mwotlap morphology: namely, the mechanism of vowel copy on eight prefixes (François I999; 2000; 200I:96-I28). For historical reasons, this rule applies exclusively to those lexical roots that begin with a single consonant (reflecting a protoform in which the prefix was pretonic, as in $n I-\beta I n \varepsilon-k<*_{n a}$ ßanu'a-gu) and never to those that begin with two consonants (reflecting a protoform in which the prefix received secondary stress, such as na-pnu<*,na ßa'nua).

Incidentally, the need to formulate this principle as an ongoing phonological rule in synchrony-rather than just considering it as the vestigial result of historical changes - is proved by the shape of certain loanwords. Thus \#CV-loans must make the vowel copy (nu-bus 'cat' < Eng. puss; no-bomdete 'potato' < Fr. pomme de terre) whereas \#CCV- loans normally do not (na-mlekat 'playing cards'; na- $\widetilde{k p}^{w}$ lismen 
'policeman'). In other words, Mwotlap speakers have reanalyzed as a phonological constraint in synchrony what is fundamentally the result of complex vowel changes in history involving vowel hybridization and feature assimilation.

5.2.4 The pretonic vowel is altered. Finally, the last possibility is for the pretonic vowel $V_{i}$ to be reflected with neither its original quality nor a quality directly borrowed from the following vowel, but with yet another vowel.

In Hiu and Lo-Toga, this occurs systematically, because all pretonic vowels are reflected as the central vowel /a/: see (24) LTG ya'httwa, pa' yewa, ya' ritz. Marginally, a tendency toward vowel copy seems to be emerging in Hiu, with such forms as yt'stwo as a variant to $y$ 'stwo.

A language that appears to be less predictable in this respect is Mwerlap. On the one hand, Mwerlap shows instances both of pretonic vowel preservation (e.g., *papine

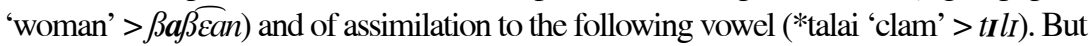
on the other hand, it also has numerous instances in which $V_{i}$ became a different vowel:

(45) Alteration of pretonic vowels in Mwerlap:

POC *ma-turuR 'sleep' > mstur; POC *katou 'hermit crab' > yotur ;

POC *tama-gu 'my father' $>t o m s-k ;$ POC *tob ${ }^{w}$ a-gu 'my belly' $>t \nless k^{w} \mathrm{o}-k$;

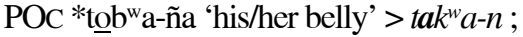

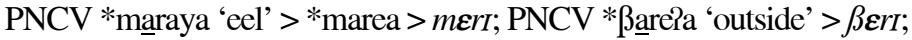

PNCV *b" ariki 'today' $>k^{w} \varepsilon r i m$; PNCV *gamuyu 'you pl.' $>$ *kamiu $>$ kEmi.

A probable scenario is that the pretonic vowel was first reduced to schwa before undergoing partial assimilation to the following vowel: $* \mathrm{~V}_{\mathrm{i}}>*_{\partial}>/ \varepsilon /$ before spread vowels, $* V_{\mathrm{i}}>*_{\partial}>/ \mathrm{s} /$ before rounded vowels, $* \mathrm{~V}_{\mathrm{i}}>*_{\partial}>/ \mathrm{a} /$ before /a/. In this sense, Mwerlap followed essentially the same change mechanism as vowel-copying languages, with the only difference being that the assimilation of $\mathrm{V}_{\mathrm{i}}$ to the following stressed vowel was only partial.

In a way similar to Mwotlap, the article *na in Mwerlap is integrated into the noun as a prefix. As a consequence, it takes part in these vowel alterations in the same way as any initial syllable would - sometimes fully assimilating to the next vowel (e.g., $n I-k^{w} I t$ 'taro'), and sometimes showing only partial assimilation:

(46) Alteration of the vowel of the article *na in Mwerlap:

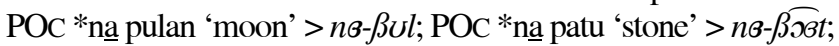

POC *na ma-gu 'my drink (POSS CLF)' >ns-mo-k;

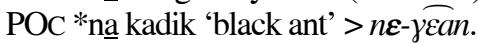

Finally, the language of Vurës shows a situation similar to Mwerlap. While the general rule was for $\mathrm{V}_{\mathrm{i}}$ to copy the quality of the following vowel (PEOC *bakuRa 'Calophyllum sp.' > boyur; POC *katou 'hermit crab' > $ø \varnothing t \phi$; POC *kuRita 'octopus' $>$ wrrtt), there was one exception. When the stressed vowel resulting from hybridization was a high monophthong (either /i/ or / $/ \mathrm{i} /$ ), then $V_{\mathrm{i}}$ became the corresponding high mid vowel. This explains why so many words in Vurës have the shape $(\mathrm{C}) \boldsymbol{r}(\mathrm{C}) i(\mathrm{C})$ or $(\mathrm{C}) \boldsymbol{\varphi}(\mathrm{C}) \ddot{u}(\mathrm{C})$ : 
(47) Alteration of pretonic vowels in Vurës:

POC *paliji 'grass' > Brlis; PNCV *gamuyu 'you pl.' > *kamiu > kami;

POC *banic 'wing' $\rightarrow$ *bani-gu 'my arm/hand' $>$ brni-k;

PNCV *ßasusu 'give birth' > $\beta$ øsüs; POC *natu-gu 'my child' >nøtü- $k$;

POC *takuRu 'back' > tøwür 'behind, after'.

In the spirit of (42-43) above, these modern forms could be represented using a simple, autosegmental formula:

$$
\left\{\mathrm{C}_{\mathrm{I}-[- \text { high }]} \mathrm{C}_{2}-\mathrm{C}_{3}\right\}_{\mathrm{C}} \times\{\mathrm{V}\}_{\mathrm{V}}
$$

This formula should cover both total assimilation (copy) and partial assimilation of the pretonic to the following vowel, and thus fit most lexical items based on three-syllable etyma:

(48) Total and partial assimilation of the pretonic in Vurës (an autosegmental representation):

\begin{tabular}{|c|c|}
\hline $\begin{array}{l}\text { 'Calophyllum' } \\
\text { 'hermit crab' } \\
\text { 'octopus' } \\
\text { 'grass' } \\
\text { 'behind' }\end{array}$ & 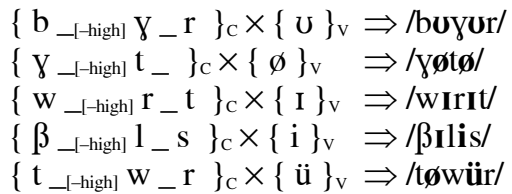 \\
\hline
\end{tabular}

Just as in Mwotlap and Mwerlap, several morphemes in Vurës behave like any word-initial pretonic syllable, thereby revealing their prefixal status. For example, the four TAM markers $t \mathrm{~V}$ - 'PROG', $m \mathrm{~V}$ - 'PRF', $\gamma \mathrm{V}$ - 'STATIVE-FUT', $\gamma \mathrm{V} t \mathrm{~V}$ - 'NEG' inherit their vowel from the first syllable of the following verb root (e.g., $\gamma \boldsymbol{a}-\beta a n$ 'will go', $\gamma^{\prime} t \varepsilon-l \varepsilon$ 'did not take'). But when the latter is a high vowel /i/ or /ï/, then the rule is normally for the prefix vowel to take the corresponding high mid quality, as in

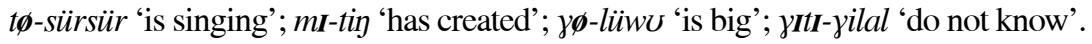

This last point illustrates once again how the complex patterns of vowel change can still affect the synchronic morphology of modern languages. Section 6 examines in detail the various ways in which vowel hybridization, as a phonological process in history, has left its traces in the lexicons and grammars of all these northern Vanuatu languages.

5.3 SUMMARY TABLE. The various analyses presented in the preceding pages are summarized in table 4. For each language, the following information is given:

- whether etymological posttonic vowels $\left(\mathrm{V}_{2}\right)$ were lost during vowel reduction in "all" or in just some instances (3.I, 4.4);

- whether vowel hybridization took place: that is, whether the reflexes of stressed $\mathrm{V}_{\mathrm{I}}$ were regularly conditioned by posttonic $\mathrm{V}_{2}$ before their deletion (3.2);

- whether the outcome of vowel hybridization under secondary stress was the "same as" or "different from" the outcome under primary stress (5.I);

- whether etymological pretonic vowels $\left(\mathrm{V}_{\mathrm{i}}\right)$ were preserved unchanged, or were altered, or underwent total or partial assimilation to the following vowel (5.2).

Where more than one option was valid for the same language, I indicate the one that is statistically most significant. 


\section{VOWEL HYBRIDIZATION AND LANGUAGE RECONSTRUCTION.}

Beyond its intrinsic interest for Oceanic linguistics or typological phonology, the historical model of evolution I propose here also constitutes a useful key to the understanding of a variety of linguistic facts in all the languages of northern Vanuatu.

I divide this section into two parts: first, the domain of LEXICAL RECONSTRUCTION; and second, the study of HISTORICAL MORPHOLOGY and its syntactic corollaries, especially regarding the marking of objects on the verb and possessors on the noun.

\subsection{LEXICAL RECONSTRUCTION}

6.1.1 Methodological preliminaries. Through a detailed examination of all Torres and Banks languages, I have attempted to track the evolution of their vowels, whether positioned at the end, middle, or beginning of words. Setting aside a certain number of exceptions, most of the modern forms attested in the Torres and Banks languages should now appear unproblematic from a historical point of view.

\section{TABLE 4. PATTERNS OF VOWEL CHANGE IN NORTHERN VANUATU:} SUMMARY

\begin{tabular}{|c|c|c|c|c|c|}
\hline LGG & NAME & $\begin{array}{l}\text { LOSS OF } \\
\text { POSTTONIC V2? }\end{array}$ & $\begin{array}{l}\text { VOWEL } \\
\text { HYBRID- } \\
\text { IZATION? }\end{array}$ & $\begin{array}{l}\text { PRIMARY VS. } \\
\text { SECONDARY } \\
\text { STRESS OUTCOME? }\end{array}$ & PRETONIC VOWEL VI \\
\hline HIU & Hiu & $\begin{array}{l}{[- \text { sonorous }]>\emptyset} \\
{[+ \text { sonorous }]>/ \partial /}\end{array}$ & yes & different & altered $>/ \partial /$ \\
\hline LTG & Lo-Toga & $\begin{array}{l}{[- \text { sonorous }]>\emptyset} \\
{[+ \text { sonorous }]>/ \partial /}\end{array}$ & yes & different & altered $>/ \partial /$ \\
\hline LHI & Lehali & all & yes & different & total assimilation \\
\hline LHR & Lehalurup & all & yes & same & total assimilation \\
\hline VLW & Volow & all & yes & same & total assimilation \\
\hline МтP & Mwotlap & all & yes & $\begin{array}{l}\text { same } \\
\text { except } * a . . .(i, u)\end{array}$ & $\begin{array}{l}\text { total assimilation } \\
\text { (including prefixes) }\end{array}$ \\
\hline LMG & Lemerig & all & yes & same & total assimilation \\
\hline VRA & Vera’a & $\begin{array}{l}{[- \text { sonorous }]>\emptyset} \\
{[+ \text { sonorous }]>V_{f}}\end{array}$ & yes & same & total assimilation \\
\hline VRS & Vurës & all & yes & $\begin{array}{l}\text { same } \\
\text { except diphthong }\end{array}$ & $\begin{array}{l}\text { partial assimilation } \\
\text { (including prefixes) }\end{array}$ \\
\hline MSN & Mwesen & all & yes & same & total assimilation \\
\hline MTA & Mota & high $* \mathrm{i} / \mathrm{u}>\emptyset$ & no & same & $\begin{array}{l}\text { unchanged } \\
(\text { except high } * \mathrm{i} / \mathrm{u}>\emptyset)\end{array}$ \\
\hline NuM & Nume & all & yes & same & total assimilation \\
\hline DRG & Dorig & all & yes & $\begin{array}{l}\text { same } \\
\text { except long vowel }\end{array}$ & deleted \\
\hline KRO & Koro & all & yes & $\begin{array}{l}\text { same } \\
\text { except diphthong }\end{array}$ & total assimilation \\
\hline OLR & Olrat & all & yes & same & total assimilation \\
\hline LKN & Lakon & all & yes & same & unchanged \\
\hline MRL & Mwerlap & all & yes & $\begin{array}{l}\text { same } \\
\text { except diphthongs }\end{array}$ & $\begin{array}{l}\text { partial assimilation } \\
\text { (including prefixes) }\end{array}$ \\
\hline
\end{tabular}


To take just one example, such forms as MTP na-tys, VRA ?urus, and LKN taro 'Columba vitiensis' now clearly appear to be perfectly regular and predictable reflexes - taking into account each language's own history—of their PNCV etymon *taroa ('white-throated pigeon'). Even better, had not this etymon already been reconstructed based on other languages (Clark, in prep.), the model and rules proposed in the present study should be powerful enough to calculate the form *taroa based only on these three modern reflexes.

Indeed, the absence of vowel copy on the article $n a$ - in Mwotlap indicates that it was followed by an odd number of syllables, in this case three: hence * $\mathrm{VrVV}$. The quality of the pretonic vowel is revealed by Lakon: hence *tarVV. As for the identity of the last two vowels, the charts in appendix I for both Mwotlap and Lakon show that $/ \mathrm{J} /$ may reflect either ${ }^{*} \mathrm{o} . . . \mathrm{e},{ }^{*} \mathrm{o} . . . \mathrm{a}$, or ${ }^{*} \mathrm{o} . . . \mathrm{o}$ : the penultimate vowel of the protoform was thus necessarily *o, hence *taroV. Finally, the Vera'a final sequence /us/ is the regular reflex of a sequence *oa with no intervening consonant (see fn. 26). Consequently, the only possible source for these three modern forms necessarily had the form *taroa.

Up until now, I have always endeavored to illustrate each phonetic change with etyma already well established, either from Proto-Oceanic or from Proto-North-Central Vanuatu (see fn. 5). But now that all regular correspondences (appendix I) as well as the general processes of change have been firmly established, it becomes possible to utilize them as a tool for the discovery of new unknowns. In particular, one can reconstruct certain lexical items that are particularly well reflected in northern Vanuatu, but whose protoforms were until now unclear, due to the complexity of modern vowel systems and the embarrassing variety of attested forms. The result of this research takes the form of a selection of lexical reconstructions, given in appendix 2 .

6.1.2 Paving the way for subgrouping studies. The reconstructions proposed in appendix 2 are not necessarily intended to describe any specific protolanguage, such as a hypothetical "Proto Torres-Banks." Such a claim would require external data and further discussion that lie beyond the scope of the present study. Nevertheless, subgrouping matters are not totally absent from this list of reconstructions, albeit indirectly.

The rationale behind this list is to show how the understanding of vowel hybridization constitutes the first necessary step in any effort toward unraveling the genetic history of northern Vanuatu languages. Indeed, not only does it help assess the cognacy of modern forms, but it even permits us to reconstruct protoforms. To take just one example, the correspondences regarding vowels and consonants now make it clear that LHI hoy and LKN $s a$ ' ('put on, wear') are cognate; and that they both point toward an etymon of the form ${ }^{\circ}$ saru..$^{30}$ The other languages of the area suggest the same protoform:

(\#I34) 'saru 'put on, wear (clothes+)': LTG hor; LHI hoy; MTP hey; VRS sor; MTA sar; DRG sa'r; LKN sa'.

Obviously, this stage of identifying cognate sets and reconstructing likely protoforms is a prerequisite before any language comparison - whether inside or outside the area under study — can even begin. Only then will it become possible to track the geo-

30. In order to distinguish typographically my own reconstructions from already established etyma, I shall use the degree sign ${ }^{\circ}$ instead of the asterisk *, hence ${ }^{\circ}$ saru. 
graphic expansion of each etymon's reflexes, and thus to tackle the issues of subgrouping and protolanguage reconstruction per se. The complex issues of genetic classification must be kept for future research. However, I briefly illustrate here, with two examples, the usefulness of the vowel hybridization model when it comes to formulating fine-grained subgrouping hypotheses based on lexical data.

Despite their variety, the forms taken by the I.EXCL DU pronoun can be grouped in two sets. In the first set, the pronoun's last vowel is the regular reflex of a sequence $*_{u}$...a: this is the expected outcome of a protoform ${ }^{\circ}$ gama'rua (<*rua 'two'). In the second set (underlined below), the hybridization pattern involved is $*_{\mathrm{a}}$...u, pointing to a truncated variant ${ }^{\circ}$ ga'maru:

(\#67) 'gamarua 'gamaru 'I.EXCL.DU independent pronoun': HIU kamař LTG kamor; LHI mayo; VLW gemyu; MTP kamyu; LMG kamaru; VRA kamaduv; VRS kumuruk; MSN kememru; MTA (kara); NuM kamar; DRG kma'r; KRO kemear; OLR kimIy; LKN yamar; MRL kamar.

Interestingly, the reflexes of ${ }^{\circ}$ gamaru (setting aside Lo-Toga) outline a consistent geographical area: the six southernmost languages of the Banks group. Along with additional evidence (François 2004), this sort of observation could well prove helpful in defining shared innovations and diagnosing subgroups - in this case, a possible southern Banks branch (?) within the small group of northern Vanuatu languages.

The same method can also help define the precise form taken by a well-known Oceanic etymon in this particular area. For example, Torres and Banks languages designate kava with forms that generally contain a front vowel:

(\#6I) … 'kava': HIU $a$; LTG $\gamma i$; VLW na- $a$; LHR $n$ - $\gamma a$; MTP na- $a$; LMG $n-\gamma a$; VRA $\gamma \boldsymbol{i} \boldsymbol{\varepsilon} ;$ VRS $\gamma \boldsymbol{I}$; MSN $\gamma \boldsymbol{\varepsilon}$; MTA $\gamma \boldsymbol{e} a$; DRG $\gamma \boldsymbol{\varepsilon}$; KRO $\gamma \boldsymbol{\varepsilon}$; OLR $\gamma \boldsymbol{\varepsilon}$; LKN $\gamma \boldsymbol{\varepsilon}$; $\operatorname{MRL}($ ns-mslup).

Most of these items reflect a premodern form *yea, while a few (HIU, LHR, VLW, MTP, LMG) suggest * yaa. This matches exactly the usual distribution of reflexes when the etymon shows a sequence */aya/. Consider the forms for 'eel' (PNCV *maraya):

(\#95) maraya 'moray, eel' [PNCV *maraya]: HIU ?; LTG məri; LHR ?; VLW n-maya; MTP na-mya; LMG ?; VRA merie; VRS marı; MSN ?; MTA marea; NUM ?; DRG mre; KRO mere; OLR mere; LKN mare; MRL $n \varepsilon$-merI.

This means that the most probable reconstruction for 'kava' in the Torres and Banks would take the form ${ }^{\circ}$ yaya. Crucially, this might be an irregular reflex of POC *kawar(i) 'root with special properties; ${ }^{31}$ kava' (Lynch 2002), involving an unexpected change of glide from ${ }^{*} \mathrm{w}$ to $*_{\mathrm{y}}$ : ${ }^{\mathrm{k}} \mathrm{kawa}(\mathrm{R}) \rightarrow *$ kaya $>$ *yaya. If this hypothesis were to be confirmed by additional data, such an instance of irregular sound change would constitute strong evidence toward the identification of a shared innovation, and hence of a possible subgroup..$^{32}$

3I. POC *kawaRi was also retained under the form *yawari $>$ *yoari 'root'-see (\#63).

32. The precise shape of the *kaya isogloss remains to be ascertained. Although most other Vanuatu languages show a reflex of "early post-PCNV *maloku" (Lynch 2002), *kaya is also witnessed in southern Espiritu Santo, with Araki hae 'kava' (François 2002:250). The sequence /ae/ recalls the form marae 'eel' taken by PNCV *maraya in several nearby languages, such as Raga (Clark, in prep.). 
6.1.3 Tracing back the paragogic *-i. In sum, although vowel hybridization per se cannot be taken as diagnostic evidence for subgrouping matters (see 3.4), it proves useful when it comes to identifying cognate sets and reconstructing protoforms. As we have just seen, the evidence it provides is all the more valuable when it helps trace back irregular sound change. In this regard, another instance of formal irregularity in the lexicon deserves discussion here, because of its statistical significance in northern Vanuatu: the existence, in a number of lexemes scattered throughout the area, of a nonetymological final vowel *-i.

A first observation is that for some lexemes, several northern Vanuatu languages appear to have unexpectedly preserved a final consonant of a POC etymon that normally was supposed to have disappeared long ago. For example, the final *p in POC $*_{\text {Ruap }}$ 'high tide', as expected, was deleted in MTP $\left(*^{*}\right.$ Ruap $>*^{*}$ rua $>$ ) yv; but it was surprisingly preserved in MTA ruaß, NUM rue $\beta$, MRL rusp. Once again, the key to the problem is not the history of consonants, but of vowels. These three forms become perfectly regular again if their etymon is reconstructed not as *rua $(\beta)$, but as *rua $\beta$-i, with an extra vowel *i. Indeed, the charts of these three languages in appendix I reveal that the regular reflexes of $* a . . . \mathrm{i}$

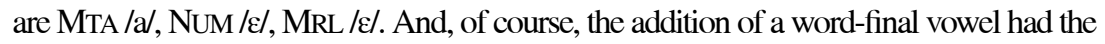
effect of shifting word stress by one syllable, which explains why the vowel hybridization subcase here is no longer * $\mathrm{u}$... a (as in $*^{\prime}$ rua $>y u$ ), but *a...i (as in *ru'aß-i > ruep). In other words, for the same etymon, two reconstructions must be proposed, one with and one without this extra vowel $*_{-i}:{ }^{\circ}$ rua $\sim{ }^{\circ}$ rua $\beta \mathrm{i}$; or to make it shorter, ${ }^{\circ}$ rua $[\beta \mathrm{i}] .{ }^{33}$

At first sight, this vowel $*_{-}$i is reminiscent of the former POC applicative suffix $*_{-}$i, which could explain its presence on transitive verbs. However, none of these modern languages uses the suffixed vs. unsuffixed contrast as a morphosyntactic device, such as opposing intransitive and transitive forms. Furthermore, *-i is found on nouns as well as on verbs, with no clear semantic contribution, and therefore must be disregarded as a genuine morpheme. This *-i should better be described as a "paragogic" vowel: that is, a device that allows consonant-final languages to regularly "create phonetically open syllables by inserting a 'default' vowel after a coda” (Klamer 2002:368).

The existence of this paragogic vowel, also known as an "echo-vowel" (Lynch 2000:73), has already been documented for several areas of the Austronesian family, including in Clark's (1985:204) reconstruction of PNCV. But whereas it is generally observed directly in the form of a word-final /i/, what makes the northern Vanuatu area worthy of mention is that due to the vowel reduction process, this paragogic *-i is never present as such in the modern forms. Its presence can only be inferred by analyzing the phonetic marks it has left in the modern lexicons, resorting to the vowel hybridization model as a heuristic tool. In the examples below, those reflexes that point to an augmented protoform are underlined. They can be recognized, thanks to the presence of the etymon's word-final consonant. ${ }^{34}$

33. When citing protoforms, I will follow here Clark's (in prep.) usage to group the final $*_{i}$ with the preceding consonant, because the latter got preserved only in the presence of the $*_{i}$ suffix: e.g., PNCV *liko-ti 'tie up, tether' rather than *likot-i.

34. In some instances, even the presence of that consonant must be inferred from the traces it has left in the modern word. For example, although LKN tu' 'stand' resembles the plain form of the etymon *tu?u, its long vowel presupposes the former presence of $/ \mathrm{r} /($ see 4.3.2), which in turn betrays the former presence of paragogic $*_{-i}$ ! That is, tu: $<*$ tur $<*$ turi $<*$ tu?u-ri $<$ *tuqur $+*_{-i}$. 
(49) $\mathrm{POC} *^{*}$ saqat $\rightarrow$ PNCV *saia-ti > 'saa[ti] 'bad': HIU sa; LTG $\overparen{\text { hia }}$; LHI $\underline{\text { satt}}$; LHR $\underline{s \varepsilon t}$; VLW $\underline{h} \underline{I} \underline{t}$ MTP $\underline{h \varepsilon t}$; LMG $\underline{s \varepsilon ?} ;$ VRA $\underline{s \varepsilon ?} ;$ VRS (tisI); MSN (tisI); MTA tatas; NUM $\underline{t t} \underline{\text { tIs; }}$ DRG $\underline{t t a} \underline{\underline{s}}$; KRO sa; OLR sa; LKN sa; MRL $\underline{s} \underline{t}$.

(50) POC *tuqur $\rightarrow$ *tuPu-ri > $>$ tuu[ri] 'stand': HIU tw; LTG $t w$; MTP tivy; LMG (?ar); VRA ?ir; VRS tür; MSN tur; MTA tur; NUM tur; DRG tur;

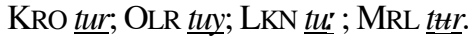

(5I) POC *ma-takut $\rightarrow{ }^{\circ}$ matayu[ti] 'fear, be afraid': LTG mə(təy)toy; LHI mots;

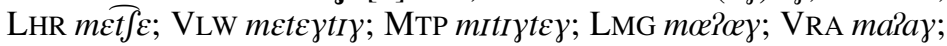

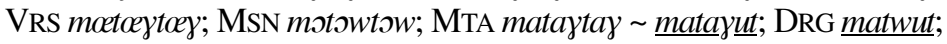

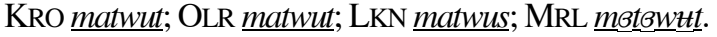

(52) PNCV *bala-ti 'wattled structure' $\rightarrow$ 'bala[ti] 'take (stones+) with tongs': MTP bal; VRS bal; MTA pala palat; NUM balet; DRG blat; LKN paelaes.

As mentioned earlier, the paragogic $*_{-} \mathrm{i}$ is not restricted to verbs or adjectives, and is also found in several nouns (see also [\#I08]):

(53) POC *tawan > 'tawa[ni] 'Pometia pinnata': LTG towa; MTP $\underline{\text { na-twen; }}$

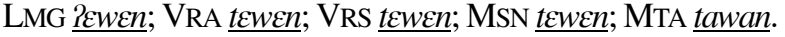

(54) POC *rarap > PNCV *rara[ßi] 'Erythrina indica': MTP na-yay; VRA rara $\beta$; VRS $\underline{\operatorname{rer} \varepsilon \beta} \beta$; MTA rara $\sim \underline{\operatorname{rara} \beta} \beta$; DRG $\underline{\operatorname{rra}} \beta \beta$; LKN $\underline{\operatorname{rar} \alpha} \beta$.

(55) POC *ñamuk > PNCV *namu-ki > 'namu[yi] 'mosquito': LTG nem; MTP $n \varepsilon-n \varepsilon m ;$ VRA nam; VRS nem; MSN nom; MTA nam; NUM nam; DRG $\underline{d \eta \underline{m}}^{w} \underline{u} \gamma ;$ KRO $\underline{m u} \gamma ;$ OLR $\underline{m u} ;$; LKN $\underline{\text { namu}} \gamma ;$ MRL ns-nom.

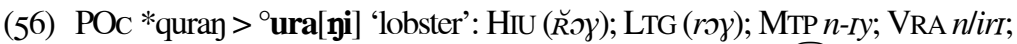

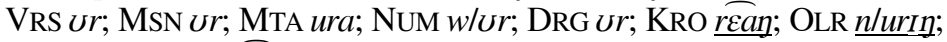
LKN uran; MRL $n-\widetilde{U \theta} r$.

Although certain augmented protoforms are well represented throughout the area-see (49), (50), (53), (54)— the phenomenon seems to be concentrated toward the south of the area, especially in Gaua. The language that possesses the greatest number of augmented reflexes is no doubt Lakon, a deviant language in many respects. Table 5 lists a selection of modern Lakon forms, whether verbs or nouns, that show indirect traces of the paragogic vowel *-i; they are shown in contrast with languages from further north (such as Mwotlap, Mwesen, and Vurës) that reflect a plain form.

6.2 HISTORICAL MORPHOLOGY. In sum, the model of vowel hybridization that is developed here makes it possible to reconstruct the precise phonological shape of words in earlier historical stages. On some occasions, it even helps us retrieve the earlier presence of certain phonemes that have now disappeared from the modern languages. This powerful tool can be of great help when it comes to unraveling the history of their morphosyntax.

In this section I mention the major aspects of grammatical analysis that can benefit from this reconstruction of vowel change: first, the verbal morphology related to object-marking and valency; second, the nominal morphology related to possession. 


\subsubsection{Verbal morphology and the coding of arguments}

6.2.1.1 Plural subject morphology in Lo-Toga. In Lo-Toga, several verbs show a different root according to the number of the subject. In some instances, the strategy used is pure suppletion, as in met 'die:SG' vs. pəptn 'die:PL'. But in other cases, the stem alternation seems to amount historically to a derivational process: thus $t t$

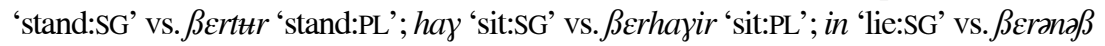
'lie:PL'; kare 'cry:SG' vs. ßerkari 'cry:PL'.

These plural verb roots, which have become opaque in synchrony, can be analyzed in the perspective of historical phonology. It appears that the modern irregularities, in fact, betray a perfectly regular morphological process in the protolanguage, combining prefixation and suffixation. On the one hand, the element $\beta \varepsilon r$ - evidently reflects the POC prefix *pari- 'unified or conjoined action by a plural subject' (Pawley I973:I5I). On the other hand, the quality of word-final vowels and the frequent presence of an extra consonant point toward a suffix *-i (table 6) in a way very similar to 6.I.3 above 35

In other words, and unlike Banks languages further south, Lo-Toga has clearly kept a trace of the POC circumfix *pari-...-i, which has been described as "combined or repeated action by a plurality of actors or affecting a plurality of entities" (Pawley I973:I52; see also

\section{TABLE 5. TRACES OF A FORMER PARAGOGIC VOWEL *-i IN LAKON}

\begin{tabular}{|c|c|c|c|c|c|}
\hline 'cut, chop’ & POC * taRaq & $*^{\prime}$ tara $>$ & MSN tar & $*$ ta'ra-i > & LKN taerae \\
\hline 'carry on back' & POC *bebe & $*$ 'bebe $>$ & MTP $b \varepsilon m$ & *be'be-i > & LKN pIpI \\
\hline 'lie flat' & $\mathrm{PNCV} * \mathrm{tab}^{\mathrm{w}} \mathrm{a}$ & $*^{\prime} \operatorname{tab}^{\mathrm{w}} \mathrm{a}>$ & MTP $t a \widehat{k p}^{w}$ & $* \operatorname{ta}^{\prime} b^{w} a-\beta i>$ & $\mathrm{LKN} t a \widehat{k p}^{w} a \beta$ \\
\hline 'step on' & PNCV * 3ara-si & *'ßara > & МтР $\beta a y$ & * $\beta a^{\prime}$ ra-si > & LKN ßarah \\
\hline 'swallow' & POC *dolom & $*^{\prime}$ dolo > & $\operatorname{VRS} d u l$ & $*$ do'lo-mi > & LKN Tfflim \\
\hline 'husk coconut' & POC *kojom & $*^{\prime}$ yoso > & МтР $\gamma \supset h$ & *yo'so-mi > & LKN yIhIm \\
\hline 'forage seafood' & POC * payoda & *ßa'noda > & МтР ßэџюn & *ßayo'da-i > & 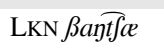 \\
\hline 'house' & POC * Rumaq & $*^{1} \mathrm{yum}^{\mathrm{w}} \mathrm{a}>$ & $\operatorname{MSN} I \widetilde{I J m}^{w}$ & $* y u^{\prime} m^{w} a-i>$ & $\mathrm{LKN} u \widetilde{\eta \eta m}^{w} a$ \\
\hline 'blood' & POC ${ }^{* n}$ raraq & $*$ 'dara > & МтР day & $*$ da'ra-i > & LKN $\overparen{t f a r a x}$ \\
\hline 'earth, ground' & POC *tanoq & $*^{\prime} \operatorname{tano}>$ & MsN tan & *ta'no-i > & LKN tanI \\
\hline 'green coconut' & PNCV *ßusa & *'ßusa > & VRS $\beta U S$ & $* \beta u^{\prime}$ sa-yi > & LKN $\beta u h a \gamma$ \\
\hline
\end{tabular}

\section{TABLE 6. TRACES OF A FORMER CIRCUMFIX *paRi-...-i IN LO-TOGA}

\begin{tabular}{|c|c|c|c|c|c|c|}
\hline \multirow[b]{2}{*}{ 'stand' } & \multicolumn{3}{|c|}{ SINGULAR SUBJECT } & \multicolumn{3}{|c|}{ PLURAL SUBJECT } \\
\hline & ttu & $<*^{\prime}$ tuu & $<*$ tuqur & ßertur & $<*$ ßari-tu'u-ri & $<*$ pari-tuqur-i \\
\hline 'sit' & hay & $<*^{\prime}$ saye & $<*_{\text {sake }}$ & ßerhayir & $<*$ ßari-sa'ye-ri & $<*$ pani-sake $(r)-\mathbf{i}$ \\
\hline lie' & in & $<*^{\prime}$ eno & $<*$ qenop & $\beta \varepsilon r ə n ə \beta$ & $<* \beta a r i-e ' n o-\beta i$ & $<*$ pari-qenop-i \\
\hline 'cry' & kəre & $<*$ ga'rai & $<* \ldots$ & ßerkari & $<*$ ßari-_gara'i-i & $<*$ pari-...-i \\
\hline
\end{tabular}

35. The consonant that occurs before $*_{-i}$ normally reflects the original consonant of the etymon (e.g., $/ \mathrm{r} /$ in *tuqur, $/ \beta /<{ }^{*} \mathrm{p}$ in *qenop), but this is not always what happens. In many instances, whether with *-i or with *-aki(n) below, a consonant appears that was not present in the etymon (e.g., /r/ added to *sake...). 
Bril 2005). Once again, the vowel hybridization model has proved capable of retrieving a morpheme even when it has disappeared as such from the modern languages.

6.2.1.2 Traces of the applicative *-aki(n). Another example is the well-known POC applicative suffix *-aki(n) 'remote-object'. Due to the phonetic erosion that took place in all the northern Vanuatu area, this suffix is often retained as a syllable of the type $-\mathrm{C} a \gamma \sim-\mathrm{C} \varepsilon \gamma$, or even $-\mathrm{C} \varepsilon$ in some languages. These reflexes make it difficult to trace back the suffix, unless careful attention is paid to vowel hybridization.

For certain etyma, the suffix *-aki(n) appears in all the languages of the area. This is true for the verb 'breathe', which in other languages reflects PNCV *mabu-si (Clark, in prep.), but for this area is best reconstructed as ${ }^{\circ} \mathrm{m}^{[\mathrm{w}]} \mathrm{ab}^{[\mathrm{w}]} \mathrm{u}$-sayi:

(57) PNCV *mabu-si $>{ }^{\circ} \mathbf{m}^{[\mathbf{w}]} \mathbf{a b}^{[\mathbf{w}]} \mathbf{u}$-sayi 'breathe; take rest': LTG $m \partial k^{w} h \varepsilon$;

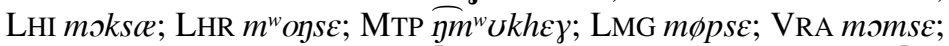

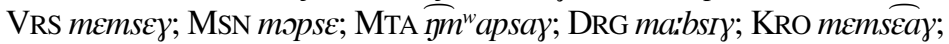
OLR mipsa; ; LKN mahpay.

For other words, suffixed and unsuffixed forms are both found in my corpus. If we take the example of ${ }^{\circ}$ rono[tayi] 'hear' (POC *royor), it appears that LTG, LHI, VRA, MTA, LKN, and MRL have maintained a semantic difference between the plain verb (LTG ruy 'feel, hear s.t./s.o.') and the same verb suffixed with *-aki(n) (LTG rupte 'pay attention, listen to s.t./s.o.'). Other languages seem to have merged the two forms, generalizing either the plain form (HIU, DRG, OLR) or the suffixed one (VLW, MTP, VRS, MSN, NUM):

(58) POC *ronor > 'romo[tayi] 'hear, feel; listen to': HIU $\breve{R} U \eta$; LTG run

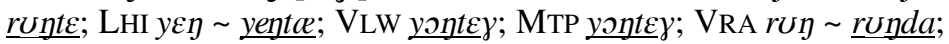

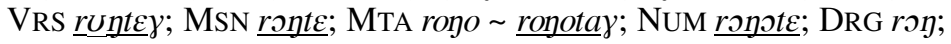

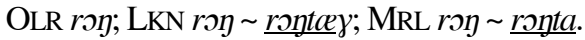

It sometimes happens that a single language even possesses three reflexes for the same root: the plain verb, the verb suffixed with $*-i$, and the verb suffixed with

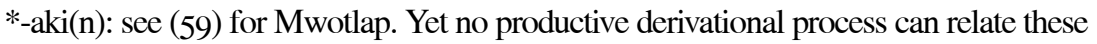
three forms in synchrony: they have become no more than an etymological triplet in the lexicon - in this case, a set of three distinct transitive verbs.

(59) An etymological triplet in Mwotlap: 'lamw $\mathrm{w}$ a(s) > läm ${ }^{w}$ 'beat s.t. (drum+) with a stick'

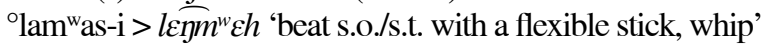
${ }^{\circ}$ lam $^{\mathrm{w}}$ as-ayi > lamm ${ }^{w} h \varepsilon y$ 'lash s.t. (a fishing line, a tail)'

To my knowledge, Mota and Lo-Toga are the only languages that still use the

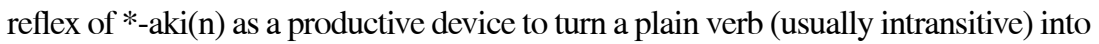
a transitive verb: see table 7 for Lo-Toga.

6.2.1.3 The massive decline of object pronoun suffixes. Somehow related to these valency-changing suffixes is the destiny of object-indexing suffixes in these languages. 
Originally, a set of personal enclitics served to encode the direct object on the verb. The forms that are reconstructed for POC (Evans 1995, cited by Lynch, Ross, and Crowley 2002:67) are *=au 'ISG', *=ko '2SG', *=a ' 3 SG', and *=ra ' 3 NON-SG'. This system is still alive in many conservative languages of Vanuatu, including Mota (Codrington I885:266). These pronominal forms (among which * $=$ au was lost) can be suffixed to verbs as well as verb-like prepositions:

(6o) Object suffixes in Mota:

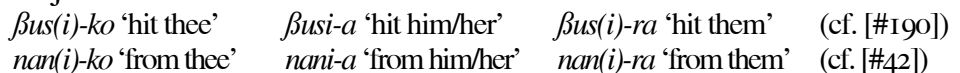

Like any other word-final syllable, object suffixes were altered during vowel hybridization. Modern Mwerlap still employs the post-hybridization reflexes of these four suffixes, or more precisely of their combination with the transitivizer *-i:

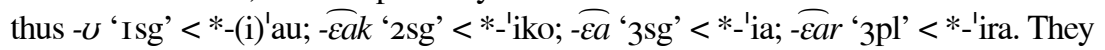
can be suffixed on transitive verbs and on verb-like prepositions as well:

(6I) Object suffixes in Mwerlap:

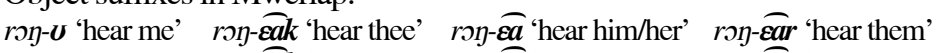

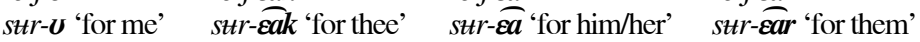

The verb (or preposition) appears unsuffixed with NPs: ron nв-lino- $k$ 'heard my voice'. This is also the way objects are encoded for other persons, by means of an independent pronoun: $r o y$ yean 'heard us'.

In fact, the effects of vowel hybridization in Mwerlap were not limited to the object suffixes themselves, but were even able to affect considerably the shape of certain verb roots. As a result, Mwerlap has developed an unusually complex system of morphological alternations between different stems that can be compared to a system of verb conjugations. Thus the verb 'bite' appears under three allomorphs: $y \varepsilon t(<*$ ' $\mathrm{yat}-\mathrm{i}$ $<$ POC *kaRat-i) for direct constructions; $\gamma \otimes t$ - for ISG suffix ( $\gamma \bullet t-u<*$ * yat-'au); $\gamma a t$ - for other suffixed forms (e.g., yat-Eak <*yat-iko). The same kind of stem alternation is attested with certain prepositions (e.g., [\#42] ${ }^{\circ}$ dani):

(62) Object suffixes and allomorphic alternations in Mwerlap:

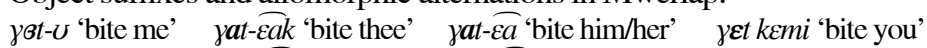

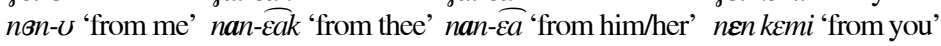

From a cognitive point of view, these morphological alternations evidently tend to be perceived as burdensome, and indeed they prove to be unstable over time. This observation is suggested by the strong tendency, which can be observed in the field, to eliminate these irregularities in favor of more transparent strategies. In the four languages that have kept object suffixes alive (Hiu, Lo-Toga, Mota, Mwerlap), this

\section{TABLE 7. TRACES OF THE APPLICATIVE SUFFIX *-aki(n) IN LO-TOGA}

\begin{tabular}{|c|c|c|c|c|c|}
\hline \multicolumn{3}{|c|}{ PLAIN VERB } & \multicolumn{3}{|c|}{ VERB SUFFIXED WITH *-aki(n) } \\
\hline 'go' & ßen & $<*$ pano & 'go with, take away' & 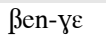 & $<*$ pano + -aki(n) \\
\hline 'return' & $\mathrm{y}^{\mathrm{w}} \mathrm{ul}$ & $<*_{\text {mule }}$ & 'return with, bring back' & $\eta^{\mathrm{w}} \mathrm{ul} \partial-\beta \varepsilon$ & $<*$ mule + -aki(n) \\
\hline 'stay' & toyə & $<*$ toka & 'stay with' & t॰үә- $\beta \varepsilon$ & $<*$ toka + -aki(n) \\
\hline
\end{tabular}


push toward functional simplification and formal transparency takes the form of alternate patterns for coding objects that manage to bypass morphological variation.

For example, the inherited stems for the verb 'lie, deceive' (PNCV *kale) are yolyol with ISG $-U$, and $\gamma \varepsilon l y \varepsilon l$ otherwise. Similarly, the verb 'watch' alternates between moton-, matan-, and mata:

(63) Object suffixes and allomorphic alternations in Mwerlap:

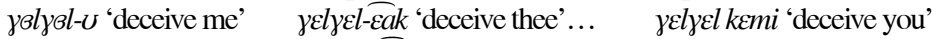

moton-U 'watch me' matan-Eak 'watch thee'... mata kemi 'watch you'

Younger speakers and adults in situations of lax speech resort to avoidance strategies that allow the use of an invariant root for each verb. This has an obvious cognitive advantage: namely, that whatever the nature of their object, all verb roots become invariant again - that is, easier to memorize and process. One strategy, attested with the verb 'deceive', consists in combining the default form ( $\gamma \varepsilon l y \varepsilon l)$ with the independent, heavy form of all personal pronouns. Another strategy, illustrated here with 'watch', resorts to a peripheral construction, using the oblique preposition yin:

(63') Alternate strategies for coding objects in Mwerlap:

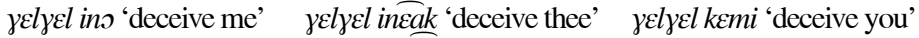
mata yin-U 'watch me' mata yin-Eak 'watch thee' mata yin kemi 'watch you'

The same simplifying tendency can be currently observed in Hiu, Lo-Toga, and Mota. Everywhere, object suffixes are in declining use, and are being slowly replaced by free invariant pronouns and/or with oblique structures.

Remarkably, this evolution has even come to its extreme in the I3 remaining languages of the Banks and Torres, which have now simply lost all traces of all object suffixes, whether on verbs or prepositions. For example, the translation of (62) in Mwesen would be:

(62') The generalization of free pronouns for object marking (Mwesen): yarns 'bite me' yarnik 'bite thee' yarnI 'bite him/her' yarkimi 'bite you' nen no 'from me' nen nIk 'from thee' nen $n_{I}$ 'from him/her' nen kimi 'from you'

Even if the use of independent pronouns for object cross-referencing was probably already a tendency in earlier stages of the protolanguage, it is most likely that its generalization to all persons was accelerated by the drastic effects of vowel hybridization upon verbal morphology.

6.2.2 Nominal morphology and the coding of possessors. The last important domain where the history of vowels plays an important role is the morphology of possession. ${ }^{36}$

6.2.2.1 Emergence of stem alternations. Originally, the marking of inalienable possession involved the combination of a fixed root with a set of personal suffixes:

(64) POC: 'my eyes' *na mata-gu 'his/her eyes' *na mata-ña

The double phenomenon of vowel reduction and vowel hybridization deleted the final vowel of the suffix and regularly modified the penultimate vowel, usually rais-

36. Also related to this domain is the proposed reconstruction of (\#89) ${ }^{\circ} \mathrm{m}[\mathrm{ay}] \mathrm{u}-$, the general possessive classifier in most languages of the area. 
ing it in the case of ISG *-gu and lowering it in the case of 3 SG *-ña. This situation is witnessed, for example, in Mwotlap:

(65) Possessive suffixes and allomorphic alternations in Mwotlap: 'my eyes' na-mte-k

'his/her eyes' na-mta-n

This historical process had the following consequence. In most languages of the Torres and Banks Islands, inalienable nouns present two distinct allomorphs, one ending with a vowel higher than the other. Each language normally presents five pairs of such reflexes, corresponding to the five possible (root-final) vowels of the original etymon, and to their hybridization with posttonic *u and *a. For example, all etyma ending in $*_{\mathrm{o}}$ are reflected in Mwotlap by a pair of stems, one ending in $/ \mathrm{I} /\left(<*_{0} \ldots u\right)$, the other in $/ \mathrm{J} /$ (<*o...a): for example, POC *lipon 'teeth' $\rightarrow n I-l w I-k: n I-l w o-n$; POC *nakon 'face' $\rightarrow$ na-nyı- $k: n a-n y \boldsymbol{0}-n$; POC *laso 'testicles' $\rightarrow$ na-hlı- $k: n a-h l o-n$.

One could draw a parallel with the process of transphonologization defined in 3.2 , and speak here of a process of "transmorphologization." That is, what was historically a difference of vowel on the possessive suffixes has become a rule of stem alternation affecting the noun roots themselves. Interestingly, this pattern of evolution is paralleled in several Micronesian languages, in which vowel changes have resulted in the emergence of similar inflectional morphology—see Goodenough (I992:IOI) for Chuukese, Lee (I975:62-73) for Kosraean, Rehg (I98I:I66-78) for Ponapean. New Caledonia is another area where such metaphony-induced inflections are common, such as in Iaai (Ozanne-Rivierre I976:96-I05) or Cèmuhî (Rivierre I980:83).

In several languages - Volow, Vurës, Mwesen, Mwerlap, for example — the alternation actually involves not just a change in one vowel, but affects the phonetic shape of the whole word. Table 8 shows five such pairs of forms in Vurës. The final vowels found on the noun stems, namely $\{\mathrm{i}$ I $\varnothing \ddot{\mathrm{u}}\}$ for the ISG and $\{\widetilde{\mathrm{I}} \widetilde{\mathrm{ia}} \mathrm{\rho} \mathrm{U}\}$ for the $3 \mathrm{SG}$, correspond rigorously to the hybridization of the five protovowels $\{*$ i e a o $u$ with, respectively, posttonic $* u$ and $* a$ (see the chart of Vurës in appendix I). Furthermore, due to the total or partial assimilation of the pretonic to the stressed vowel (5.2.4), it looks as if the features [ $[$ higher] and [ \pm back] had diffused across syllable boundaries. This recalls the way features spread across the word in languages with vowel harmony. ${ }^{37}$

\section{TABLE 8. MORPHOLOGY OF POSSESSION: STEM ALTERNATIONS IN VURËS}

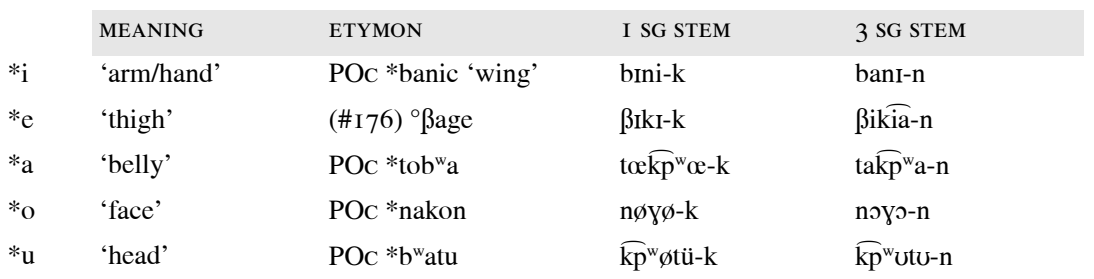

37. And indeed, Mwotlap can be said to have developed a genuine case of ATR vowel harmony, directly resulting from these stem alternations: e.g., iplu- $k$ 'my friend' $(<* \mathrm{i} \beta \mathrm{a}$ 'lu-gu, cf. PAN *baliw) vs. Iplu-n 'his friend' (<*i ßa'lu-na). See François (200I:95; 2005). 
In most languages, the two stems thus created are also used with other persons in such a way that each alienable noun alternates between two allomorphs. For example, Mwotlap presents complex rules of combination for stem I and stem 2 with the different possessive suffixes or other kinds of possessors (François 200I:468-75; 2005). Basically, stem I is found on ISG and 2SG as well as with [-human] possessors (e.g., na-mte bayo 'shark's eyes') and stem 2 is used for 3SG and most nonsingular forms (e.g., na-mta-muyu 'the eyes of you-DU').

6.2.2.2 Tracing back $2 S G$ possessive suffixes. The model of vowel hybridization proves indispensable when it comes to understanding the history of the 2SG possessive suffix. Among the I7 languages of northern Vanuatu, only three have preserved the *-mu suffix of POc: Lemerig, Vera'a, and Mwesen. They combine a suffix $-m$ with a noun stem that reflects a posttonic vowel /u/, the same as for ISG: e.g., MSN tomo- $k$ 'my father', tomo- $m$ 'thy father' (<*tama-mu), tama- $n$ 'his/her father'.$^{38}$

Four other languages, namely Hiu, Lo-Toga, Volow, and Mwotlap, encode their 2sG possessor in the form of a $\varnothing$ suffix. The modern stem-final vowel regularly points to a former posttonic vowel /u/: for example, MTP na-nyI- $k$ 'my face', na-nyI 'thy face', $n a-n y$ - $n$ 'his/her face'. In other words, these four languages reflect a truncated variant of the 2 SG possessive suffix, a form *-u with no consonant: $n a-n \gamma I<*$ na nayo-u.

But the majority of northern Vanuatu languages (namely LHI, VRS, NUM, DRG, KRO, OLR, LKN, and MRL) show an even less expected 2sG suffix /-y/. Crucially, in all of these languages, the stem that combines with this /-n/ suffix is not stem I used with ISG /-k/, but stem 2 used with 3SG /-n/. Table 9 illustrates this for Dorig.

Are we going to reconstruct a protosuffix *-na? Such a form would be hard to explain historically. The solution to the problem is given by Mota, where the 2SG suffix has the form $/-\widetilde{y m}^{\mathrm{w}} \mathrm{a}$ /, e.g., nayo- $\widetilde{\eta m}^{w} a$ 'thy face'. This form $/ \widetilde{\mathrm{ym}}^{\mathrm{w}} \mathrm{a}$ /, which is also witnessed in other Vanuatu languages in the form $/-\mathrm{m}^{\mathrm{w}} \mathrm{a} /$ or $/-\eta^{\mathrm{w}} \mathrm{a} /$ (Clark I985:207), is an irregular reflex of the original suffix *-mu (Pawley I972: I I3). The labial consonant in *-mu went through a first stage of labiovelarization, while its vowel was dissimilated into /a/ (*-mu $\left.>*-m^{\mathrm{w}} \mathrm{a}>*-\widetilde{\mathrm{ym}}^{\mathrm{w}} \mathrm{a}\right)$. With the exception of Mota, which has preserved final /a/ until today, the process of vowel reduction in all other languages resulted in the labiovelar consonant forming the end of the word. Eventually, the labial element in this final consonant got lost, resulting in a plain velar $\left(*-\widehat{\mathrm{nm}}^{\mathrm{w}} \#>-\eta\right)-$ a sound change

\section{TABLE 9. MORPHOLOGY OF POSSESSION: THE 2SG SUFFIX IN DORIG}

\begin{tabular}{|c|c|c|c|c|c|}
\hline & MEANING & ETYMON & I SG & $2 \mathrm{SG}$ & $3 \mathrm{SG}$ \\
\hline$* \mathrm{i}$ & 'shoulder' & POC *banic 'wing' & bni-k & bnI-n & bni-n \\
\hline$* \mathrm{e}$ & 'thigh' & (\# I 76) ${ }^{\circ}$ ßage & $\beta \mathrm{kI}-\mathrm{k}$ & $\beta \mathrm{k} \varepsilon-\mathrm{\eta}$ & $\beta \mathrm{k} \varepsilon-\mathrm{n}$ \\
\hline$* \mathrm{a}$ & 'belly' & POC $*$ tob $^{w} \mathrm{a}$ & $\mathrm{tkp}^{\mathrm{w}} \mathrm{a}-\mathrm{k}$ & $\mathrm{t}_{\mathrm{kp}}^{\mathrm{w}} \mathrm{a}-\mathrm{y}$ & $\mathrm{t} \overbrace{\mathrm{kp}}^{\mathrm{w}} \mathrm{a}-\mathrm{n}$ \\
\hline$*_{\mathrm{O}}$ & 'face' & POC *nakon & nyu-k & nуว-1 & nyo-n \\
\hline$* \mathrm{u}$ & 'head' & POC $* b^{w} a t u$ & $\overbrace{\mathrm{kp}^{\mathrm{w}}}^{\mathrm{tu}} \mathrm{- \textrm {k }}$ & $\widehat{\mathrm{kp}}^{\mathrm{w}} \mathrm{t} u-\eta$ & $\widetilde{\mathrm{kp}}^{\mathrm{w}} \mathrm{t} \mathrm{u}-\mathrm{n}$ \\
\hline
\end{tabular}

38. Apart from these three languages, Hiu, Volow, and Mwotlap show a vestigial suffix *-mu in the irregular inflection of their possessive classifiers: e.g., VLW $n-\gamma \supset-m<*$ na ka-mu 'thy X (food classifier)'. 
common in the area. ${ }^{39}$ The path I propose to reconstruct here would thus be as follows:

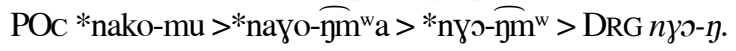

6.2.2.3 Retrieving lost morphemes. Certain languages present an even greater complexity, as they use not two but three or even four sets of allomorphs, depending on the morphological and syntactic context. For example, besides the two stems moetoand mata-for 'eye', Vurës requires a third stem $m \varepsilon t \varepsilon$ in two cases. One is the combination with a construct suffix $-n$ introducing an overt human NP (compare na mata- $n$ ' his eyes' with na mete-n $i$ Wemal 'Wemal's eyes'); incidentally, this "overt human NP" also includes all nonsingular independent personal pronouns: na mete-n kumurun [lit. 'the eyes of you-DU'] 'your eyes'. The second context is when the possessor is an overt nonhuman (and generally nonspecific) NP, in which case this stem 3 is constructed directly: mete buyu 'shark's eyes'.

Thanks to what we now know of vowel hybridization in Vurës, it becomes possible to formulate a hypothesis on the origin of this third stem (François 200I:494-508). While mata- $n$ comes from $3 \mathrm{sG} *$ mata-ña, mete- $n$ is the regular reflex of a form *mata-ni. This suggests that Vurës has transmorphologized onto the noun root an earlier contrast between two suffixes: *-na '3SG possessor' ( $<$ POC *-ña) and a genitive suffix of the form *-ni. This hypothesis is supported by other languages of Vanuatu such as Araki (François 2002:97) and Northeast Ambae (Hyslop 200I:I67), which make use of a suffix *-ni in exactly the same conditions as Vurës-namely the introduction of [+specific] [+human] NP possessors with inalienable nouns..$^{40}$ Furthermore, the contrast between *-ña '3SG possessor' and *-ni 'construct suffix' is explicitly set forth by Dyen (1949:422) to account for similar pairs in modern Chuukese: masa-n 'his eye' < *mata-ña vs. mese-n 'eye of' < *mata-ni.

As for the unsuffixed form VRS mete, it necessarily proceeds from the hybridization of a premodern form *mata-i. In all likelihood, this corresponds to POC *qi, indeed a possessive linker used between inalienable nouns and [-specific] possessors (Hooper I985, Ross 200I): thus VRS mete buyu <*ma'ta-i bayoa < POC *mata qi bakewa. As table Io shows, when inalienable nouns are followed in Vurës by a nonspecific nonhuman possessor, their final vowels are $\left\{\begin{array}{l}\mathrm{i} \\ \text { I } \\ \varepsilon \emptyset \ddot{u}\}\end{array}\right.$. Once again, this matches exactly the hybridization of the five original vowels $\left\{{ }^{*} \mathrm{i}\right.$ e a o $\left.\mathrm{u}\right\}$ with a posttonic *i. In other words, POC *qi is no longer reflected as a segmental suffix: it only survives in the subtle, hidden form of a raised vowel on the possessed noun.

Other languages of the Banks also provide evidence for the same conclusion. For example, Mwotlap would translate 'shark's eyes' as na-mte bayo < *na ma'ta=qi bakewa. This is worthy of mention, because the same *qi has been wrongly attributed by Ross

39. Total delabialization of syllable-ending labiovelars is well attested across the area: e.g., see the reflexes under (\#I03), (\#I04), (\#I37), (\#I4I). In two languages, Lehali and Mwerlap, it is even the rule. This is how certain consonants that were originally plain labials eventually became plain velars, via a labiovelar stage: e.g., POC *Rumaq 'house' $>$ PNCV *yum ${ }^{w}$ a $>$ *inm ${ }^{w}$ a $>$ LHI en

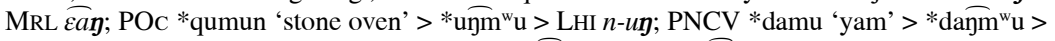

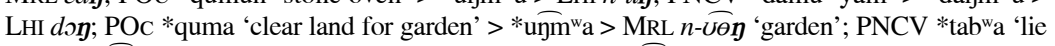
flat' > *takp" ${ }^{w}$ a $>$ LHI/MRL tak; POC *karab"wa 'new' > *yarakpwa $>$ MRL yarak.

40. A morpheme *ni has been reconstructed with a different function for POc (Hooper I985, Ross I998); namely, the introduction of [-specific] [-human] possessors with alienable nouns. 
(200I) to another morpheme of Mwotlap: ${ }^{41}$ the suffix $-\gamma \varepsilon$, which is used, among other things, to encode the generic human possessor of an inalienable noun (François 200I:527-39), e.g., na-mte- $\gamma \varepsilon$ 'the (human) eye'. In fact, the history of Mwotlap vowels now makes it clear that $-\gamma \varepsilon$ can reflect neither *qi nor *ki, and is more certainly the reflex of a disyllable: POC *kai 'native, inhabitant of a place, person' (Pawley I976). ${ }^{42}$ Ironically, *qi is not totally absent from a form like na-mte- $\gamma \varepsilon$, because the latter should be reconstructed as *na ma'ta=qi 'kai, lit. 'the eye of a (nonspecific) person'-which is exactly parallel to na-mte bayo 'the eye of a (nonspecific) shark'.

6.2.2.4 Reacting against morphological complexity. The historical process of vowel hybridization constitutes the direct source for these stem alternations, and for the intricate morphology of possession that is characteristic of the whole linguistic area. One language, namely Mwerlap, even shows allomorphic alternations both in the domain of inalienable possession and in the morphology of object marking. The parallel between the two patterns is striking:

(66) Allomorphic alternations in (a) verbs and (b) nouns, in Mwerlap:

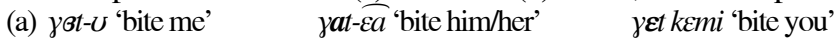

(b) $n \boldsymbol{s}-k^{w} \boldsymbol{\theta} t \boldsymbol{t}-k$ 'my head' $n a-k^{w} \boldsymbol{a t} v-n$ 'his/her head' $n \varepsilon-k^{w} \varepsilon t k \varepsilon m i$ 'your heads'

Although it is still well represented throughout the northern Vanuatu area, this sort of vestigial morphology is, again, structurally unstable. The functional pressure toward morphological transparency later triggered the four languages Lo-Toga, Vera'a, Nume, and Lakon to react against this emergent complexity. They have suppressed the alternation between stems by generalizing one allomorph for all persons: for example, LTG məte- $k$ 'my eyes', məte-nə 'his/her eyes', məte- $n$ Wemal 'Wemal's

\section{TABLE 10. TRACES OF POC *qi ON INALIENABLE NOUNS IN VURËS}

\begin{tabular}{|c|c|c|c|}
\hline MEANING & VURËS & PRE-VURËS & POC \\
\hline 'pig's bone' & $\operatorname{siri} \widehat{\mathrm{kp}}^{\mathrm{w}} \mathrm{U}$ & $<*^{*}$ su'ri-i bºe & $<*$ suri qi borok \\
\hline 'pig's feces' & tir $\widehat{\mathrm{kp}}^{\mathrm{w}} U$ & $<*$ ta $^{\prime} \mathrm{e}-\mathrm{i} \mathrm{b}^{\mathrm{w}} \mathrm{oe}$ & $<*$ taqe qi borok \\
\hline 'pig's belly' & $\mathrm{t} \varepsilon \widetilde{\mathrm{kp}}^{\mathrm{W}} \boldsymbol{\varepsilon} \widetilde{\mathrm{kp}}^{\mathrm{W}} \mathrm{U}$ & $<*$ to $^{\prime} b^{w} a-i b^{w} o e$ & $<*$ tob $^{\mathrm{w}}$ a qi borok \\
\hline 'pig's tusk' & lüwø $\widehat{\mathrm{kp}}^{\mathrm{w}} \mathrm{U}$ & $<* \operatorname{li}^{\prime} \beta \mathrm{O}-\mathrm{i} \mathrm{b}^{\mathrm{w}} \mathrm{Oe}$ & $<* \operatorname{lipo(n)}$ qi borok \\
\hline 'pig's head' & $\widehat{\mathrm{kp}}^{\mathrm{w}} \emptyset \mathbf{t u ̈} \widehat{\mathrm{kp}}^{\mathrm{w}} U$ & $<* b^{w} a^{\prime} t u-i b^{w} o e$ & $<* b^{w}$ atu qi borok \\
\hline
\end{tabular}

4I. More precisely, Ross (200I:274) claims that $-\gamma \varepsilon$ results from a merger of POC *ki 'free-form derivative suffix' and *qi 'nonspecific inalienable possessive marker', and explains this merger saying “*qi has no productive reflexes in Mwotlap." In fact, Mwotlap possesses reflexes of both *qi and *ki, neither of which is $-\gamma \varepsilon$. Ross's *ki seems to have a phonetically regular reflex in the form of an anaphoric suffix - $\gamma i$ in several Banks languages. The latter combines with inalienable nouns, with different but related meanings: MSN/LMG - $\gamma i$ 'nonhuman possessor suffix'; VRA - $\gamma i$ '3SG possessor suffix'; MTP - $y i$ 'anaphoric suffix' (François 200I:334). As for the personal article *i, mentioned by Hooper (I985) and Ross (200I) in their discussion of *qi, it is also reflected in northern Vanuatu languages: see François (forthcoming).

42. The same etymon *kai is found in several Banks languages, including Mwotlap, as part of the

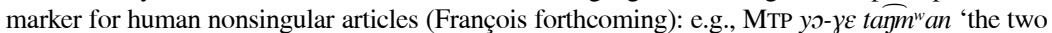
men' <*rua kai tamwane (contra Ross 200I:269). In both instances, *kai can be said to have specialized from a lexical meaning 'inhabitant, person' to a grammatical function, coding for a human referent in general (cf. French on $<$ Lat. homo). 
eyes', məte рәуєwə 'shark's eyes'. Due to this process of morphological realignment, the vowels in most of these forms are historically irregular. Indeed, the expected LoToga reflexes of *mata-gu, *mata-ni, and *mata-qi (respectively **məto-k,**məte-n, **mote) have gone through a process of analogical leveling based on a unique stem mote-. The latter proceeds from the segmentation of mote-na, itself the perfectly regular outcome of $3 \mathrm{SG}$ *mata-ña.

In sum, the origins of the various possessive suffixes attested today in the modern languages of northern Vanuatu can only be understood properly provided precise vowel correspondences are taken into account. This patient work of reconstruction helps lift the veil of their morphological intricacies, and brings to light their profound continuity with the grammar of their Proto-Oceanic ancestor.

7. CONCLUSION. As the final part of this study has shown, the double process of vowel reduction and vowel hybridization is not merely a matter of phonology. The understanding of this massive phenomenon is also a prerequisite for whomever may want to unravel the often complex morphology of the Banks and Torres languages, and track the history of their syntax. Yet, if one were to analyze in any detail all the grammatical aspects of these languages to which the vowel hybridization model provides the key, much more than one paper would be necessary.

\section{APPENDICES}

\section{Appendix 1. Charts of Regular Vowel Correspondences}

The following tables present the regular vowel correspondences I have been able to establish for the $\mathrm{I} 7$ languages of my corpus. These charts of regular vowel correspondences are introduced in more detail in 2.3.

For each sequence of protovowels $* \mathrm{~V}_{\mathrm{I}}(\mathrm{C}) \mathrm{V}_{2}$, the stressed vowel $* \mathrm{~V}_{\mathrm{I}}$ is represented in rows, while the posttonic vowel $* \mathrm{~V}_{2}$ appears in columns. Most of the time, posttonic $* \mathrm{~V}_{2}$ disappears altogether from the modern forms, following a pattern $\left\{* \mathrm{~V}_{\mathrm{I}}(\mathrm{C}) \mathrm{V}_{2}>\right.$ $\mathrm{V}^{\prime}(\mathrm{C})$ \} - for example, *kani > yeen. In this case, one can consider that $\mathrm{V}_{\mathrm{I}}$ and $\mathrm{V}_{2}$ regularly hybridized into a single vowel $\mathrm{V}^{\prime}$, and this appears in the corresponding box: for example, in Lehali, the sequence *a(C)i regularly hybridized into /æ/.

In four languages (Hiu, Lo-Toga, Vera'a, Mota), the sequence $* \mathrm{~V}_{\mathrm{I}}(\mathrm{C}) \mathrm{V}_{2}$ is sometimes reflected by another sequence of syllables $\left\{{ }^{*} \mathrm{~V}_{1}(\mathrm{C}) \mathrm{V}_{2}>{ }^{*} \mathrm{~V}^{\prime}(\mathrm{C}) \mathrm{V}_{\mathrm{f}}\right\}$. In this case, the (optional) consonant slot between * $\mathrm{V}^{\prime}$ and $* \mathrm{~V}_{\mathrm{f}}$ is indicated by an empty underscore "..". For example, in Hiu, ${ }^{*} \mathrm{u}(\mathrm{C}) \mathrm{o}$ regularly hybridized into ${ }^{*}(\mathrm{C})$. In all other languages, this optional consonant slot is not indicated, because it systematically follows the modern vowel.

When there is more than one regular reflex for a given combination of vowels, these are indicated in the same box (either in two different lines, or separated by ' $\|$ '). In those cases where a sequence of two adjacent vowels $* \mathrm{~V}_{\mathrm{I}} \mathrm{V}_{2}$ did not hybridize in the same way as a sequence $* \mathrm{~V}_{1} \mathrm{CV}_{2}$, this is indicated by angled brackets: for example, in Vurës, a sequence *eCa hybridized into $\overparen{\text { ial}} /$, whereas *ea became /I/ (see 4.2). 
HIU

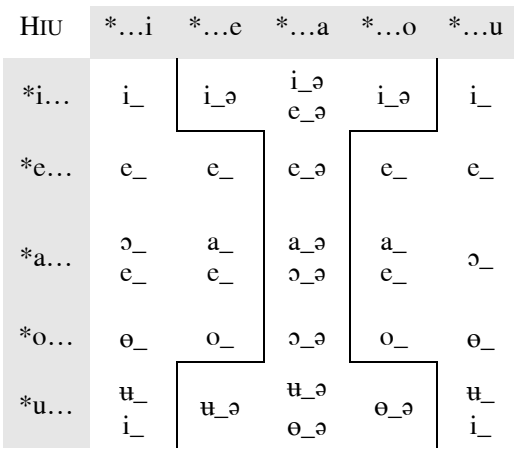

\section{LEHALI}

\begin{tabular}{c|ccccc} 
LHI & $* \ldots i$ & $* \ldots e$ & $* \ldots a$ & $* \ldots o$ & $* \ldots u$ \\
$* i \ldots$ & $\mathrm{i}$ & $\mathrm{e}$ & $\mathrm{e}$ & $\mathrm{e}$ & $\mathrm{i}$ \\
$* e \ldots$ & $\mathrm{e}$ & $\varepsilon$ & $æ$ & $\varepsilon$ & $\mathrm{e}$ \\
$* a \ldots$ & $æ$ & $\mathrm{a}$ & $\mathrm{a}$ & $\mathrm{a}$ & 0 \\
$* o \ldots$ & $\mathrm{o}$ & 0 & 0 & о $\| \varepsilon$ & $\mathrm{e}$ \\
$* u \ldots$ & $\mathrm{u}$ & $\mathrm{o}$ & $\mathrm{o}$ & $\mathrm{o}$ & $\mathrm{u}$
\end{tabular}

VOLOW

\begin{tabular}{|c|c|c|c|c|c|}
\hline VLW & $* \ldots i$ & *...e & *...a & $* \ldots o$ & *...u \\
\hline$* i \ldots$ & $\mathrm{i}$ & I & I & I & $\mathrm{i}$ \\
\hline$* e \ldots$ & I & $\varepsilon$ & $\varepsilon$ & $\varepsilon$ & I \\
\hline$* a \ldots$ & $\varepsilon \|_{\mathrm{I}}$ & $\mathrm{a}$ & $\mathrm{a}$ & $\mathrm{a}$ & $\varepsilon$ \\
\hline$* o \ldots$ & $U \|_{I}$ & 0 & 0 & 0 & $U \|_{I}$ \\
\hline$* u \ldots$ & $\mathrm{u} \| \mathrm{i}$ & $U$ & $U$ & $U$ & $\mathrm{u} \| \mathrm{i}$ \\
\hline
\end{tabular}

LO-TOGA

\begin{tabular}{|c|c|c|c|c|c|}
\hline LTG & * ...i & *...e & *...a & *...o & *...u \\
\hline$*_{\mathrm{i}} \ldots$ & $i_{-}$ & i_ə & $\begin{array}{l}\text { i_ə } \\
\text { e_ə }\end{array}$ & i_ə & $i_{-}$ \\
\hline$* \mathrm{e} .$. & $e_{-}$ & $i_{-}$ & $\begin{array}{c}\text { e_ə } \\
\text { (i) } \varepsilon \_\partial\end{array}$ & $\begin{array}{l}i_{-} \\
\varepsilon_{-}\end{array}$ & e_ \\
\hline$* a \ldots$ & (i) $\varepsilon_{-}$ & $\begin{array}{c}\text { (i) } \mathrm{a}_{-} \\
\mathrm{e}_{-}\end{array}$ & $\begin{array}{c}\text { (i)e_ə } \\
\text { (i)a_ə } \\
0 \_\partial\end{array}$ & $\begin{array}{l}a_{-} \\
e_{-}\end{array}$ & $\begin{array}{l}\rho_{-} \\
\varepsilon_{-}\end{array}$ \\
\hline$*_{0} \ldots$ & (o) $\partial_{-}$ & $\mathrm{O}_{-}$ & (o)0_ə & $\mathrm{o}_{-}$ & $\partial_{-}$ \\
\hline$*_{\mathrm{u}}^{\mathrm{u}} \ldots$ & $u_{-}$ & U_o & $\begin{array}{l}\partial \_\partial \\
\text { u_ə }\end{array}$ & $\partial \_\partial$ & $\begin{array}{l}u_{-} \\
i_{-}\end{array}$ \\
\hline
\end{tabular}

\section{LEHALURUP}

\begin{tabular}{|c|c|c|c|c|c|}
\hline LHR & $* \ldots i$ & *...e & *...a & *...o & *...u \\
\hline$*_{i} \ldots$ & $\mathrm{i}$ & $?$ & $\overparen{\mathrm{ie}}$ & $\overparen{\mathrm{ie}}$ & $?$ \\
\hline$* e \ldots$ & e & $\varepsilon$ & $\varepsilon$ & $\varepsilon$ & $\mathrm{e}$ \\
\hline$* a \ldots$ & $\varepsilon$ & $\mathrm{a}$ & $\mathrm{a}$ & $\mathrm{a}$ & $\varepsilon \| \propto$ \\
\hline$* o \ldots$ & o & 0 & o & 0 & $œ$ \\
\hline${ }^{*} u \ldots$ & $\mathrm{u} \| \mathrm{i}$ & $\mathrm{O}$ & o & $\mathrm{O}$ & $\mathrm{u} \| \mathrm{i}$ \\
\hline
\end{tabular}

\section{MWOTLAP}

\begin{tabular}{c|ccccc} 
МтP & $* \ldots i$ & $* \ldots e$ & $* \ldots a$ & $* \ldots o$ & $* \ldots u$ \\
\hline$i \ldots$ & $\mathrm{i}$ & $\mathrm{I}$ & $\mathrm{I}$ & $\mathrm{I}$ & $\mathrm{i}$ \\
$* e \ldots$ & $\mathrm{I}$ & $\varepsilon$ & $\varepsilon$ & $\varepsilon$ & $\mathrm{I}$ \\
$* a \ldots$ & $\varepsilon \| \mathrm{I}^{\dagger}$ & $\mathrm{a}$ & $\mathrm{a} \| \mathrm{o}$ & $\mathrm{a}$ & $\varepsilon \|_{\mathrm{I}}^{\dagger}$ \\
$* o \ldots$ & $\mathrm{U} \| \mathrm{I}$ & 0 & 0 & 0 & $\mathrm{U} \| \mathrm{I}$ \\
$* u \ldots$ & $\mathrm{u} \| \mathrm{i}$ & $\mathrm{U}$ & $\mathrm{U}$ & $\mathrm{v}$ & $\mathrm{u} \| \mathrm{i}$
\end{tabular}

For $*$ a...i and $* a . . . u$, the two reflexes /I/ are only found in word-internal syllables: see 5.1.2.1.

\section{LEMERIG}

LMG $\quad * \ldots i \quad * \ldots e \quad * \ldots a \quad * \ldots o \quad * \ldots u$

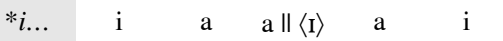

$\begin{array}{llllll}* e \ldots & \text { I } & \varepsilon & \text { a } & \varepsilon & \text { I }\end{array}$

$* a \ldots \quad \varepsilon \| \propto \quad$ a $\quad$ a $\|$ p $\quad$ a $\quad \varepsilon \| \rightsquigarrow$

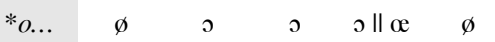

$\begin{array}{llllll}* u \ldots & \mathrm{u} & \mathrm{u} & \mathrm{u} & \mathrm{u} & \mathrm{u}\end{array}$
VERA'A

\begin{tabular}{|c|c|c|c|c|c|}
\hline VRA & $* \ldots i$ & $* \ldots e$ & * ...a & $* \ldots o$ & *...u \\
\hline$* i \ldots$ & $i_{-}$ & i_I & i_I & i_I & $i_{-}$ \\
\hline$* e \ldots$ & I_ & I_ & $\begin{array}{l}\varepsilon \_\varepsilon \\
\langle i \varepsilon\rangle\end{array}$ & I_ & I_ \\
\hline$* a \ldots$ & $\begin{array}{l}a_{-} \\
\varepsilon_{-}\end{array}$ & $\begin{array}{l}\mathrm{a}_{-} \\
\langle\mathrm{i} \varepsilon\rangle\end{array}$ & a_a & $a_{-}$ & $\begin{array}{l}a_{-} \\
\varepsilon_{-} \\
0_{-}\end{array}$ \\
\hline$*_{o \ldots}$ & $U_{-}$ & $U_{-}$ & $\begin{array}{l}\text { o_o } \\
\langle\text { uo }\rangle\end{array}$ & $U_{-}$ & $U_{-}$ \\
\hline${ }^{*} u \ldots$ & $\begin{array}{l}\mathrm{i}_{-} \\
\mathrm{u}_{-}\end{array}$ & u_U & u_U & u_U & $\begin{array}{l}\mathrm{i}_{-} \\
\mathrm{u}_{-}\end{array}$ \\
\hline
\end{tabular}




\section{VURËS}

\begin{tabular}{|c|c|c|c|c|c|}
\hline VRS & ${ }^{*} \ldots i$ & *...e & $* \ldots a$ & $* \ldots o$ & *...u \\
\hline$* i \ldots$ & i & I & I & I & $\mathrm{i}$ \\
\hline$* e \ldots$ & I & I & $\overparen{\mathrm{ia}} \|\langle\mathrm{I}\rangle$ & I & I \\
\hline$* a \ldots$ & $\varepsilon \| \rightsquigarrow$ & $\overparen{\mathrm{ia}} \|\langle\mathrm{I}\rangle$ & $\mathrm{a}$ & $\mathrm{a}$ & $\varepsilon \| œ$ \\
\hline$* o \ldots$ & $\varnothing$ & U & 0 & U & $\varnothing$ \\
\hline${ }^{*} u \ldots$ & $\ddot{u}$ & $U$ & $U$ & $U$ & $\ddot{\mathrm{u}}$ \\
\hline
\end{tabular}

MOTA

\begin{tabular}{|c|c|c|c|c|c|}
\hline МтA & $* \ldots i$ & *...e & * ...a & $* \ldots o$ & *...u \\
\hline$* i \ldots$ & $i_{-}$ & (i)_e & (i) _a & (i) $\_0$ & $i_{-}$ \\
\hline$* e \ldots$ & $e_{-}$ & e_e & e_a & e_o & $e_{-}$ \\
\hline$* a \ldots$ & $a_{-}$ & a_e & a_a & a_o & $a_{-}$ \\
\hline$* o \ldots$ & $\mathrm{O}_{-}$ & o_e & o_a & O_O & $\mathrm{O}_{-}$ \\
\hline${ }^{*} u$. & $u_{-}$ & (u)_e & (u)_a & $(\mathrm{u}) \_\mathrm{o}$ & $u_{-}$ \\
\hline
\end{tabular}

\section{DORIG}

\begin{tabular}{|c|c|c|c|c|c|}
\hline DRG & $* \ldots i$ & *...e & $*_{\ldots} \ldots a$ & $*^{*} \ldots o$ & *...u \\
\hline$* i \ldots$ & i & I & I & I & $\mathrm{i}$ \\
\hline$* e \ldots$ & I & $\varepsilon$ & $\varepsilon$ & $\varepsilon$ & I \\
\hline$* a \ldots$ & $\begin{array}{l}\mathrm{a} \\
\langle\mathrm{a}\rangle\end{array}$ & $\mathrm{a}$ & $\mathrm{a}$ & $\mathrm{a}$ & $\begin{array}{l}\mathrm{a}: \\
\langle\mathrm{a}\rangle\end{array}$ \\
\hline$*_{o \ldots}$ & U & 0 & 0 & 0 & U \\
\hline$* u \ldots$ & $\mathrm{u}$ & $U$ & $U$ & $U$ & $\mathrm{u}$ \\
\hline
\end{tabular}

\section{OLRAT}

\begin{tabular}{c|ccccc} 
OLR & $* \ldots i$ & $* \ldots e$ & $* \ldots a$ & $* \ldots o$ & $* \ldots u$ \\
\hline$* i \ldots$ & $\mathrm{i}$ & $\mathrm{I}$ & $\mathrm{I}$ & $\mathrm{I}$ & $\mathrm{i}$ \\
$* e \ldots$ & $\mathrm{I}$ & $\varepsilon$ & $\varepsilon$ & $\varepsilon$ & $\mathrm{I}$ \\
$* a \ldots$ & $\mathrm{a} \| \mathrm{I}$ & $\mathrm{a}$ & $\mathrm{a}$ & $\mathrm{a}$ & $\mathrm{a}$ \\
$* o \ldots$ & $\mathrm{u} \| \mathrm{I}$ & 0 & 0 & 0 & $\mathrm{u} \|_{\mathrm{I}}$ \\
$* u \ldots$ & $\mathrm{u}$ & $\mathrm{u}$ & $\mathrm{u}$ & $\mathrm{v}$ & $\mathrm{u}$
\end{tabular}

\section{MWERLAP}

\begin{tabular}{|c|c|c|c|c|c|}
\hline MRL & $* \ldots i$ & $* \ldots e$ & * ...a & $* \ldots o$ & *...u \\
\hline$* i \ldots$ & $\mathrm{i}$ & $\widehat{\varepsilon a}$ & $\overparen{\varepsilon a}$ & $\widehat{\varepsilon a}$ & $\mathrm{i}$ \\
\hline$* e \ldots$ & I & I & I & I & I \\
\hline$* a \ldots$ & $\begin{array}{c}\varepsilon \| \widehat{\varepsilon a} \\
\langle\mathrm{I}\rangle\end{array}$ & $\varepsilon$ & $\mathrm{a}$ & $\mathrm{a}$ & $\begin{array}{c}0 \| \widehat{\partial B} \\
\langle u\rangle\end{array}$ \\
\hline$* o \ldots$ & $u \| \Theta$ & $œ$ & 0 & 0 & $\widetilde{U \Theta} \| U$ \\
\hline$* u \ldots$ & u & U & U & $U$ & u \\
\hline
\end{tabular}

\section{MWESEN}

\begin{tabular}{|c|c|c|c|c|c|}
\hline MSN & *...i & $* \ldots e$ & $*_{\ldots} \ldots a$ & $*_{\ldots .}$. & $*_{\ldots} \ldots u$ \\
\hline$* i \ldots$ & $\mathrm{i}$ & I & I & I & $\mathrm{i}$ \\
\hline$* e \ldots$ & I & $\varepsilon$ & $\varepsilon$ & $\varepsilon$ & I \\
\hline$* a \ldots$ & $\varepsilon$ & $\mathrm{a}$ & $\mathrm{a}$ & $\mathrm{a}$ & o \\
\hline$* o \ldots$ & U & 0 & 0 & 0 & $U$ \\
\hline$* u \ldots$ & $\mathrm{u}$ & $U$ & $U$ & $U$ & $\mathrm{u}$ \\
\hline
\end{tabular}

\section{NUME}

\begin{tabular}{c|ccccc} 
Num & $* \ldots i$ & $* \ldots e$ & $* \ldots a$ & $* \ldots o$ & $* \ldots u$ \\
$* i \ldots$ & $\mathrm{i}$ & $\mathrm{i}$ & $\mathrm{i} \| \mathrm{I}$ & $\mathrm{i}$ & $\mathrm{i}$ \\
$* e \ldots$ & $\mathrm{I}$ & $\varepsilon$ & $\varepsilon$ & $\varepsilon$ & $\mathrm{I}$ \\
$* a \ldots$ & $\mathrm{a} \| \varepsilon$ & $\mathrm{a} \| \varepsilon$ & $\mathrm{a}$ & $\mathrm{a}$ & $\mathrm{a}$ \\
$* o \ldots$ & $\mathrm{u}$ & 0 & 0 & 0 & $\mathrm{u}$ \\
$* u \ldots$ & $\mathrm{u}$ & $\mathrm{u}$ & $\mathrm{u} \| \mathrm{u}$ & & $\mathrm{u}$
\end{tabular}

\section{KORO}

\begin{tabular}{|c|c|c|c|c|c|}
\hline KRO & $* \ldots i$ & $* \ldots e$ & $* \ldots a$ & $* \ldots o$ & *...u \\
\hline$* i \ldots$ & $\mathrm{i}$ & I & I & I & $\mathrm{i}$ \\
\hline$* e \ldots$ & I & $\varepsilon$ & $\varepsilon$ & $\varepsilon$ & I \\
\hline$* a \ldots$ & $\begin{array}{l}\widehat{\varepsilon a} \\
\langle a\rangle\end{array}$ & a & a & a & $\begin{array}{l}\widetilde{\varepsilon a} \\
\langle a\rangle\end{array}$ \\
\hline$*^{*} o \ldots$ & U & 0 & 0 & 0 & $U$ \\
\hline$*^{*} u$. & $\mathrm{u}$ & U & U & U & $\mathrm{u}$ \\
\hline
\end{tabular}

\section{LAKON}

\begin{tabular}{c|ccccc}
$\mathrm{LKN}$ & $* \ldots i$ & $* \ldots e$ & $* \ldots a$ & $* \ldots o$ & $* \ldots u$ \\
$* i \ldots$ & $\mathrm{i}$ & $\mathrm{I}$ & $\mathrm{I}$ & $\mathrm{I}$ & $\mathrm{i}$ \\
$* e \ldots$ & $\mathrm{I}$ & $\varepsilon$ & $\varepsilon$ & $\varepsilon$ & $\mathrm{I}$ \\
$* a \ldots$ & $æ$ & $æ$ & $\mathrm{a}$ & $\mathrm{a}$ & $\mathrm{a}$ \\
$* o \ldots$ & $\mathrm{I}$ & 0 & 0 & 0 & $\mathrm{I}$ \\
$* u \ldots$ & $\mathrm{u}$ & $\mathrm{v}$ & $\mathrm{U}$ & $\mathrm{U}$ & $\mathrm{u}$
\end{tabular}

\section{SAKAO}

\begin{tabular}{|c|c|c|c|c|c|}
\hline SAK & $* \ldots i$ & $* \ldots e$ & $* \ldots a$ & $* \ldots o$ & $* \ldots u$ \\
\hline$* i \ldots$ & ü & $œ \|\langle i\rangle$ & $œ \|\langle i\rangle$ & $œ \|\langle i\rangle$ & ü \\
\hline${ }^{*} e \ldots$ & $œ \|\langle\mathrm{e}\rangle$ & $\mathrm{p}$ & $\mathrm{p}$ & $\mathrm{p}$ & $\rightsquigarrow \|\langle\mathrm{e}\rangle$ \\
\hline$* a \ldots$ & $\varepsilon$ & a & $\mathrm{a}$ & $\mathrm{a}$ & $\varepsilon$ \\
\hline$* o$. & $\propto \|\langle\varnothing\rangle$ & o & 0 & o & $œ \|\langle\varnothing\rangle$ \\
\hline${ }^{*} u$. & ü & $œ \|\langle u\rangle$ & $œ \|\langle\mathrm{u}\rangle$ & $œ \|\langle\mathrm{u}\rangle$ & ü \\
\hline
\end{tabular}

$\dagger \quad$ In order to help the reader compare Sakao (see 3.4) with northern Vanuatu languages, I reproduce here (as the I8th chart) the correspondences outlined in Guy (I977). 


\section{Appendix 2. A selection of northern Vanuatu reconstructions}

Thanks to the vowel correspondences set out in appendix I, it is possible to reconstruct lexical items in the premodern stages of the attested languages, that is, to calculate their form before the processes of vowel reduction and vowel hybridization. The reconstructions below constitute a selection of such premodern forms taken from the shared lexicon of northern Vanuatu languages. For more details, the reader is referred to the explanations in section 6.I.

Each premodern reconstruction is cited together with its reflexes when they are known, and when indeed they are cognate. I have selected only those lexical items that are shared by at least five languages of the Torres and Banks area, eliminating many items that belong to smaller linguistic areas. Even under such a condition, the list is by no means comprehensive, and represents no more than an arbitrary selection, based on frequency or linguistic significance. I generally avoid protoforms that can be easily linked to an already well-established POc or PNCV reconstruction (they appeared in sections I through 5), and prefer to list here words that were developed particularly in northern Vanuatu. By so doing, I do not claim that these etyma are found exclusively in the Torres and Banks Islands - in fact, Tryon (1976) and Clark (in prep.) often show evidence of cognate forms further south — but that either a phonetic or a semantic peculiarity, or simply their importance in the vocabulary, make them worthy of mention here. It is likely that other cognate forms will be found in other languages of the Pacific.

All reconstructions are invariably stressed on their penultimate: e.g., ${ }^{\circ} a_{1}$ mara ${ }^{\prime}$ zai. In general, the consonant inventory used for these premodern northern Vanuatu forms matches that of POc, with a few differences: POC $* \mathrm{p}>{ }^{\circ} \beta$; POC $* \mathrm{k}>{ }^{\circ} \gamma$; POC ${ }^{*} \mathrm{n} r>{ }^{\circ} d ;$ POC $* \mathrm{j}>{ }^{\circ} s ; \mathrm{POC} * \mathrm{R}>{ }^{\circ} r$; POC $* \mathrm{q}>\emptyset$. All voiced stops must be understood as prenasalized (see fn. 6). Whenever useful, I use numbered tags in order to select, for each modern form, either one out of several reconstructed protoforms (as in \#55 or \#86), or one out of several meanings (as in \#I I I or \#I5I).

(\#I) ${ }^{\circ}$ abena 'instrumental anaphoric (with it); inanimate oblique anaphoric (at/about... it); Existential predicate' [<PNCV *abe-na 'his/her/its body' (?)]: LHI pan; VLW ben; LMG pan; VRA bene; MSN pen; MTA apena; NUM abene; MRL bin.

(\#2) ${ }^{\circ}$ aia 'locative anaphoric (there); inanimate oblique anaphoric (at/about... it); Existential predicate': HIU iz; LTG $I$; MTP ar; VRA ar; VRS ar; MTA aia; DRG ar; KRO ir; OLR iI; LKN (IhI).

(\#3) ${ }^{\circ}$ alasi 'Semecarpus vitiensis': MTP ne-leh; VRA les; VRS les; MTA las; DRG walars; LKN alach.

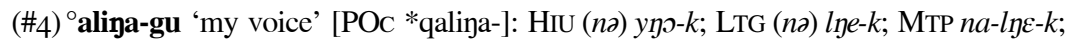

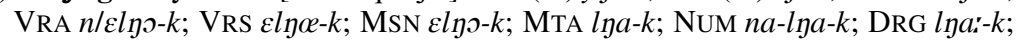
OLR linI-k; LKN $\varepsilon l \eta a-k ;$ MRL no-lino- $k$.

(\#5) ${ }^{\circ}$ aloa 'sun': LTG elo; VLW n-lo; MTP na-lo; VRA luo; VRs lo; MSN lo; MTA loa; NUM w/alb; DRG $l b$; OLR $l b$; LKN alb; MRL $n$-alb.

(\#6) ${ }^{\circ}$ arasu 'far, remote': LHR yoes; VLW yeh; MTP yeh; VRS arøes; MSN aros; MTA aras; NUM aras; DRG arais; KRO areas; OLR ras; LKN rah.

(\#7) ${ }^{\circ}$ asi 'song': LTG $\varepsilon h$; LHI $n$ - $c h$; VLW $n$-I $h$; MTP $n$ - $\varepsilon h$; LMG $n$ - $\varepsilon s$; VRA $n / \varepsilon s ;$ VRS $\propto s ;$ MSN es; MTA as; NUM w/es; DRG ass; KRO zas; OLR $n / I s ;$ LKN $a h a h ;$ MrL $n$-es. 
(\#8) ${ }^{\circ}$ awua ${ }^{\circ}$ auwa 'turtle' [PNCV *?aßua]: LTG eyor; LHI ow; MTP na- $\mho$; LMG $n-v w$;

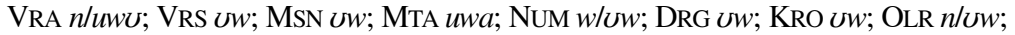
LKN aww; MRL n-Uw.

(\#9) 'baeyo 'breadfruit, Artocarpus' [PNCV *baeko; see (\#I5)]: LTG pey; LHI pa;

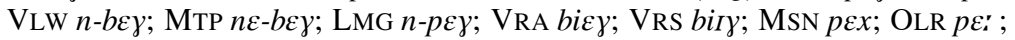
LKN pey.

(\#Io) 'bayabayaloa 'swallow, Collocalia sp.' [PNCV *kabakaba 'swiftlet']: MTP baybaylo; VRA baybayluo; VRS baybaylv; MSN paypaylo; MTA paypayaloa; NUM baybaylo; DRG baybaylo; LKN paypaylo.

(\#I I) 'balago-mwotu 'squirrelfish, Sargocentron spiniferum' [lit. 'broken (fruits? of) Ficus wassa']: MTP na-mlak- $\widehat{y m}^{w} I t$; MTA palako- $\widehat{y m}^{w} o t$; DRG blak- $\widehat{y m}^{w} v t$; OLR palak- $\widehat{y m}^{w} I t$; LKN palak- $\widehat{y m}^{w} I t$.

(\#I2) ${ }^{\circ}$ bala $_{[1]} \sim{ }^{\circ}$ balati $_{[2]}$ 'take (stones+) with tongs' [PNCV *bala-ti 'wattled structure']: MTP bal $_{[1]}$; VRS bal $_{[1]}$; MTA pala MI] $_{2} \sim$ palat $_{[2]}$; NUM balet $_{[2]}$; DRG blait $t_{[2]}$; LKN paelaes $s_{[2]}$.

(\#I3) 'balu 'steal': LHI pol; VLW bel; MTP bel; VRA bol; VRS boel; MSN pol; MTA pal; NUM bal; DRG ball; KRO beal; OLR pal; LKN pal; MRL bol.

(\#I4) 'baso 'finish; do completely; then; all': HIU pa; LTG pah; VLW bah; MTP bah; MTA paso; NUM bas; DRG bas; KRO bas; OLR pas; LKN pah; MRL bas.

(\#I5) 'batau 'breadfruit, Artocarpus' [PNCV *bataßu; see (\#9)]: МTP na-mte; MTA patau; NUM bata; DRG bta; MRL butu.

(\#I6) 'bei 'fresh water' [PNCV *bei]: HIU pe; LTG pe; LHI $p e$; VLW nI-br; MTP nI-br; LMG $p_{I}$; VRA $b r$; VRS $b r$; MSN $p r$; MTA $p e i$; NUM $b r$; DRG $b r$; KRO $b i$; OlR $p r$; MRL $n I-b I$.

(\#I7) 'bewu 'Dioscorea bulbifera': HIU pew; LTG pew; LHI pew; MTP nI-bIw; VRA wu/brw; MSN pIw; MTA pewu; NUM bIw; MRL nI-bIw.

(\#I 8) 'biy(i,u) 'eat meat': MTP biy; LMG piy; VRA biy; VRS biy; MSN pix; MTA piy; DRG biy; LKN piy; MRL biu.

(\#I9) 'birin(i,u) 'help, join (s.o.); with': LHI piyin; VLW biyiy; MTP biyin; LMG piriy; VRA birip; VRS birip; MSN piriy; MTA pirip; DRG brip; LKN pirip.

(\#20) ${ }^{\circ}$ buyoro "woven food-chest standing above fire for storing almonds and dried breadfruit': VLW no-boyor; MSN poyor; MTA puyoro; NUM buyor; DRG byor; OLR puyəy; LKN puyor; MRL boyur.

(\#2I I 'bula-gu 'possessive classifier for farming valuables (pig, garden+)': VRS bülce-k; MSN polo-k; MTA pula-k; DRG blv-k; OLR pule-k; LKN pula-k; MRL no-buts-k.

$(\# 22)^{\circ} \mathbf{b}^{\mathrm{w}}$ ayare 'porcupine fish, Diodon sp.' [PNCV *b' ${ }^{w}$ akaRe]: MTP na- $\widehat{k p}^{w} y a y$; VRA $\widehat{k p}^{w}$ ayar; VRS $\widehat{k p}^{w}$ ayar; MSN $\widehat{k p}^{w}$ ayar; MTA $\widehat{k p}^{w}$ ayare; DRG $\widetilde{k p}^{w}$ yar; LKN $\overparen{k p}{ }^{w}$ ayar:

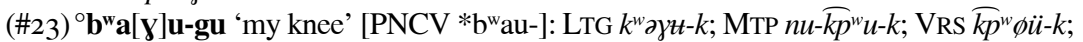

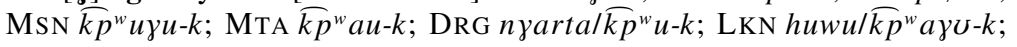
MRL $n t t-k^{w} t-k$.

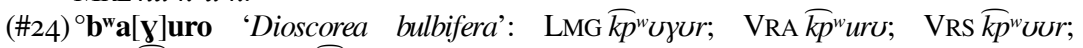
MSN $k^{w}$ Uyur; MTA $\overline{k p}^{w}$ auro; MRL $n \theta-k^{w} \theta r$.

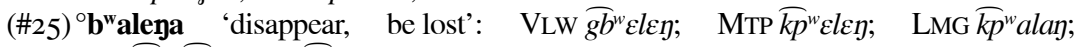

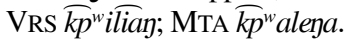

(\#26) ${ }^{\circ} \mathbf{b}^{w}$ araja 'hole': HIU $k^{w} \breve{R} a \eta \partial ; \quad$ LTG $k^{w}$ ərenz; LHI $k^{w}$ oyan; LHR $\widehat{k p}^{w}$ ayan;

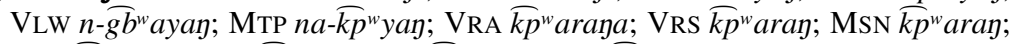

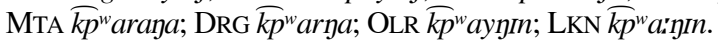

(\#27) ${ }^{\circ} \mathbf{b}^{w}$ aratu 'flying-fox': HIU $k^{w} \breve{R} s t$; LTG $k^{w}$ rort; LHI $k^{w}$ oyst; LHR $\widehat{k p}^{w} \propto y \propto e t ;$ VLW $n-\widetilde{g b}^{w} \varepsilon y \varepsilon t$; MTP $n a-\widetilde{k p}^{w} y \varepsilon t$; LMG $\widetilde{k p}^{w}$ oro?; VRA $\widehat{k p}^{w}$ ara?; VRs $\widetilde{k p}^{w}$ erert; MSN $\overparen{k p^{w}}$ orot; MTA $\overparen{k p^{w}}$ arat; NUM $\widehat{k p}^{w}$ arat; DRG $\overparen{k p^{w}}$ ra:t; MRL $k^{w}$ arat. 


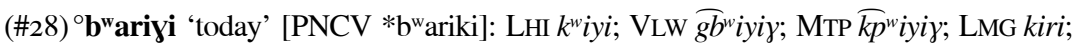
VRA $\widehat{k p}^{w}$ iri; VRS ( $\left.\operatorname{larkp}^{w} \varepsilon\right)$; MSN (yarkp $\left.{ }^{w} \varepsilon\right)$; MTA $\widehat{k p}^{w}$ ariy; NUM a/kp ${ }^{w}$ iri; DRG $\widehat{k p}^{w} r i$;

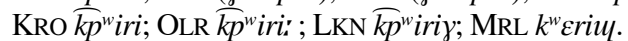

(\#29) ${ }^{\circ}\left(\mathbf{b}^{\mathrm{w}} \mathbf{a t u}\right) \mathbf{b}^{\mathrm{w}} \mathbf{a t u}-\mathbf{m a n u}$ 'Myzomela cardinalis' [lit. 'head of bird']: MTP nI- $\widehat{k p}^{w}$ It-men;

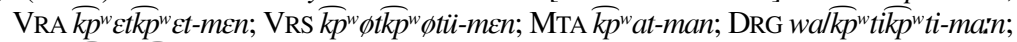
LKN $\left(k^{w}\right.$ cetkp ${ }^{w}$ cetce-mach).

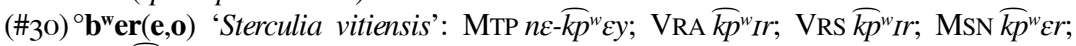
LKN $\widehat{k p}{ }^{w} \mathcal{E}$.

(\#3 I) ${ }^{\circ} \mathbf{b}^{\mathrm{w}}$ ero 'mushroom; (slang) glans' [PNCV *b'ero 'mushroom']: VLW $n-\widehat{g b}^{w} \varepsilon y$; MTP $n \varepsilon-\widehat{k p}^{w} \varepsilon y$; VRA $\widehat{k p}^{w} I r$; VRS $\overparen{k p}^{w}$ Ir; MSN $\widehat{k p}^{w} \varepsilon r$; MTA $\widehat{k p}^{w} e r o$; DRG $\overline{k p}^{w} \varepsilon r$; LKN $\widehat{k p^{w}} \mathcal{E}^{\prime} ;$ MRL $n_{I}-k^{w} I r$.

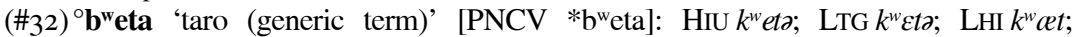

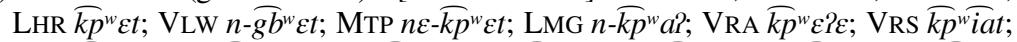
MSN $\overparen{k p^{w}} \varepsilon t$; MTA $\overparen{k p^{w}} e t a$; NUM $\overparen{k p^{w}} \varepsilon t$; DRG $\overparen{k p^{w}} \varepsilon t$; KRO $\widehat{k p}^{w} \varepsilon t$; OLR $\overparen{k p^{w}} \varepsilon t$; LKN $\overparen{k p^{w}} \varepsilon t$; MRL $n I-k^{w} I t$.

(\#33) ${ }^{\circ} \mathbf{b}^{\mathrm{w}}$ eti 'be finished; completely; then; all': VLW $\overparen{g b}^{w} I t$; MTP $\widehat{k p}^{w} I t$; LMG $\widehat{k p}^{w} I$; VRA $\widehat{k p}^{w} I$ I ; VRS $\widehat{k p}^{w} I t$; MSN $\widehat{k p^{w}} I t$; MTA $\widehat{k p}^{w} e t$.

(\#34) ${ }^{\circ}\left(\mathbf{b}^{\mathbf{w i}} \mathbf{i}\right) \mathbf{b}^{\mathbf{w}}$ ilo 'mangrove, Rhizophora': LTG turolkwila; MTP nI- $\widehat{k p}^{w} I \widehat{k p}^{w} I$;

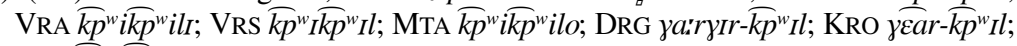
LKN $k p^{w} i k p^{w} i l$.

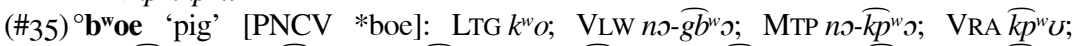

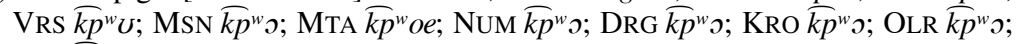
LKN $k p^{w}$.

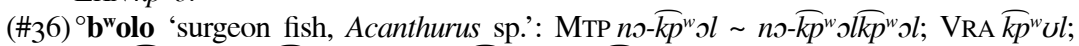
VRS $\overparen{k p^{w}} u l$; MTA $\overparen{k p^{w}}$ olo; DRG wa/ $/ \mathrm{kp}^{w} \mathrm{ol}$; LKL $\overparen{k p^{w}} \mathrm{ol}$.

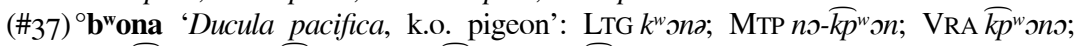
VRS $\widehat{k p}{ }^{w}$ on; MTA $\overline{k p}^{w}$ ona; DRG $\widehat{k p}^{w}$ on; LKN $\widehat{k p}^{w}$ on.

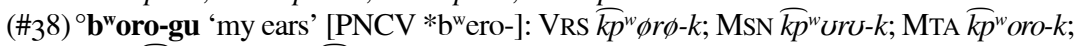
NUM $\overparen{k p}{ }^{w}$ oro- $k$; DRG $k^{w} r u-k$; MRL $n u-k^{w} U r u-k$.

(\#39) ${ }^{\circ}$ daeru 'coconut crab, Birgus latro' [PNCV *daweru]: MTP na-diy; VRA dirr; VRS dir; MSN nir; MTA naer; DRG $y / d r r ;$ KRO dir; OLR tffy; LKN $\overparen{t f L}$.

(\#40) ${ }^{\circ} \mathbf{d a}[\mathbf{\gamma}] \mathbf{o}$ 'do, make': HIU ta; LTG ta; LHI da; LMG ta; VRA da; VRS da; MSN nay; MTA $n a$; NuM da; Drg daw; Kro daw; OLR $\widehat{t f a} a$; MrL da.

(\#4I) ${ }^{\circ}$ damu 'yam (generic term)' [PNCV *damu]: LHI don; LHR $n$-døem; LMG $n$-toem; VRA dom; VRS dom; MSN nom; MTA nam; NUM dam; DRG da:m; Kro deam; OLR TfIm; LKN Tfam; MRL no-dom.

(\#42) ${ }^{\circ}$ dani 'ablative prep./conj.: from; away; because; lest; than': LTG ten; VLW den; MTP $d \varepsilon n$; LMG $d \varepsilon n$; VRA $d \varepsilon n$; VRS $d \varepsilon n$; MSN $n \varepsilon n$; MTA $n a n$; NuM $d \varepsilon n$; DRG $d i n$; KRO $d \varepsilon n$; OLR $\overparen{t f} I n ; \operatorname{LKN} \overparen{t f} \varepsilon n$; MRL $n \varepsilon n$.

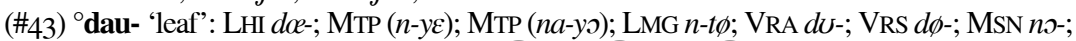

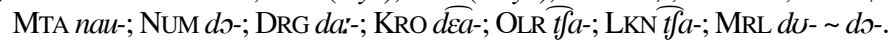

(\#44) ${ }^{\circ}$ dau-talise 'Lutjanus gibbus, k.o. snapper' [lit. 'leaves of Terminalia (due to yellow color)']: MTP na-baw yo-tlis; VRA du-Pilisi; VRS da-talis; MTA no-salte; DRG da-tlis; KRO da-tills; LKN $\overparen{t f a-t a l i h . ~}$

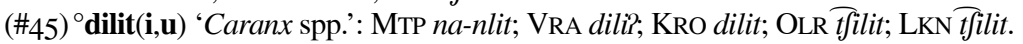

(\#46) ${ }^{\circ}$ dina 'reach; until': VLW din; MTP din; LMG tan; VRA dinI; VRS din; MSN niz;

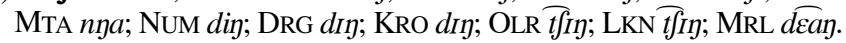

$(\# 47)^{\circ} \mathbf{d o}[\mathbf{m i}]$ domi 'think; worry' [PNCV *domi 'think (about), love']: HIU ttem; LTG tamtoom; LHI (den); VLW (dodon); MTP dimdim; VRA dudum; VRS $d \phi d \phi m$;

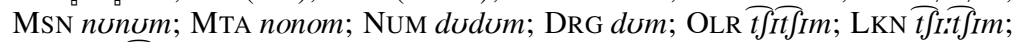
MRL ded 


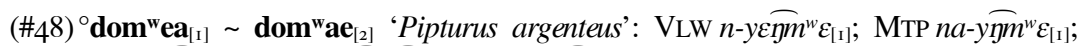

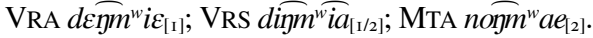

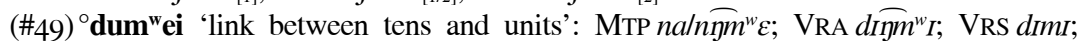

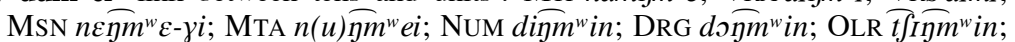
LKN Tfinm ${ }^{w}$ in; MRL don ${ }^{w} I$.

(\#50) ${ }^{\circ}$ esu 'live, be alive': LTG (ah); MTP I $h$; LMG Is; VRA Is; VRS Is; MSN Is; MTA es; NUM Is; DRG Is; OLR Is; LKN Is; MRL Is.

(\#5I) ${ }^{\circ} \mathbf{Y a b a n}[\mathbf{i , e}]$ '[ $\left.n\right]$ sail' [PNCV *kabani]: LTG yəpen; MTP naVRS yeben; MSN yepen; MTA yapan yapane; MRL ( үəm).

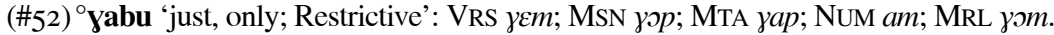

(\#53) ${ }^{\circ}$ yale 'lie, deceive' [PNCV *kale 'tease, joke, deceive']: LHI yal; VLW yal; MTP yal; VRA yal; VRS yial; MSN yal; MTA yale; DRG yal; KRO yal; OLR yal; LKN yal; MRL $y \varepsilon l$.

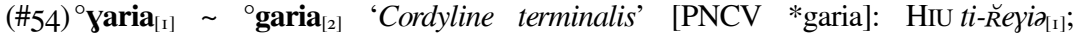

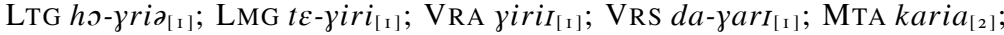
NUM do-kiri $i_{[2]}$; DRG $k r I_{[2]}$; LKN (kahrae).

(\#55) ${ }^{\circ} \mathbf{y a o} \beta \mathbf{a}_{[1]} \sim{ }^{\circ} \mathbf{g a o} \beta \mathbf{a}_{[2]} \sim{ }^{\circ} \mathbf{o} \mathbf{\beta a} \mathbf{a}_{[3]}$ 'reef heron, Ardea sacra': LTG $\gamma \supset \beta \partial_{[I]} ;$ MTP na-yop $p_{[1]}$;

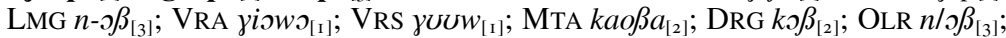
LKN $\gamma a \supset \beta_{[1]}$; MRL $n o-k o p_{[2]}$.

(\#56) ${ }^{\circ}$ Yasali 'knife': VLW na-yasel; MTP na-yasel; LMG n-yasel; VRA yasel; VRS yasel; MTA yasal; NuM yasel; OLR yasal; LKN yaharl; MRL ni-yisel.

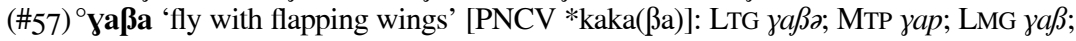
VRS $\gamma a \beta$; MSN $\gamma a \phi$; MTA $\gamma a \beta a$; DRG $\gamma a \beta$; KRO $\gamma a \beta$.

$(\# 58)^{\circ}$ ya-ßaruru 'great bean vine': LTG $\gamma \supset \beta \partial r u R$, MTP na-yapyuy; VRA yaßurur; VRS yaßarür; MTA yaßarur; OLR yaßuruy; LKN yaßaru'.

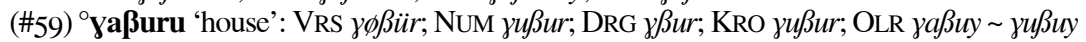
$\sim \beta u \beta u y$.

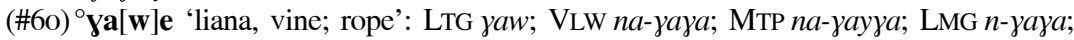

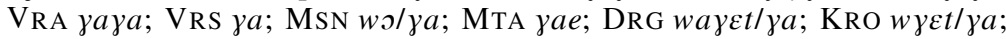
LKN ( $\gamma$ )awutce/ $\gamma a$; MRL $n \varepsilon-\gamma \varepsilon$.

(\#6I) ${ }^{\circ}$ yaya 'kava': HIU $y a$; LTG $y i$; LHR $n-\gamma a$; VLW na- $y a$; MTP na- $a a ;$ LMG $n$ - $y a$; VRA $\gamma i \varepsilon$; VRS $\gamma I$; MSN $\gamma \varepsilon$; MTA yea; DRG $\gamma \varepsilon$; KRO $\gamma \varepsilon$; OLR $\gamma \varepsilon$; LKN $\gamma \varepsilon$.

(\#62) ${ }^{\circ}$ [yi]da-ru[a] 'IST INCL DUAL' [PNCV *kida-rua]: HIU t $\theta \breve{R} \theta$; LTG tor; LHI yinyo; VLW duyv; MTP du dvyv; LMG yatru; VRA yiduv; VRS durvk; MSN ninru; MTA nara; DRG dar $r$; KRO du duru; OLR tfurv; LKN wutfu; MRL duru.

(\#63) ${ }^{\circ}$ yoari 'root' [PNCV *kawa(ri), POC *kawaRi]: LTG yərəh; VLW $n$ - yryi; MTP nu-yuyi; LMG $n$-yœr; VRA yuri; VRS yeri; MTA yari; DRG yari; KRO year; OLR yay; LKN yi'yi:; MRL yoer.

(\#64) ${ }^{\circ}$ Yoro '[ $[a d v$.] (so as to) surround, cover, obstruct, prevent, protect...' [PNCV *koro]:

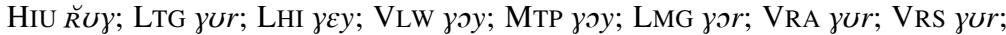
MSN yor; MTA yoro; NUM yor; DRG yor; KRO yor; OLR woy; LKN (tu)wo: ; MRL yor.

(\#65) ${ }^{\circ}$ yunu-gu 'spouse': VLW yini- $\eta$; MTP $i / \gamma n i-k ; \quad$ VRA yunu- $k$; VRS yün $\phi-k$; MSN zunu- $k$; LKN wunu- $k$.

(\#66) ${ }^{\circ}$ galo 'go up, climb up; crawl; enter, exit; upward' [PNCV *galo]: HIU kay; LTG kal; LHI kal; VLW gal; MTP kal; LMG kal; VRA kal; VRS kal; MSN kal; MTA kalo; NUM kal; DRG kal; KRO kal; OLR kal; LKN kal; MRL kal.

(\#67) ${ }^{\circ}$ gama-ru[a] 'Ist EXCL DUAL (indep. pronoun)': HIU kamař $\theta$; LTG kəmor; LHI mayo; VLW gemyu; MTP kamyu; LMG kamaru; VRA kamaduv; VRS kumuruk; MSN kememru; MTA (kara); NuM kamar; DRG kmarr; KRO kemear; OLR kImry; LKN yama: ; MRL kamar.

(\#68) ${ }^{\circ}$ gamuyu '2nd PLURAL (indep. pronoun)' [PNCV *gamuyu]: HIU kimi; LTG kəmi; LhI kimi; VlW gimi; MTP kimi; LMG kimi; VRA kImi; VRs kımi; Msn kimi; MTA kamiu; DRG kmi; Kro kimi; OlR kimi; LKN jamu; MrL kemi. 
(\#69) 'gelu 'back, backward, again; Reflexive': LHI (lek); MTP (lok); LMG kIl; VRA kIl; VRS kIl; MSN kIl; MTA kel; NUM kIl; DRG kIl; KRO kIl; OLR kIl; LKN kIl; MRL kIl.

$(\# 70)^{\circ}$ gore 'horizontal slit drum' [PNCV *[k,g]ore 'make musical sound']: LTG kor; LHI keykey; MTP no-koy; VRS wukur; MSN wokor; MTA kore; DRG wkor-duy; KRO wkor; OLR wokoy; MRL woksr.

(\#7I) ${ }^{\circ}$ gula-gu 'my back': HIU kyo-k; LTG kile-k; MTP nI-kle-k; LMG kolo-k; VRA kolo-k; VRS küllo-k; MSN kolo-k; MTA kula-k.

(\#72) ${ }^{\circ}$ guRio $_{[1]} \sim{ }^{\circ}$ gio $_{[2]}$ 'dolphin' [PNCV *guRio 'porpoise']: HIU $k^{w} \breve{R} e_{[1]}$; LTG $k^{w} u r i \partial_{[1]}$; MTP $n_{I}-k_{[2]}$; VRS $k I_{[2]} ;$ MSN $k I_{[2]} ;$ MTA $k i o_{[2]}$; NUM wilki $i_{[2]}$; KRO $k I_{[2]}$; OLR $k I_{[2]}$; LKN $k I_{[2]} ;$ MRL $n \varepsilon-k \varepsilon a_{[2]}$.

(\#73) ${ }^{\circ} \mathbf{l a}[\boldsymbol{\beta}] \mathbf{i}$ 'take, receive; give' [PNCV *la[ß]]i, POC *alap]: HIU (əуə); LTG (olə); VlW $l \varepsilon$; MTP $l \varepsilon p$; VRA $l \varepsilon$; VRS $l \varepsilon$; MSN $l \varepsilon$; MTA $l a \beta$; Num $l \varepsilon$; DRG $l a$; OlR $l a$; LKN la; MRL $l \varepsilon$.

(\#74) ${ }^{\circ}$ lado 'name of a chiefly rank': VLW wellan; MTP wellan; MTA lano; LKN latf.

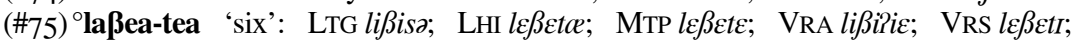

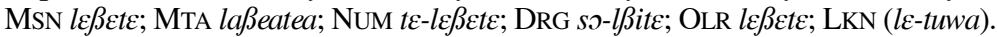

(\#76) ${ }^{\circ}$ lawe 'blenny fish, Ecsenius sp.': MTP nI-kp ${ }^{w}$ It/law; VRA law; MSN law; MTA lawe; DRG law; OLR law; LKN law.

(\#77) ${ }^{\circ}$ leasi 'change; translate; replace': LTG $\overparen{l i \varepsilon}$; VLW leh; MTP leh; VRS lies; MTA leas; DRG lis; LKN ßallih.

(\#78) ${ }^{\circ}$ liwoa 'big': HIU iwe; LTG lawo; LHI lowo; VLW ye/lwo; MTP liwo; LMG lowo; VRA luwo; VRS lüwv; MSN lowo; MTA lwoa; DRG lwo; KRO luwo.

(\#79) ${ }^{\circ}$ lolo-b ${ }^{w}$ oni 'be ignorant; forget' [lit. 'mind in night']: LTG (lionək $\left.k^{w} \partial \eta\right)$;

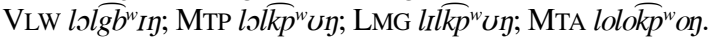

(\#80) 'lolo-marani 'be intelligent; remember, understand, know' [lit. 'mind in daylight']: HIU yөymə̌̌en; LTG lolmaren; VLW lolmeyen; MTP lolmeyen; VRA lulmaran; VRS lulumeren; MSN lolmeren; MTA lolomaran; DRG llomra:n; LKN lolma:ren; MRL lolmeren.

(\#8I) ${ }^{\circ}$ lolo-na 'its inside; his/her mind': HIU yo-nə; LTG lio-n $ә$; LHI lo-n; VLW $n-l o l o-n$; MTP $n a-l o-n$; LMG $l \phi l \phi-\gamma i$; VRA lolo- $\gamma i$; VRS lolo-n; MSN lolo-n; MTA lolo-na; NUM $n a-l l o-n$; DRG $l l o n$; KRO lo- $n$; OLR lolo- $n$; LKN lolo-n; MRL no-llo-n.

(\#82) ${ }^{\circ}$ lotu 'mashed breadfruit': VLW $n$-lit; MTP nI-lit; LMG $n$-l $\phi t$; VRS l $l$; MSN lut; MTA lot; NUM lut; DRG lut; MRL no-let.

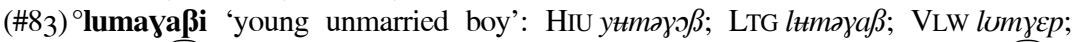

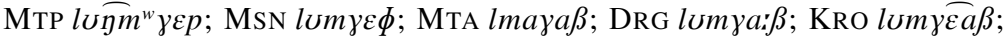
MRL lumyep.

(\#84) ${ }^{\circ}$ madu-gu 'my nose': HIU miti-k; LTG məttu-k; MTP ni-mdi-k; VRA midi-k; VRS $m \phi d \ddot{u}-k$; MSN munu-k; MTA manu-k; DRG $m d u-k$; LKN matJo-k; MRL no-modtt-k.

(\#85) ${ }^{\circ}$ madua 'orphan': VLW wo/mdv; MTP wolmdv; VRS mvdv; MTA manua; DRG mdv 'hungry'; LKN wi/matfu.

$(\# 86)^{\circ} \mathbf{m a y a r o s a}_{[1]} \sim{ }^{\circ} \mathbf{m a m a r o s a}_{[2]} \sim{ }^{\circ} \operatorname{mayarosina}_{[3]} \sim{ }^{\circ}$ mamarosayi $_{[4]}$ 'sad, sorry': HIU $\beta$ oy/maməर̆ ${ }_{[2]}$; LTG məyarhin ${ }_{[3]}$; LHI mayaysen $_{[3]}$; VLW mayaysIn $_{[3]}$; MTP mayaysIn $_{[3]}$; LMG mayarsan $_{[3]}$; VRA mayarsin ${ }_{[3]}$; VRS mamarsey ${ }_{[4]}$; MSN mamarsey ${ }_{[4]}$; MTA mayarosa $a_{[1]}$; NUM mayurus $[1]$; DRG (matnero $\left.\beta\right)$; KRO mamros ${ }_{[2]}$; OLR mamros $_{[2]}$; LKN mamroh $[2]$; MRL (mitinarop).

(\#87) ${ }^{\circ}$ may[a,e]se-gu 'myself, on my own': LTG mayi- $k$; MTP mahyI- $k$; LMG masyI- $k$;

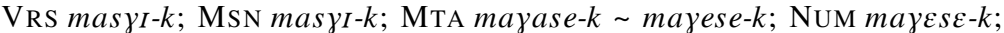
DRG maysI- $k$; OLR $\widetilde{y m}^{w} a r s I-k$; LKN $\widetilde{\eta m}^{w} a h y I-k$.

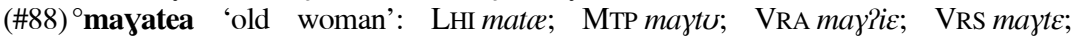
MSN mayte; MTA mayatea; DRG mayte; OLR ma'te; LKN mayte. 
(\#89) ${ }^{\circ} \mathbf{m}[\mathbf{a y}] \mathbf{u}$-gu 'general possessive classifier': LHI mu- $k$; VLW n-mi-g-is; MTP na-mu- $k$; LMG $m u-k \sim m u \gamma u-k$; VRA $m u-k$; VRS $m \phi \gamma \ddot{u}-k$; MSN $m u \gamma u-k$; MTA $\widehat{\eta m}^{w} o-k$; NUM $m u-k$; DRG $m u-k$; KRO $m u-k$; OLR $m u-k$; LKN $m o-k$; MRL $m u-k$.

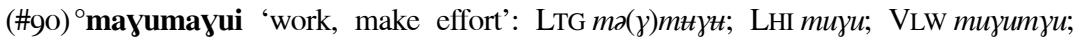
MTP muwumwu; MSN muwmuwu; MTA mawmawui; DRG mumyu; KRO muүтиүu; OLR ти'тияи; LKN тиятияи.

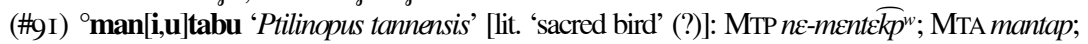
DRG ma'nta'b; LKN maentap.

(\#92) ${ }^{\circ}$ maranaya 'village chief': HIU mă̌ənayə; LTG marənayə; VLW mayanay; MTP mayanay; VRA maranaya; VRS maranay; MSN maranax; MTA maranaya; DRG mranya; OLR maranaya; LKN maranaya; MRL marnam.

(\#93) ${ }^{\circ}$ marau-gu '(my) maternal uncle; (my) nephew': LTG mert- $k$; VLW n-møyu- $\eta$; MTP moyu- $k$; VRA maru- $k$; VRS marü- $k$; MSN marıu- ; MTA marau- $k$; DRG maru- $k$; LKN maru- $k$.

(\#94) ${ }^{\circ}$ marawa 'spider; name of a spirit': HIU mə̌̆awə; LTG mərawə; VLW n-mayaw; MTP na-myaw; VRA marawa; VRS maraw; MSN maraw; MTA marawa; DRG mraw; KRO maraw; OLR maraw; LKN maraw.

(\#95) ${ }^{\circ}$ maraya 'moray, eel' [PNCV *maraya]: LTG məri; VLW n-maya; MTP na-mya; VRA merie; VRS marI; MTA marea; DRG mre; KRO mere; OLR mere; LKN mare; MRL ne-merI.

(\#96) ${ }^{\circ}$ maraya b boe 'giant moray, Gymnothorax sp.' [lit. 'eel pig']: МTP na-mya $\widehat{k p}^{w} v$;

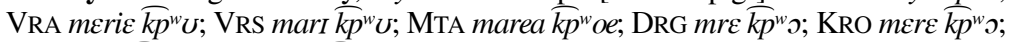

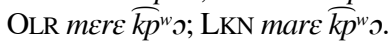

(\#97) ${ }^{\circ}$ maremare 'hard, strong; stubborn’: LTG mərmer; VLW maymay; MTP maymay; VRA marmar; MTA maremare; NUM (mmartiy); DRG marmar; KRO marmar; OLR maymay; LKN marmar; MRL mermer.

(\#98) ${ }^{\circ}$ marosi 'want, like': LHI ne-myes; VLW n-muyus; MTP ne-myus; LMG murus; VRA murus; VRs m $\phi r \phi s ;$ MSN murus; MTA maros; NuM murus; DRG mrus; KRO murus; OLR miris; LKN maIs; MRL mores.

(\#99) ${ }^{\circ}$ mataßa(si) 'morning': HIU mətaßə; LTG mətaß;; LHI matap; $\quad$ VLW mtap;

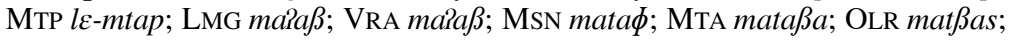
LKN matpaeh.

(\#IOO) ${ }^{\circ} \mathbf{m a t u}[\mathbf{\gamma}] \mathbf{i}_{[\mathrm{I}]} \sim{ }^{\circ} \mathbf{m a t u}(\mathbf{e}, \mathbf{a}, \mathbf{o})_{[2]}$ 'dry coconut, coconut tree': HIU $m u_{t t_{[I]}} ;$ LTG $\operatorname{mott}_{[\mathrm{I}]}$;

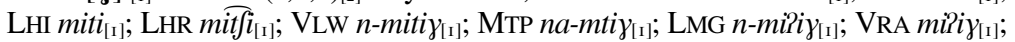

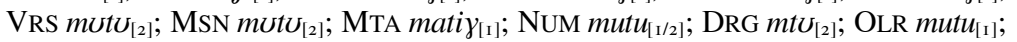
LKN matu $_{[1]} ;$ MRL na-matu $U_{[2]}$.

(\#IOI) ${ }^{\circ}$ matu[Y] $]$ itu[y]i 'Areca catechu': MTP no-wo/mtiytiy; LMG yalmiiripiiy; VRA woyal miiri?iz; DRG walmtutu; KRO mututu; LKN matutu; MRL metimtiu.

(\#I02) ${ }^{\circ}$ maßatoa 'name of a dance': MTP na-mapts; MSN maфts; MTA maßatoa; DRG maßts; LKN maßts.

$(\# I 03)^{\circ} \mathbf{m}^{[\mathrm{w}]} \mathbf{a b}^{[\mathrm{w}]} \mathbf{u}$ 'put down, lay s.t.': VLW mun; MTP $\widehat{y m}^{w} u k$; LMG $m o p$; VRA $m o m$; VRS mem; MSN mop; MTA map; MRL mom.

(\#IO4) ${ }^{\circ} \mathbf{m}^{[\mathrm{w}]} \mathbf{a b}^{[\mathrm{w}]} \mathbf{u s a y i}$ 'breathe; take rest' [PNCV *mabu-si]: LTG $m ə k^{w} h \varepsilon$; LHI $m o k s a$;

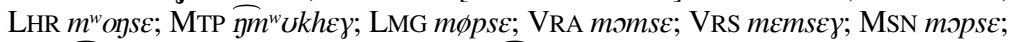

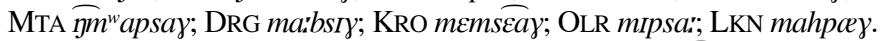

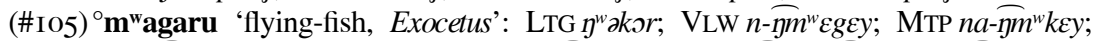
VRS $\widetilde{y m}^{w} e k \propto r$; MTA makaru; DRG $\widetilde{y m}^{w} k a r r ;$ KRO $\widehat{y m}^{w} \varepsilon k \widetilde{\varepsilon a r}$; OLR $\widehat{y m}^{w}$ okay; MRL $\eta^{w}$ okor.

(\#Io6) ${ }^{\circ} \mathbf{m}^{w} \mathbf{a i}$ 'sea snake, Laticauda semifasciata': LHI $\eta^{w} \alpha$; MTP $n \varepsilon-\widehat{\eta ̆ m}^{w} \varepsilon$; VRA $\widehat{\eta m}^{w} \varepsilon$;

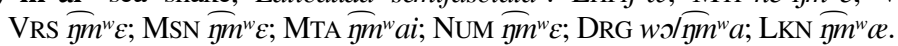

(\#I07) ${ }^{\circ} \mathbf{m}^{\mathrm{w}} \mathbf{a l a m}{ }^{\mathrm{w} a l a}$ 'young unmarried girl' [PNCV * $\mathrm{m}^{\mathrm{w}} \mathrm{ala}\left(\mathrm{m}^{\mathrm{w}} \mathrm{ala}\right)$ 'naked' (?)]:

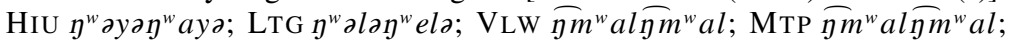




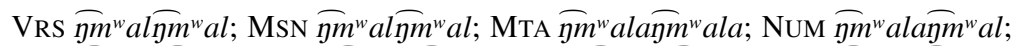

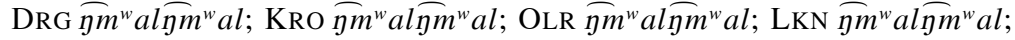
MRL $\eta^{w}$ aly $\eta^{w}$ al.

(\#I08) ${ }^{\circ} \mathbf{m}^{\mathrm{w}}$ ara[yi] 'Chalcophaps indica, k.o. dove': MTP na- $\widehat{\eta ̆}^{w} a y ;$ LMG $\widehat{\eta m}^{w} \varepsilon r \varepsilon y$;

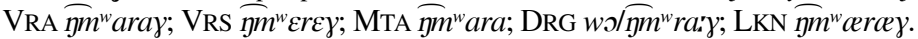

(\#I09) ${ }^{\circ} \mathbf{m}^{w}$ atiga 'purple swamphen, Porphyrio porphyrio': LMG $\overline{\eta m}^{w} a$ ?ak; VRA $\overline{\eta m}^{w} i ? i k r$;

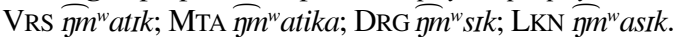

(\#IIO) ${ }^{\circ} \mathbf{m}^{\mathrm{w}}$ asa 'goatfish, Mullidae spp.' [see (\#I54)]: MTP na- $\widehat{y m}^{w} a h$; VRA $\widehat{\eta m}^{w} a s a$; VRs $\widehat{\eta m}^{w} a s ;$ MTA $\widehat{\eta m}^{w} a s a$; OLR $\widehat{\eta m}^{w} a s ;$ LKN $\widehat{\eta m}^{w} a h$.

(\# I I I ) ${ }^{\circ} \mathbf{m}^{[\mathbf{w}]}$ asawa[i] 'empty space, place; moment' ${ }_{[1]}$; 'garden' ${ }_{[2]}[\mathrm{PNCV}$ *masawa 'space,

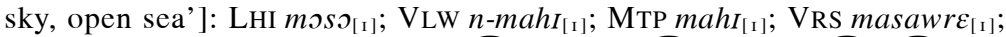

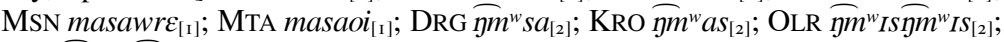

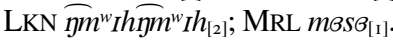

(\#I I2) ${ }^{\circ} \mathbf{m}^{w}$ ele-dolu 'a hundred' [lit. 'a whole Cycas palm']: LHI $\eta^{w} \varepsilon l d e l$; MTP $\widehat{\eta m}^{w} \varepsilon l d I l$;

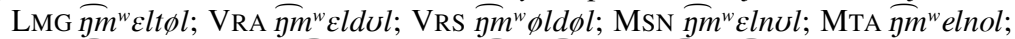

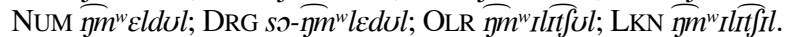

(\# I I3) ${ }^{\circ} \mathbf{m}^{w}$ era 'child' [PNCV *mwera 'child']: LTG $\eta^{w} e r \partial$; LHI sus/ $\eta^{w} \varepsilon y$; VLW $n \varepsilon t / \widehat{\eta m}{ }^{w} \varepsilon y$; MTP $n I t \widehat{\eta m}^{w} \varepsilon y$; VRA $\widehat{\eta m}^{w} \varepsilon r \widehat{\eta m}^{w} \varepsilon r \varepsilon$; VRS $\widehat{\eta m}^{w} i r \widehat{\eta m}^{w} i \overrightarrow{i a r}$; MSN $\widehat{\eta m}^{w} \varepsilon r \widehat{\eta m}^{w} \varepsilon r$;

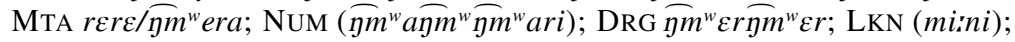
MRL $n u-l v / \eta^{w} I r$.

(\# I I4) ${ }^{\circ}$ nanara 'Pterocarpus indicus': LTG $\overparen{\text { ier }}$; VlW na-nay; MTP na-nay; VRA nanara; VRS nanar; MSN nanar; MTA nanara; DRG nnar; LKN nana:

(\#I I5) ${ }^{\circ}$ nau 'Ist SG free pronoun' [PNCV *nau]: HIU nokə; LTG nokə; LHI $n \diamond ;$ VLW $n \varepsilon$;

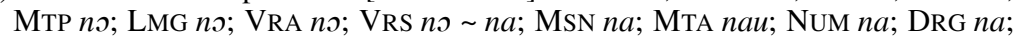
KRO $n a ;$ OLR $n a ;$ LKN $n a ;$ MRL $n$.

(\#I I6) ${ }^{\circ}$ nigo ‘2nd SG free pronoun' [PNCV *nigo]: HIU ikə; LTG nikə; LHI nek; VLW nIn; MTP nIk; LMG nak; VRA nikı; VRS nIk; MSN nık; MTA niko; NUM nIk; DRG nık; KRO $n I k$; OLR $n I k ;$ LKN $n I k ;$ MRL neak.

(\# I I7) ${ }^{\circ}$ oraora 'play; game': VRA ororo; VRS oror; MSN oror; MTA oraora; NUM oror; DRG oror; KRO oror; LKN or ${ }^{\prime 2} s^{\prime}$; MRL oror.

(\#I I 8) ${ }^{\circ}$ raga '[v.] lift up; [adv.] up, upward; immediately; (take) away/off...': HIU řakə; LTG raka; LHI yak; VLW yan; MTP yak; LMG rak; VRA raka; VRS rak; MSN rak; MTA raka; MRL rak.

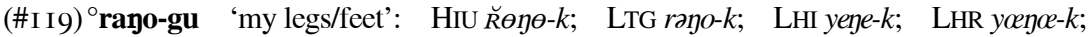

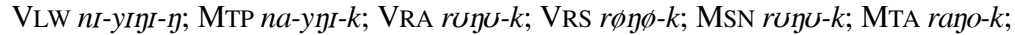

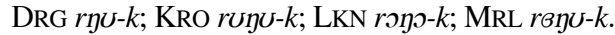

(\#I20) ${ }^{\circ}$ rayorayo 'Acalypha spp.': MTP na-yayyan; VRA rayray; VRS rayray; MTA rayorano; DRG w/rayray; LKN rayray.

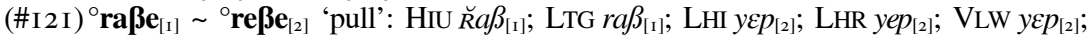
MTP $y a p_{[1]} ;$ LMG $r \varepsilon \beta_{[2]} ;$ VRA $r \varepsilon \beta_{[2]} ;$ VRS $r \varepsilon \beta_{[2]} ;$ MSN $r \varepsilon \phi_{[2]} ;$ MTA $r a \beta e_{[1]} ;$ NuM $r \varepsilon \beta_{[2]}$; DRG $r \varepsilon \beta_{[2]}$; KRO $r \varepsilon \beta_{[2]}$; OLR $r \varepsilon \beta_{[2]}$; MRL $r i \beta_{[2]}$.

(\#I22) ${ }^{\circ}$ reyasi 'Charmosyna palmarum, k.o. parrot': MTP na-ynes; VRA rejes; VRS rejes; MTA regas; DRG walrnas; LKN tjanceh.

(\#I23) ${ }^{\circ}$ riya 'swell; fat, big': MTP yry; VRA riyr; VRS rry; MSN rix; MTA riya; DRG rry; KRO rry; OLR $r I$; ; LKN rry; MRL rIm.

(\#I24) ${ }^{\circ}$ ririyo 'porpoise; whale': VRA ririzi; VRS rirry; MSN rirry; MTA ririyo; DRG rriy; OLR riri: ; LKN ririy; MRL ne-rereau.

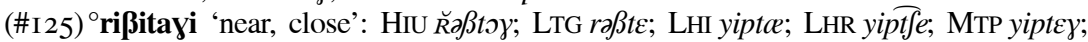

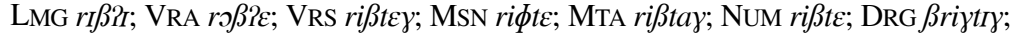
KRO ßirita; OLR rißta:; LKN riytay. 
(\#I 26) ${ }^{\circ}[$ ro]royo 'quiet, silent; sacred' [PNCV *roroyo 'be quiet, pay attention']: LTG rarop; VLW yoy; MTP yoy yoyoy; VRA roroy; VRS roroy; MSN roroy; MTA rono roroyo; DRG roy; LKN rorop; MRL roroy.

(\#I27) ${ }^{\circ}$ rowou 'bonito, Thunnus sp.': LTG rawz; MTP na-ywr; MTA rowou; DRG rwu; KRO rUwu; OLR rIwI; LKN rIwI.

(\#I28) ${ }^{\circ}$ rowo '[direc.] out, outward; seaward': HIU řow; LTG row; LHI yow; VLW yo; MTP yow; LMG row; VRA row; VRS ruw; MSN row; MTA rowo.

(\#I29) ${ }^{\circ}$ saye $_{\mathrm{I}}$ 'up, upward; upwind, toward southeast' [POC *sake 'go upward, go southeast']: HIU tI/iay; LTG (i)ay; LHI ha; VLW ha; MTP hay; LMG say; VRA say; VRS siay; MSN say; MTA saye; NUM sa; DRG say; KRO say; OLR sa:; LKN hay; MRL seam.

(\#I30) ${ }^{\circ}$ saye $_{2}$ 'sit, stay' [POC *sake 'go upward']: HIU say; LTG hay; LHR say; VLW hay; MTP hay; VRA say; VRs siay; MSN say; MTA saye; NuM sa; DRG say; Kro say; OLR sa: ; LKN hay; MRL sEam.

(\#I3I $)^{\circ}$ salayoro 'secret; secret meeting place in the bush for men during initiation rituals': LTG holayor; VLW n-halyoy; MTP na-halyoy; VRS salyur; MSN salyor; MTA salayoro; DRG salyor; KRO salyor; OLR salyoy; LKN salwo'.

(\#I32) 'saraßi 'rub, stroke': LTG hare $\beta$; LHI heyaep; VLW hryıp; MTP heyep; LMG sœrœe $\beta$; VRA sara $\beta$; VRS ser $\propto \beta$; MsN sere $\phi$; MTA sara $\beta$; NUM sara $\beta$; DRG sra: $\beta$; KRO serea $\beta$; LKN hara $\beta$; MRL serep.

(\#I33) ${ }^{\circ}$ sari '[n.] spear' [PNCV * sari 'to spear, thrust']: LTG her; MTP n-Iscy; VRA ser; VRS ser; MTA sar; DRG sri/tuk; KRO teaß/sear.

(\#I34) 'saru 'put on, wear (clothes+)': LTG hor; LHI høy; MTP hey; MTA sar; DRG sarr; LKN sa:

(\#I35) ${ }^{\circ}$ [sa]sae 'different': HIU $a$; LTG ha; LHI tyalha; MTP haha tey/ha; LMG sesa; VRA sisie; VRS sisia; MSN sasa; MTA sasae; NuM sisI.

(\#I36) 'sasa-gu 'my name': HIU yo- $k$; LTG ie-k; LHI na-he-k; VLW ne-hehe- $n$; MTP na-he- $k$; VRA so-k; VRS sioe- $k$; MSN so- $k$; MTA sasa-k; NUM na-ssi-k; DRG ssai-k; OLR sasi-k; LKN haha-k; MRL no-sso- $k$.

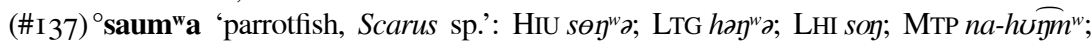

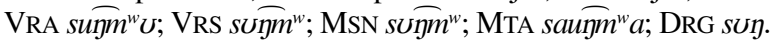

(\#I38) 'sili 'darkness': MTP sil; VRS sil; MSN sil; MTA sil; NUM sil; Drg sil; KRO sil; OLR sil; LKN hil; MRL sil.

(\#I39) ${ }^{\circ}$ sirißi 'waterfall': MTP na-syip; VRS siri $\beta ; \quad$ MTA siri $\beta ; \quad$ DRG sriß; OLR siri $\beta$; LKN hiriß; MRL siriw.

(\#I40) ${ }^{\circ}$ somu 'shell money' [PNCV *zomu]: MTP nI-sIm; VRS s $\phi m$; MSN sum; MTA som; DRG sUm; OLR sIm; LKN hIm.

(\#I4I) ${ }^{\circ} \mathbf{s u b}^{\mathrm{w} e}$ 'initiation ceremony in graded society' [PNCV * $\operatorname{sub}^{\mathrm{w} e}$ ]: HIU $s u k^{w} ə$; LTG $h u k^{w} \partial$; VLW $n u-s u \widehat{y m^{w}}$; MTP $n u-s u \widehat{k p^{w}}$; VRA $s u \widehat{k p}^{w} U$; VRS $s u \widehat{k p^{w}}$; MTA sukp ${ }^{w} e$; DRG $\beta / s u k$; KRO $\beta u / s u k ;$ LKN $\beta a l s u k$.

(\#I42) ${ }^{\circ}$ sura 'entrance of Hell': VLW wv/suy; MTP wv/suy; VRS wirI/sur; MTA sura; DRG wrI/sur; KRO wIrI/sur; OLR wirI/suy; LKN wore/hu:

(\#I43) ${ }^{\circ}$ sußusußu 'bathe, wash (o.s.)': LTG həht; MTP suwsuw; VRA siwsiw; VRS süßsüß; MSN suwsuw; MTA suysuy; NUM suwsuw; OLR (suwa); LKN (huwce); MRL suwsuw.

(\#I44) 'suwe 'downward; toward northwest': LHI how; VLW hu; MTP how; LMG suw; VRA suwv; VRS suw; MSN suw; DRG swIl; LKN how sIwIl; MRL suw.

(\#I45) 'tabia 'wooden dish': LTG topiz; MTP na-tbr; LMG n-?ipr; VRA 2ibir; VRS tabr; MSN trpr; MTA tapia; NUM tibi; DRG tbr; OLR tipr; LKN tapr; MRL tabea.

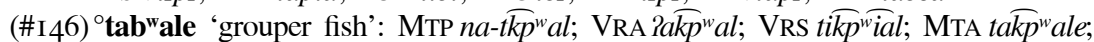
DRG $t \widehat{k p}^{w} a l$; KRO $t a \overline{k p}^{w} a l ;$ LKN takp ${ }^{w} a l$.

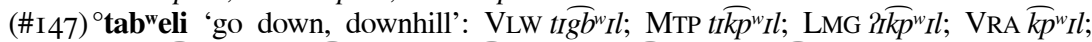

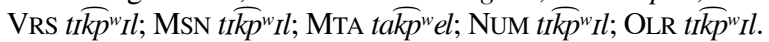


(\#I48) ${ }^{\circ}\left[\mathbf{t a}-\mathbf{b}^{\mathrm{w}}\right.$ onayi 'cuttlefish, Sepia sp.' [lit. 'shy person']: LTG $k^{w} a k^{w} u n \varepsilon y ;$ MTP na-tatakp ${ }^{w} n \varepsilon t$; MTA takp ${ }^{w}$ onay; DRG wltakp ${ }^{w} n a^{\prime} \gamma ;$ OLR $\widehat{k p}^{w}$ InI: ; LKN $\widehat{k p}^{w}$ on $\widehat{k p}^{w}$ ona $\gamma ;$ MRL tokna.

$\left(\# \text { I49) }{ }^{\circ} \text { tayere[yere }\right]_{[1]} \sim{ }^{\circ}$ tageregere $_{[2]}$ 'swiftlet, Rhipidura fuliginosa' [PNCV *takere

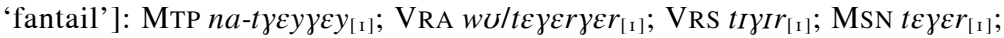

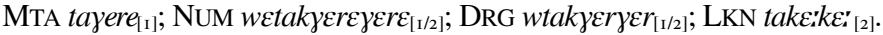

(\#I50) 'tayuru 'behind; afterward' [PNCV *takuRu 'back, behind, after']: HIU tiर̌iz; LTG tzyur; MTP tiyiy; VRS tøwür; MSN yorltuwur; MTA tayir tawur; DRG twur tawri; LKN tawu'.

(\#I5I) ${ }^{\circ}$ taluyo 'morning ${ }_{[1]} ; \quad$ tomorrow $_{[2]}$ ': LHI talow $w_{[2]} ;$ LHR talow $w_{[2]} ; \quad$ VLW talow $w_{[2]}$;

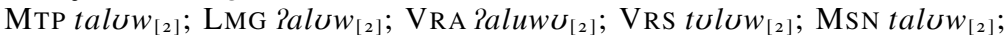

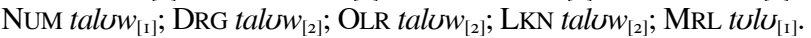

(\#I52) ${ }^{\circ}$ ta-marayai 'old man' [lit. 'quivering person']: LHI tamayya; VLW tamayze; MTP tamayye; VRA Pamarya; VRS tamarye; MSN tamarye; MTA tamarayai; DRG tmarya; LKN tama'za; MRL temerye.

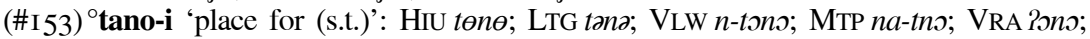

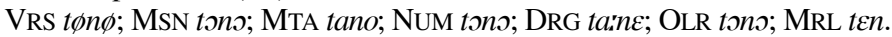

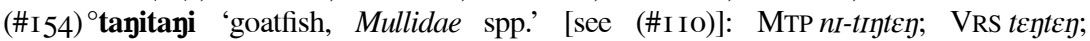
MTA tantay; DRG ta:yta:y; LKN tantary.

(\#I55) 'tari 'a thousand': LTG ter; MTP tey; VRA Per; VRS tar; MTA tar; DRG ta:r; OLR tar; MRL ter.

(\#I56) 'taru 'cover; bake food in stone oven overnight': HIU tor̆; LTG tor; VLW tey; MTP tey; VRA Por; VRS toer; MSN tor; MTA tar; MRL tor.

$\left(\#\right.$ I 57) ${ }^{\circ}$ tasisi 'small bird, prob. Lichmera incana': MTP na-tsis; VRS wiltrsisis; MTA tasis; NUM tisis; DRG waltsis; LKN tistisis.

(\#I58) ${ }^{\circ}[$ ta] tarisa $[$ [sa]sarita 'equal, identical, sufficient': LTG tatorihə; LHI ttares; VLW haytryIh; MTP haytryIh; LMG Paras; VRA PirisI; VRS sasarit; MSN tatırIs; MTA sasarta; DRG tatris; MRL ttareas.

(\#I59) ${ }^{\circ}$ tauri ${ }^{\circ}$ tori 'hold in ones hands': HIU (tวřsy); LTG tər; LHI tey; VLW try; MTP try; MSN tur; MTA taur; NUM tIr; DRG tur; KRO tur; MRL ter.

(\#I60) ${ }^{\circ}$ tauwe $_{\mathrm{I}}$ 'conch shell, Charonia tritonis' [PNCV *taßui; POC *tapuri]: LTG tawə; MTP $n a-t u ;$ VRs $t u w ;$ MSN $t u w$; MTA tawe; Drg tuw; OlR $t u w$; LKN tau; MRL no-tU.

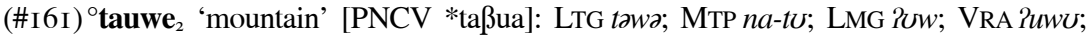
VRS tow; MSN tow; MTA tawe; DRG tow; KRO tuw; OLR tuw; LKN taww.

(\#I62) 'tawa[Ya]si 'flower': LTG toweh; LHI towah; LHR n-tawsi; VLW n-tIwih; MTP na-tawhi na-tweh; LMG wes; VRA Pawas; VRS tewes tawayas; MTA tawayasi; NUM taßayes; DRG twais; KRO teweas; OLR tawas; LKN tawah.

(\#I63) ${ }^{\circ}$ terit(i,u) 'urchin fish, Diodon spp.': VRS tIrIt; MTA terit; DRG trit; OLR tirit wulttritrit; MRL ne-terit.

(\#I64) 'toyo 'wild cane, Miscanthus floridulus': HIU toy; LTG toy; VLW no-toy; MTP no-toy; LMG $n$-?oey; VRA wo/?oy; MTA toyo; DRG waltoy; KRO wo/toy; OLR wultor' ; LKN toy.

(\# I65) 'tomayo 'sweet yam, Dioscorea esculenta': LTG tomey; LHI toma; MTP no-tomay; LMG $n$-Pamay; VRA Pomay; VRS tamay; MSN tamay; MTA tomayo; DRG waltmay; OLR wo/tama'; LKN tamay.

(\#I66) 'tua-gu 'my fellow; me and X': MTP (i/tan); VRA 20-k; VRS toe- $k$; MSN to-k; MTA tua- $k$; NUM $t a-k$; DRG $t u-k$; LKN $t$ - $-k$; MRL $t o-k$.

(\#I67) ${ }^{\circ}$ tuara 'another; one... the other one; a, indefinite article': VRS tuar; MSN tuar; MTA tuara; NUM tuar; DRG tuar; KRO tuar; OLR tay; LKN to; MRL tuar.

(\#I68) 'tuatua-gu 'my opposite-sex sibling': HIU tut $\beta o-k$; LTG sase- $k$; LHI teto- $k$; MTP tItE-k; VRA 2owo-k; VRS tütüoc- $k$; MSN tutuo-k; MTA tutua- $k$; DRG tuta:-k; KRO tetea- $k$; OLR tati- $k$; LKN tata-k; MRL toto- $k$. 
(\#I69) ${ }^{\circ}$ tubu-gu 'my grandparent; my grandchild' [POC *tubu-]: LTG $t u k^{w} u$; MTP ilttkp ${ }^{w} u-k$; VRA ?ubu-k; VRS tübü-k; MSN tupu-k; MTA tupu-k; NUM tubu-k; DRG tbu-k; KRO tubu- $k$; LKN tupu- $k$.

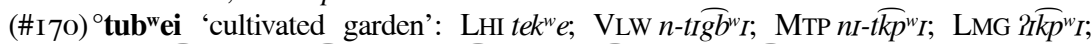

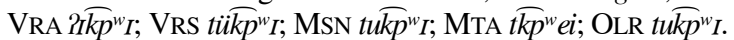

(\#I7I) ${ }^{\circ}$ tumus(i,u) ${ }^{\circ}$ sumut(i,u) 'picot, Siganus sp.': VRA ?umus; MTA sumut; DrG smut; LKN tumuh.

(\#I72) ${ }^{\circ} \operatorname{tur}[\mathbf{i}, \mathbf{u}](\mathbf{\gamma i})$ 'body, trunk; the real, main, very X; really': HIU tiR̆; LTG sir; MTP tiy; VRA Pir; VRS türyü; MTA tur turia-; DRG tru $\sim$ turyi; KRO turu; OLR tiri'; LKN tiriy; MRL tur.

(\#I73) ${ }^{\circ}$ tuwa[1]e 'one': LTG ttwe; LHI $\beta e-t w a ;$ LHR $\beta u-\widehat{t f u w a ; ~ M T P ~} \beta i$-tway; VRA fulwal; VRS tiwial; MSN tawal; MTA twale; NUM ti-twal; DRG su-twal; KRO $\beta u$-twal; LKN tuwa; MRL tuwel.

(\#I74) ${ }^{\circ} \mathbf{u n}(\mathbf{i}, \mathbf{u})$ 'drink': LtG $t n ;$ VlW in; MTP in; LMG in; VRA in; MTA un; OlR un; LKN un.

(\#I75) ${ }^{\circ}$ ulusu-i 'top of (tree); end': VLW n-lisi; MTP n-ulsi; VRS ilsi; MSN ulsu; MTA ulus; NUM lus; DRG lus-yi; LKN uhli; MRL n-ulsi.

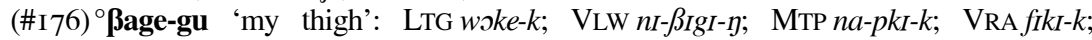
VRS $\beta I k I-k$; DRG $\beta k I-k$; LKN $\beta a k \varepsilon-k$.

(\#I 77) ${ }^{\circ}$ Bala-gu 'my (inner) mouth': LTG $\beta \partial l e-k$; LHI $\beta o l o-k$; LHR $\beta a e l o-k$; MTP na-ple- $k$; VRS ßoel $x-k ;$ MSN ßolo-k; MTA ßala-k; NUM fala-k; DRG ßlar-k; LKN ßala-k; MRL $n \theta-\beta B l o-k$.

(\#I78) ${ }^{\circ}$ Baraba 'twins': LTGßarepə; MTP na-pyam; VRAßaraba; VRS ßaram; MTA ßarapa; LKN ßarap.

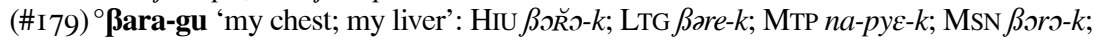
MTA ßara- $k$; NUM fara- $k$; DRG $\beta r a r-k$; LKN $\beta a r r I-k$; MRL no- $\beta$ oro- $k$.

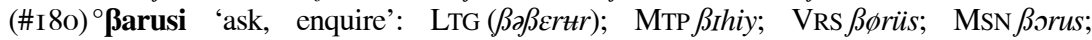

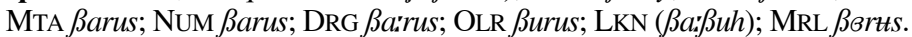

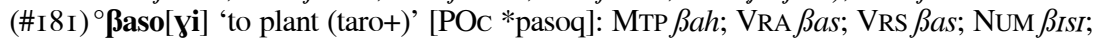
DRG $\beta$ suy; KRO ßusuy; OLR $\beta$ ust'; LKN $\beta$ ahu:.

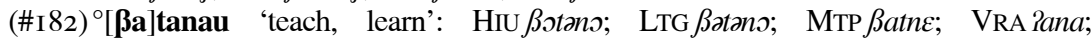
VRS (ßo)tono; MTA ßatanau; KRO ßatna; OLR ßatna; LKN ßatna; MRL ßutnu.

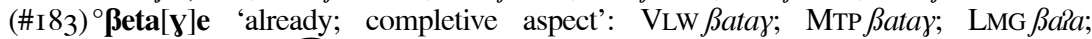
VRA faPa; VRs ßitia; MSN ßatay; MTA ßeta; NuM fata; MrL ßita.

(\#I84) ${ }^{\circ}$ Betali 'banana (generic term)' [PNCV *ßetali]: HIU ßatsy; LTG ßatel; LHI ßetael; LHR $\beta \widetilde{\varepsilon t f} \varepsilon l$; VLW $n$ - $\beta \varepsilon t \varepsilon l$; MTP $n a-p t \varepsilon l$; LMG $n-\beta \varepsilon ? \varepsilon l$; VRA fa?al; VRS $\beta \varepsilon t \varepsilon l$;

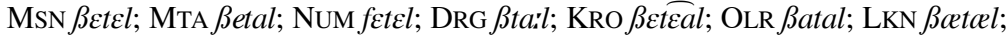
MRL ni-ßitel.

(\#I 85) ${ }^{\circ}$ Beße-gu 'my mother': MTP $i / \beta I-k ; \quad$ VRA $f \mathcal{E} f \mathcal{E}-k ; \quad$ MTA $\beta e \beta e-k ; \quad$ NUM ralffI- $k$; DRG $\beta \beta \beta_{I}-k$; KRO $i / \beta \beta I-k$; OLR $\beta i \beta I-k$; LKN $\beta \varepsilon \beta \varepsilon-k$; MRL $i-f f I-k \sim i-\beta \varepsilon p$.

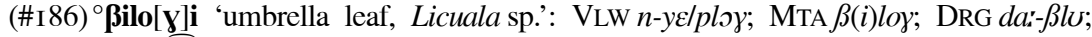

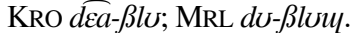

(\#I87) ${ }^{\circ}$ Bina 'shoot (arrow)' [PNCV *ßana-i]: LTG ßiniz; VLW $\beta I n ;$ MTP $\beta I n ;$ VRS $\beta I n$; MSN ßIn; MTA (ßene); DRG ßIn; KRO ßIn; OLR ßini; LKN ßince.

(\#I 88) ${ }^{\circ}$ Bini[ti] 'skin; bark' [PNCV *ßunu-ti 'skin, husk, rind']: LHI $\beta i n$; VLW ni-ßini;

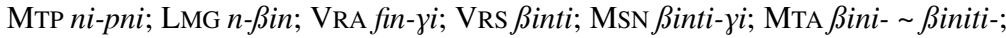
NuM fni; DRG $\beta n i ;$ LKN $\beta i n \eta i ;$ MRL $\beta u n i$.

(\#I89) ${ }^{\circ}$ Burußuru bilaye 'Plectorhynchus orientalis' [lit. '...(striped like) rail bird']: MTP wuywuy bilay; VRA wurwur balay; MTA wurwur pilaye; DRG ßirßir blay; KRO yoryor bilay; OLR wuywuy pila: ; LKN wu'wu' pilay.

(\#I90) 'Busi 'hit; kill': HIU wu; LTG wuh; VLW wih; MTP wuh; VRA fus; VRS $\beta u s ;$ MSN $\beta u s ;$ MTA $\beta u s ;$ DRG $\beta u s ;$ KRO $\beta u s ;$ OLR $\beta u s ;$ LKN $\beta u h ;$ MRL $\beta u s$. 
(\#I9I) ${ }^{\circ}$ Butoßuto 'puffer fish, Tetraodontidae spp.': MTP nu-wutwut; VRA futfuto; VRS wutwut; MTA wutowuto; DRG $\beta u t \beta u t$.

(\#I92) ${ }^{\circ}$ walu[su] $\sim{ }^{\circ}$ walu-gu '(my) brother-in-law; (my) sister-in-law': LTG woltt-k; VLW wulus; MTP wulus wuluk; VRA wulu- $k$; VRS wølüs $\sim$ reelwel; MSN wulu-k; MTA walu walu- $k$; MRL rolwol.

(\#I93) ${ }^{\circ}$ weda 'rain': HIU wetz; LTG wetz; VLW $n$-wen; VRA wede; VRS wian; MSN wen; MTA wena.

(\#I94) ${ }^{\circ}$ wia 'good': HIU wiz; LTG $y \varepsilon / w i z ;$ VLW $y \varepsilon / w r ;$ MTP wr; LMG wi; VRA wir; VRS wr; MSN wr; MTA wia; DRG wr; KRO wr; OLR wr; LKN wr; MRL wea.

(\#I95) ${ }^{\circ}$ wisi 'owl': LTG wih; LHI wis; MTP ni-wis; VRA wis; VRS wis; MTA wis; NUM wis; DRG wis; OLR wis; LKN wis; MRL ni-wis.

(\#I96) ${ }^{\circ}$ wota 'be born': HIU wotz; LTG wotz; MTP wot; VRA wo?o; VRS wot; MSN wot; MTA wota; DRG wot; KRO wot; OLR wata; LKN wota; MRL wot.

(\#I97) ${ }^{\circ}$ wotaya 'Barringtonia edulis': LTG watayz; MTP na-wtay; VRA wa?ay; VRS wutay; MSN watay; MTA wotaya; DRG wtay; LKN wota; MRL na-wataw.

\section{REFERENCES}

Besnier, Niko. 1987. An autosegmental approach to metathesis in Rotuman. Lingua 73:20I-23.

Blevins, Juliette, and Robert Blust. 2003. Towards a theory of drift: Patterns of Austronesian syncope. Unpublished manuscript. University of California, Berkeley.

Blust, Robert. I990. Patterns of sound change in the Austronesian languages. In Linguistic change and reconstruction methodology, ed. by Philip Baldi, 23I-67. Trends in Linguistics: Studies and Monographs 45. Berlin: Mouton de Gruyter.

Bril, Isabelle. 2005. Semantic and functional diversification of reciprocal and middle prefixes in New Caledonian and other Austronesian languages. Linguistic Typology 9:25-76.

Clark, Ross. 1985. Languages of North and Central Vanuatu: Groups, chains, clusters and waves. In Austronesian linguistics at the I5th Pacific Science Congress, ed. by Andrew Pawley and Lois Carrington, 199-236. Series C-88. Canberra: Pacific Linguistics.

. In prep. North and Central Vanuatu: A comparative study. Computer files.

Codrington, Reverend. I885. The Melanesian languages. Oxford: Clarendon Press.

Codrington, Reverend, and Jim Palmer. I896. A dictionary of the language of Mota, Sugarloaf Island, Banks Islands. London: Society for Promoting Christian Knowledge.

Dyen, Isidore. 1949. On the history of the Trukese vowels. Language 25:420-36.

François, Alexandre. I999. Mouvements et clonages de voyelles en motlav: Entre phonologie et morphologie. Bulletin de la Société de Linguistique 94(I)г: 437-86.

- 2000. Vowel shifting and cloning in Motlav: Historical explanation vs formal description. In Proceedings of AFLA 7 (The Seventh Meeting of Austronesian Formal Linguistics Association), ed. by Marian Klamer, 49-68. Amsterdam: Vrije Universiteit.

. 200I. Contraintes de structures et liberté dans l'organisation du discours. Une description du mwotlap, langue océanienne du Vanuatu. Doctoral dissertation, Université Paris-IV Sorbonne. 3 vols., I078 pp. [Downloadable at: http://alex.francois.free.fr/]

. 2002. Araki: A disappearing language of Vanuatu. No. 522. Canberra: Pacific Linguistics.

- 2004. Subgrouping hypotheses in North Vanuatu. Paper presented at the 6th International Conference on Oceanic Linguistics (COOL6), University of the South Pacific, Port Vila, Vanuatu, July.

. 2005. A typological overview of Mwotlap, an Oceanic language of Vanuatu. Linguistic Typology 9(I): I I 5-46. 
Forthcoming. Noun articles in Torres and Banks languages: Conservation and innovation. In Linguistic description and linguistic applications: Studies in memory of Terry Crowley, ed. by Jeff Siegel, John Lynch, and Diana Eades. New York: John Benjamins.

Goodenough, Ward H. I992. Gradual and quantum changes in the history of Chuukese (Trukese) phonology. Oceanic Linguistics 3 I:93-I I4.

Gordon, Raymond G., Jr., ed. 2005. Ethnologue: Languages of the world. I5th ed. Dallas: SIL International. [Online version: http://www.ethnologue.com/]

Grimes, Barbara F., Joseph E. Grimes, Malcolm Ross, Charles E. Grimes, and Darrell T. Tryon. I995. Listing of Austronesian languages. In Comparative austronesian dictionary: An introduction to Austronesian studies, ed. by Darrell T. Tryon, pt. I: fasc. I, I 2 I-279. Trends in Linguistics, Io. Berlin: Mouton de Gruyter.

Guy, Jacques. I977. On the origins of the Sakao vowel system (New Hebrides). Journal of the Polynesian Society 86:97-I03.

Hagège, Claude, and André-Georges Haudricourt. 1978. La phonologie panchronique. Le Linguiste. Paris: Presses Universitaires de France.

Hooper, Robin. I985. Proto-Oceanic *qi. In Austronesian linguistics at the 15th Pacific Science Congress, ed. by Andrew Pawley and Lois Carrington, I4I-98. Series C88. Canberra: Pacific Linguistics.

Hyslop, Catriona. 200I. The Lolovoli dialect of the North-East Ambae language, Vanuatu. No. 5I 5. Canberra: Pacific Linguistics.

- n.d. a. Vera'a-English lexicon. Computer files.

- n.d. b. Vurës-English lexicon. Computer files.

Jespersen, Otto. I904. Lehrbuch der Phonetik. Leipzig, Berlin: Teubner.

Klamer, Marian. 2002. Typical features of austronesian languages in Central/Eastern Indonesia. Oceanic Linguistics 4I:363-83.

Lee, Kee-Dong. I975. Kusaiean reference grammar. Honolulu: University of Hawai'i Press.

Lee, Kee-Dong, and Judith W. Wang. I984. Kosraean reflexes of Proto-Oceanic phonemes. In Studies in Micronesian linguistics, ed. by Byron W. Bender, 403-42. Series C-8o. Canberra: Pacific Linguistics.

Lynch, John. 2000. Reconstructing Proto-Oceanic stress. Oceanic Linguistics 39:53-82.

. 200 I. The Linguistic history of Southern Vanuatu. No. 509. Canberra: Pacific Linguistics.

- 2002. Potent roots and the origin of kava. Oceanic Linguistics 4I:493-5I3.

. 2003. Low vowel dissimilation in Vanuatu languages. Oceanic Linguistics 42:359-406.

Lynch, John, Malcolm Ross, and Terry Crowley. 2002. The Oceanic languages. Richmond: Curzon Press.

Martinet, André. I970 [1955]. Économie des Changements Phonétiques. Traité de Phonologie Diachronique. Bibliotheca Romanica. Berne: Francke.

McCarthy, John. I989. Linear order in phonological representation. Linguistic Inquiry 20:7 I-99.

Ozanne-Rivierre, Françoise. 1976. Le iaai, Langue mélanésienne d'Ouvéa (NouvelleCalédonie). Phonologie, morphologie, esquisse syntaxique. Langues et cultures du Pacifique. Paris: Société d'Etudes Linguistiques et Anthropologiques de France.

Ozanne-Rivierre, Françoise, and Jean-Claude Rivierre. I989. Nasalization/oralization: nasal vowel development and consonant shifts in New Caledonian languages. In VICAL I: Oceanic Languages, Papers from the Fifth International Conference on Austronesian Linguistics, vol. 2, ed. by Ray Harlow and Robin Hooper, 4I3-32. Auckland: Linguistic Society of New Zealand.

Pawley, Andrew. 1973. Some problems in Proto-Oceanic grammar. Oceanic Linguistics I 2: IO3-88.

ـ I976. Some new Oceanic comparisons. Unpublished manuscript. 
Rehg, Kenneth. I98I. Ponapean reference grammar. Honolulu: University of Hawai'i Press.

Rivierre, Jean-Claude. I980. La langue de Touho. Phonologie et grammmaire du cèmuhî (Nouvelle-Calédonie). LACITO-documents. Paris: SELAF.

. 200I. Tonogenesis and evolution of the tonal systems in New Caledonia: The example of Cèmuhî. In Proceedings of the Symposium on Cross-Linguistic Studies of Tonal Phenomena: Tonogenesis, Typology, and Related Topics, ed. by S. Kaji, 2342. Tokyo: Institute for the Study of Languages and Cultures of Asia and Africa, Tokyo University of Foreign Studies.

Ross, Malcolm. I998. Possessive-like attribute constructions in the Oceanic languages of Northwest Melanesia. Oceanic Linguistics 37:234-76.

200I. Proto Oceanic *i, *qi and *-ki. In Issues in Austronesian morphology: A focusschrift for Byron W. Bender, ed. by Joel Bradshaw and Kenneth L. Rehg, 25978. Canberra: Pacific Linguistics.

Ross, Malcolm, Andrew Pawley, and Meredith Osmond, eds. I998. The lexicon of Proto Oceanic, vol. I, Material culture. Series C-I52. Canberra: Pacific Linguistics.

- 2003. The lexicon of Proto Oceanic, vol.2, The physical environment. No. 545. Canberra: Pacific Linguistics.

Sapir, Edward. I92 I. Language. New York: Harcourt Brace.

Thieberger, Nicholas. 2004. Topics in the grammar and documentation of South Efate, an Oceanic language of Central Vanuatu. Doctoral dissertation, University of Melbourne. 536 pp.

Trask, R. L. 1996. A dictionary of phonetics and phonology. New York: Routledge.

Tryon, Darrell. 1976. New Hebrides languages: An internal classification. No. C-50. Canberra: Pacific Linguistics.

\section{LACITO-CNRS}

7, rue Guy Môquet

9480 I Villejuif

FRANCE

Alexandre.Francois@vjf.cnrs.fr 